LUCAS PIRES DA COSTA

METODOLOGIA DE ANÁLISE E OTIMIZAÇÃO DE ABSORVEDORES DE ENERGIA EM AUTOMÓVEIS 
LUCAS PIRES DA COSTA

\section{METODOLOGIA DE ANÁLISE E OTIMIZAÇÃO DE ABSORVEDORES DE ENERGIA EM AUTOMÓVEIS}

Trabalho apresentado à Escola Politécnica da Universidade de São Paulo para a obtenção do título de Mestre em Ciências. 


\title{
METODOLOGIA DE ANÁLISE E OTIMIZAÇÃO DE ABSORVEDORES DE ENERGIA EM AUTOMÓVEIS
}

\author{
Versão Corrigida
}

Trabalho apresentado à Escola Politécnica da Universidade de São Paulo para a obtenção do título de Mestre em Ciências.

Área de Concentração:

Engenharia Mecânica de Projeto e Fabricação

Orientadora:

Larissa Driemeier 
Autorizo a reprodução e divulgação total ou parcial deste trabalho, por qualquer meio convencional ou eletrônico, para fins de estudo e pesquisa, desde que citada a fonte.

Este exemplar foi revisado e corrigido em relação à versão original, sob responsabilidade única do autor e com a anuência de seu orientador.

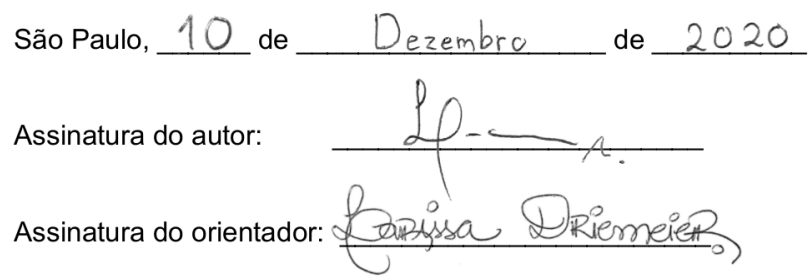

\section{Versão Corrigida}

Catalogação-na-publicação

da Costa, Lucas

Metodologia de análise e otimização de absorvedores de energia em automóveis / L. da Costa -- versão corr. -- São Paulo, 2020.

$115 \mathrm{p}$.

Dissertação (Mestrado) - Escola Politécnica da Universidade de São Paulo. Departamento de Engenharia Mecânica.

1.Otimização Não Linear 2.Mecânica dos Sólidos 3.Segurança Veicular 4.Superfícies de Resposta I.Universidade de São Paulo. Escola Politécnica. Departamento de Engenharia Mecânica II.t. 


\section{AGRADECIMENTOS}

À minha orientadora Prof. a Dra. Larissa Driemeier pela orientação, suporte e paciência. Sua atuação foi essencial para o desenvolvimento do trabalho e consolidação de meus conhecimentos como engenheiro.

Aos meus pais por sempre apoiarem meus estudos, minhas escolhas de vida e de carreira.

Aos meus amigos mais próximos, adquiridos ao longo do tempo, por estarem presentes tanto nos momentos de descontração quanto por me reerguerem nos momentos mais difíceis.

Ao corpo docente do Programa de Pós-Graduação em Engenharia Mecânica da USP por compartilhar conhecimentos e disponibilizar apoio nas pesquisas. 
"A conquista é um acaso que talvez dependa mais das falhas dos vencidos do que da genialidade do vencedor" (Anne-Louise Germaine Necker) 


\section{RESUMO}

O desenvolvimento contemporâneo de automóveis leva em consideração diferentes fatores, como desempenho, viabilidade econômica, normas de segurança e emissões. No entanto, certos objetivos almejados competem entre si. Melhorar o desempenho ao impacto de um carro, muitas vezes, afeta negativamente em seu custo e desempenho. O uso de técnicas de otimização é uma boa alternativa quando se busca aumentar uma métrica sem comprometer outros resultados ligados a ela. O trabalho em questão foca especificamente na otimização paramétrica da longarina de veículos leves, que é um componente estrutural responsável por mitigar lesões em ocupantes em caso de colisões. Por conta de sua flexibilidade e precisão para esse tipo de fenômeno, os experimentos são realizados exclusivamente pelo método dos elementos finitos, que é usualmente empregado durante as etapas iniciais do desenvolvimento de um projeto. Apesar de a peça estudada possuir geometria simples, a natureza não linear dos experimentos, associado ao número extenso de iterações necessárias para a otimização, gera um alto custo computacional para a solução do problema. Com a finalidade de reduzir o tempo do processo de otimização, foi estudado o uso de três diferentes algoritmos de otimização. Paralelamente, analisouse a viabilidade da aplicação de modelos de regressão chamados de metamodelos, cuja função principal é de reduzir o número de experimentos realizados. Explorou-se também o uso de planejamento de experimentos, responsável tanto por fornecer pontos para a composição dos metamodelos, quanto para propor projetos iniciais para as otimizações. Todas as otimizações foram capazes de propor longarinas com maior absorção de energia por unidade de volume, dentro de uma restrição de força de reação máxima. Porém, nenhum caso garantiu que a longarina possuísse o máximo desempenho possível dentro do domínio analisado. Apesar de limitações com relação à aderência das superfícies de resposta a determinados fenômenos físicos, a combinação de metamodelos com algoritmos de otimização diminuiu o tempo computacional em até $75 \%$, ao mesmo tempo em que gerou longarinas com características mais desejáveis, quando comparadas aos resultados das otimizações sem os metamodelos.

Palavras-Chave - desempenho ao impacto, otimização, metamodelo, planejamento de experimentos, método dos elementos finitos. 


\section{ABSTRACT}

The development of automobiles in the present day takes different factors into consideration, such as performance, economic viability, safety standards and emissions. However, certain desired objectives often compete with each other. Improving the crashworthiness of a car can negatively affect its cost and handling. The use of optimization techniques is a good alternative when improving one metric without deteriorating other results linked to it. This work aims specifically at parametrically optimizing the midrail of light vehicles, which is a structural part responsible for mitigating occupant injuries during traffic collisions. The experiments are conducted exclusively by the finite element method, known for its flexibility and precision for this kind of phenomenon, and it's often employed during the initial stages of a project development. In spite of the component's simple geometry, the non-linear nature of the experiments, associated with the number of iterations required for optimization, greatly increases the computational cost for solving the problem. In order to reduce the time of the optimization process, there was studied the use of three different optimization algorithms. In parallel, there was analyzed the feasibility of the use of regression models called metamodels, whose main role is to reduce the overall number of experiments. The use of design of experiments was also explored. It is responsible both for feeding data into the metamodels, and for proposing initial projects for the optimizations. All optimizations were able to offer midrails with greater energy absorption per unit of volume, within a maximum reaction force constraint. However, none of them guaranteed that the midrail had the maximum possible performance within the analyzed domain. Despite limitations regarding the response surfaces' adhesion to certain physical phenomena, the combination of metamodels with optimization algorithms reduced the computational time by up to $75 \%$, while generating midrails with more desirable characteristics, when compared to the results of optimizations without metamodels.

Keywords - Crashworthiness, optimization, metamodel, design of experiments, finite element method. 


\section{LISTA DE FIGURAS}

1 Representação da longarina estudada. . . . . . . . . . . . . . . . . . . 17

2 Curva de Tolerância de Wayne State (Adaptado pelo autor de Lu e Yu [10]). 21

3 Corpo estrutural do tipo monobloco (Adaptado de (c) nerthuz / Adobe Stock). . . . . . . . . . . . . . . . . . . 24

4 Zona de impacto e cabine (Adaptado pelo autor de Malen [20]). . . . . . . 24

5 Distribuição da absorção de energia de impacto em um carro (Malen [20]). 25

6 Modelo massa-mola de um automóvel proposto por Kamal (Adaptado por Lima [23] de Bois [18]). . . . . . . . . . . . . . . . . . . . 26

7 Velocidade do balancim traseiro de um automóvel durante um impacto

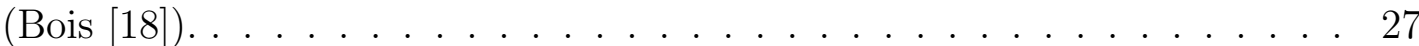

8 Geometria de um automóvel em elementos finitos, antes (A) e após $100 \mathrm{~ms}$ de impacto (B) (Adaptado de Bois [18]) . . . . . . . . . . . . . . 28

9 (a) Tubo de origami retangular, (b) tubo de origami hexagonal (Adaptado de $\mathrm{Ma}[32]) \ldots \ldots \ldots \ldots \ldots$

10 Força de reação média de tubos com mesmo perímetro e geometrias transversais díspares (Adaptado de Malen [20]) . . . . . . . . . . . . . . . . . . . 31

11 Gráfico de força por deslocamento típico de um tubo de paredes finas (Adaptado de Jones [34]). . . . . . . . . . . . . . . . . . . . . . . 32

12 Modos de falha de absorvedores de energia sob cargas axiais. Modo anel em (a); modo diamante em (b) e modo misto em (c) (Lu e Yu [10]). . . . . 33

13 Modos de falha em tubos circulares de alumínio e com paredes finas (Adaptado pelo Autor de Guillow et al. [36]) . . . . . . . . . . . . . . . . . . . . . 33

14 Modos de falha em absorvedores de energia com diferentes materiais (Adaptado pelo Autor de Karagiozova e Alves [37]). . . . . . . . . . . . . . . . . 34

15 Formação de rótulas plásticas axissimétricas em tubo circular (Adaptado pelo Autor de Jones [34]). . . . . . . . . . . . . . . . . . . . . . . . . 34 
16 Lóbulos triangulares do modo de falha assimétrico (Adaptado pelo Autor

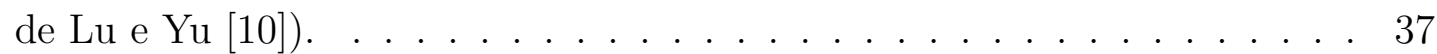

17 Comportamento do fim de curso de um tubo circular (Adaptado de Jones $[34]) \ldots \ldots \ldots \ldots \ldots \ldots$

18 Interpolação (em vermelho) de um fenômeno determinístico (em preto) através de um DoE clássico (a) e um DoE de preenchimento de espaço (b) (Adaptado pelo Autor de Nesbakken [42]). . . . . . . . . . . . . . . . . . . 40

19 Quadrado latino à esquerda e à direita uma amostra de quadrado latino baseado na letra E (Nesbakken [42]). . . . . . . . . . . . . . . . . . . . . . 41

20 Distribuição de valores entre 0 e 1 gerados por Hipercubo Latino. . . . . . . 42

21 Distribuição de valores entre 0 e 1 gerados por Sobol. . . . . . . . . . . . . . 45

22 Esquema de metamodelo em conjunto com simulação computacional. . . . 46

23 Metamodelo a partir de pontos amostrais. . . . . . . . . . . . . . . 46

24 Exemplo genérico de regressão por Kriging (Adaptado pelo Autor de Liu [54]). 50

25 Exemplo de rede neural sem alimentação (Adaptado pelo Autor de Aggarwal $[56]) \ldots \ldots \ldots \ldots \ldots$

26 Relação entre projeto, análise e otimização (Adaptado de Messac [59]). . 54

27 Taxa de convergência linear contra taxa de convergência quadrática. . . . . 57

28 Exemplo de funcionamento do algoritmo de Powell (Adaptado de [47]). . . 59

29 Continuação funcionamento do algoritmo de Powell (Adaptado de [47]). . . 59

30 Avaliação de desempenho de projetos no MOGA-II [62]. . . . . . . . . . . 61

31 Gráfico da política de penalização (Adaptado pelo autor de [47]). . . . . . 63

32 Sistema absorvedor barreira em elementos finitos. . . . . . . . . . . . . . 64

33 Fração da energia artificial pela energia de deformação plástica, em função do tempo. . . . . . . . . . . . . . . . . . . . 65

34 Projeto da Figura 33 com integração completa e 3 pontos de integração por Gauss. . . . . . . . . . . . . . . . . . . . . . . . . 66

35 Distorções do primeiro modo de flambagem, ampliadas em 55 vezes [63]. . . 67

36 Exemplo de simulação dinâmica. . . . . . . . . . . . . . . . . 67 
37 Fluxograma de preparação. . . . . . . . . . . . . . . . . . . . . . . 69

38 Fluxograma da otimização. . . . . . . . . . . . . . . . . . . . . . . 69

39 Exemplo de fluxo de trabalho. . . . . . . . . . . . . . . . . . 70

40 Comparação de flambagem progressiva em (a) e flambagem global em (b). 71

41 Exemplo de superfície de resposta . . . . . . . . . . . . . . . . . 73

42 Refinamento do metamodelo . . . . . . . . . . . . . . . 75

43 Animação de simulação de impacto do Projeto A. . . . . . . . . . . . . . . . 77

44 Força por deslocamento do Projeto A. . . . . . . . . . . . . . . 78

45 Projeto B deformado após o impacto. . . . . . . . . . . . . . . . 79

46 Força por deslocamento do Projeto B. . . . . . . . . . . . . . 80

47 Projetos C1 e C2 completamente deformados após o mesmo impacto. . . . 81

48 Força por deslocamento de $\mathrm{C} 1$ e $\mathrm{C} 2 \ldots \ldots \ldots \ldots$. . . . . . . 82

49 Energia específica por do número de iterações para o DoE de 1000 pontos. 83

50 Preenchimento de espaço por Sobol e Hipercubo Latino. . . . . . . . . . . 86

51 Histórico de convergência da otimização por AFSQP . . . . . . . . . . . . . . 88

52 Animação de simulação de impacto do melhor projeto por AFSQP. . . . . 89

53 Força por deslocamento do melhor projeto obtido por AFSQP . . . . . . . 89

54 Histórico de convergência de otimização por Powell. . . . . . . . . . . . . . 90

55 Animação do projeto $\mathrm{N}^{\circ} 5$ obtido por Powell. . . . . . . . . . . . . . . . 92

56 Força por deslocamento da melhor longarina otimizada pelo algoritmo de Powell. . . . . . . . . . . . . . . . . . . . . . . . . 92

57 Histórico da otimização por MOGA-II. . . . . . . . . . . . . . . . . . . . 93

58 Animação do melhor projeto obtido por MOGA-II. . . . . . . . . . . . . . 94

59 Força por deslocamento da melhor longarina otimizada por MOGA-II. . . . 95

60 Histórico de iterações do DoE para o primeiro treinamento de metamodelos 96

61 Histórico de iterações do DoE para o segundo treinamento de metamodelos 98 
62 Superfície para estimar a energia absorvida, obtida a partir do quinto treinamento por Kriging anisotrópico. . . . . . . . . . . . . . . . . . . . . . . 102

63 Superfície para estimar a força máxima, obtida a partir do quinto treinamento por RBF. . . . . . . . . . . . . . . . . . . . . . . . 102

64 Animação do melhor projeto obtido pela combinação de AFSQP com metamodelos. . . . . . . . . . . . . . . . . . . . 103

65 Comportamento da longarina obtida por AFSQP e metamodelagem. . . . . 104

66 Comportamento da longarina obtida por Powell e metamodelagem. . . . . 105

67 Regiões da otimização virtual por MOGA-II. . . . . . . . . . . . . . . . 106

68 Longarina sub-ótima obtida por MOGA-II e metamodelos. . . . . . . . . . 107 


\section{LISTA DE TABELAS}

1 Exemplos de polinômios primitivos para $\mathrm{GF}(2) \ldots \ldots$. . . . . . . . . . . 43

2 Propriedades do aço A36 (Adaptado de Tarlochan et al. [33]) . . . . . . . . . . 66

3 Intervalo de valores utilizados. . . . . . . . . . . . . . . . . . . . . 72

4 Parâmetros geométricos do Projeto A. . . . . . . . . . . . . . . . 77

$5 \quad$ Valores de saída do Projeto A. . . . . . . . . . . . . . . . 78

$6 \quad$ Valores de saída do Projeto B. . . . . . . . . . . . . . . . . . . . 79

$7 \quad$ Parâmetros geométricos dos Projetos $\mathrm{C} 1$ e C2. . . . . . . . . . . . . . . . 80

$8 \quad$ Valores de saída dos Projeto $\mathrm{C} 1$ e C2. . . . . . . . . . . . . . . 81

9 Melhores projetos da otimização por força bruta. . . . . . . . . . . . . . . . . 84

10 Análise de sensibilidade dos parâmetros. . . . . . . . . . . . . . . . . . . . . 84

11 Projeto de experimentos por Hipercubo Latino. . . . . . . . . . . . . . . . . . 85

12 Projeto de experimentos por Sobol. . . . . . . . . . . . . . . . 86

13 Otimização por AFSQP. . . . . . . . . . . . . . . . . . . . . 88

14 Otimização por Powell. . . . . . . . . . . . . . . . . . . . . . . . . . . . 91

15 Diferença de desempenho observada do método Powell com relação ao AFSQP. . 91

16 Última geração obtida por MOGA-II. . . . . . . . . . . . . . . . . . . . . . . 94

17 Primeiro treinamento de metamodelos . . . . . . . . . . . . . . . 96

18 Otimização obtida pelo primeiro grupo de metamodelos. . . . . . . . . . . . 97

19 Comparação entre o desempenho real e o estimado pelo primeiro grupo de metamodelos. . . . . . . . . . . . . . . . . . . . 97

20 Nova faixa de valores utilizados para construção de metamodelos. . . . . . . . . 98

21 Segundo treinamento de metamodelos . . . . . . . . . . . . . . . . . . 99

22 Otimização obtida pelo segundo grupo de metamodelos. . . . . . . . . . . . . . 99 
23 Comparação entre o desempenho real e o estimado pelo segundo grupo de metamodelos. . . . . . . . . . . . . . . . . . . 99

24 Comparação entre o desempenho real e o estimado do terceiro ao quinto grupo de metamodelos. . . . . . . . . . . . . . . . . . . . . . 100

25 Algoritmos que apresentaram as melhores métricas de acordo com seu respectivo grupo. . . . . . . . . . . . . . . . . . . . . . 100

26 Quinto treinamento de metamodelos. . . . . . . . . . . . . . . . 101

27 Quinto treinamento de metamodelos para o volume. . . . . . . . . . . . . . 101

28 Otimização obtida por AFSQP unido ao quinto grupo de metamodelos. . . . . . . 104

29 Comparação entre o desempenho real e o estimado pela otimização por Powell, a partir do quinto grupo de metamodelos. . . . . . . . . . . . . . . . . . . 104

30 Otimização obtida por Powell unido ao quinto grupo de metamodelos. . . . . . 105

31 Comparação entre o desempenho real e o estimado pela otimização por MOGAII, a partir do quinto grupo de metamodelos. . . . . . . . . . . . . . . . . 106

32 Comparação entre o desempenho real e o estimado pela otimização por MOGAII, a partir do quinto grupo de metamodelos. . . . . . . . . . . . . . . . . . 107

33 Sub-otimização obtida por MOGA-II unido ao quinto grupo de metamodelos. . . 107

34 Comparação entre os resultados das metodologias utilizadas. . . . . . . . . . . 108 


\section{SUMÁRIO}

1 Enunciado do problema $\quad 15$

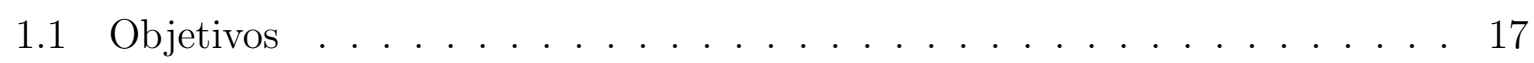

1.2 Organização do Trabalho . . . . . . . . . . . . . . . . . . . 18

2 Revisão Bibliográfica $\quad 20$

2.1 Tolerância do corpo humano ao impacto . . . . . . . . . . . . . 20

2.2 Desempenho ao impacto . . . . . . . . . . . . . . . . . 23

2.3 Absorção de energia . . . . . . . . . . . . . . . . . . . . . 29

2.4 Planejamento de experimentos $(\mathrm{DoE}) \ldots \ldots \ldots$. . . . . . . . . . 38

2.5 Metamodelamento . . . . . . . . . . . . . . . 45

2.5.1 Determinação de metamodelo . . . . . . . . . . . . . . . 47

2.5.1.1 Método Polinomial . . . . . . . . . . . . 47

2.5.1.2 Funções de Base Radial (RBF) . . . . . . . . . . . . . 48

2.5.1.3 Kriging ....................... 49

2.5.1.4 Redes Neurais Artificiais (RNA) . . . . . . . . . 50

2.5.2 Validação de Metamodelo . . . . . . . . . . . . . . . . . . . 52

2.6 Otimização . . . . . . . . . . . . . . . . . . . . 53

2.6.1 Programação Sequencial Quadrática de Filtro Adaptativo . . . . . . 55

2.6.2 Direções Conjugadas de Powell . . . . . . . . . . . . . . . . 58

2.6.3 Algoritmo Genético Multi-Objetivo II . . . . . . . . . . . . . . . . 60

2.6 .4 Restrições . . . . . . . . . . . . . . . . . . 62

3 Metodologia $\quad 64$

3.1 Modelo em Elementos Finitos . . . . . . . . . . . . . . . 64 


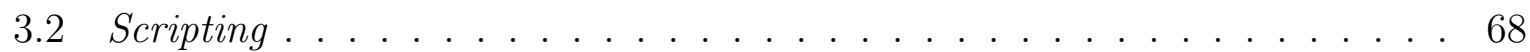

3.3 Métodos de Otimização . . . . . . . . . . . . . . . . . . . . . . . . 69

3.4 Metamodelamento . . . . . . . . . . . . . . . . . 73

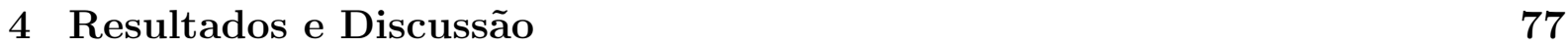

4.1 Análise Paramétrica . . . . . . . . . . . . . . . . . . . 77

4.2 Otimização Forçada . . . . . . . . . . . . . . . . . . . . . . . . 83

4.3 Planejamento de Experimentos . . . . . . . . . . . . . . . . . 85

4.4 Otimização por AFSQP . . . . . . . . . . . . . . . . . 87

4.5 Otimização por Powell . . . . . . . . . . . . . . . . . . . . . 90

4.6 Otimização por MOGA-II . . . . . . . . . . . . . . . . . . . . . 93

4.7 Otimização com Metamodelos . . . . . . . . . . . . . . . . . . . 95

5 Considerações Finais 109

5.1 Trabalhos Futuros . . . . . . . . . . . . . . . . . . 110

$\begin{array}{ll}\text { Referências } & 111\end{array}$ 


\section{ENUNCIADO DO PROBLEMA}

A função primária de um automóvel é de transportar pessoas e bens de um lugar ao outro de forma confortável, segura e acessível a diferentes tipos de consumidores [1].

A cada ano no Brasil, os acidentes de trânsito causam, em média, 47 mil mortes e sequelas de algum tipo em cerca de 400 mil pessoas, gerando um custo para o Estado de $\mathrm{R} \$ 56$ bilhões $[2,3]$.

O tipo de lesão mais comum e ao mesmo tempo mais preocupante oriundo de acidentes de trânsito é o traumatismo craniano, que ocorre em aproximadamente $70 \%$ dos casos [4] e é a causa de mais da metade das mortes geradas por esta categoria de acidente [5,6]. A fim de estimar a severidade de uma lesão cerebral durante um acidente e consequentemente avaliar dispositivos de segurança em automóveis, o cálculo do Critério de Traumatismo Craniano (HIC, do inglês Head Injury Criterion) é comumente utilizado [7]. O HIC associa a gravidade da contusão com o módulo de aceleração e tempo de exposição em que o corpo, no caso o ocupante, é submetido.

No tocante à segurança, o desempenho ao impacto (ou, do inglês, Crashworthiness) do automóvel é altamente dependente de diversos fatores, dentre eles, a fabricação e projeto do veículo. A fim de atender tais requisitos, certos critérios de engenharia devem ser atendidos, como: força, rigidez, resistência ao choque, resistência a intempéries, conformação geral, acessibilidade e sustentabilidade [1]. A proteção do passageiro à colisão é um conhecimento multidisciplinar, que envolve fatores humanos, biomecânicos, eletrônicos e de mecânica estrutural.

Do ponto de vista da colisão, a estrutura do automóvel (ou, do inglês, Body in White) pode ser separada em duas partes: cabine e zona de impacto [1]. Durante uma colisão, a primeira parte deve, idealmente, estar livre de distorções e deformações após o impacto, mantendo o espaço necessário para a sobrevivência dos ocupantes. Já a zona de impacto tem a função de absorver o máximo de energia possível, de maneira controlada, através da deformação plástica. A massa dos veículos poderia ser drasticamente reduzida caso a 
resistência ao impacto não fosse levada em consideração durante seu desenvolvimento [1].

No cenário automotivo atual, há diversas tecnologias alternativas disponíveis aos fabricantes para que os mesmos ofereçam veículos seguros mais sustentáveis e com menores emissões de carbono; dentre elas, destacam-se as tecnologias voltadas à otimização no uso da energia, pois elas aumentam o rendimento do conjunto independentemente de seu sistema de propulsão. A diminuição de peso é um elemento fundamental para atenuar a perda de energia de um veículo, visto que quanto maior a massa do sistema, maior será a energia necessária para acelerá-lo e maior será a força de resistência ao rolamento dos pneus [1].

O desenvolvimento de veículos leves, seguros e que também forneçam um espaço apropriado para os ocupantes resulta na necessidade de pesquisas em diversas áreas da engenharia, além de testes com protótipos para verificar o desempenho do produto. Um teste de impacto veicular demanda de cerca de 36 horas para a preparação de sua instrumentação [8], além do descarte subsequente do carro, tornando inviável um estudo que se utilize apenas de testes físicos iterativos, o que justifica o uso de ferramentas numéricas para determinadas análises, especialmente em etapas iniciais de projeto.

O método dos elementos finitos (MEF) representa hoje uma das principais ferramentas para o modelamento de veículos no que diz respeito à segurança [8]. Tal método permite investigar diferentes alternativas de projeto veicular em seus estágios iniciais, diminuindo consideravelmente a quantidade de protótipos a serem testados em etapas posteriores.

Dada a natureza complexa dos modos de falha de componentes veiculares em um impacto, o método dos elementos finitos passa a exigir um custo computacional maior, graças a presença de não linearidades, como grandes deformações, presença de regime plástico do material, contato e atrito. Tais fenômenos demandam do modelo numérico uma formulação mais sofisticada, gerando um número maior de cálculos [8].

Metamodelo, ou modelo de um modelo, é um método que aproxima um comportamento complexo para uma função conhecida, geralmente uma curva ou uma superfície. A partir do método de Planejamento de Experimentos (DoE, do inglês, Design of Experiments), é determinada uma quantidade de projetos iniciais, além da distribuição de seus parâmetros, para a obtenção de uma função com a aderência necessária, permitindo a previsão de comportamento de regiões não testadas, além de possibilitar o uso de diversos métodos de otimização, agilizando todo o processo de desenvolvimento [8].

Para que múltiplos requisitos sejam atendidos simultaneamente, como segurança, espaço e massa reduzida, é necessária uma otimização do problema, ou seja, a aplicação 
de uma técnica matemática em que a partir de diversos parâmetros analisados seja encontrada uma solução fisicamente possível que satisfaça as condições desejadas de maneira ótima.

Definida a metodologia, resta escolher as características do sistema a serem analisadas e posteriormente otimizadas com o intuito de melhorar a absorção de energia do sistema. No caso, a análise paramétrica do absorvedor de energia é o escopo do trabalho, ou seja, testam-se diferentes configurações geométricas e seus respectivos efeitos, com o objetivo de encontrar uma configuração ótima para o absorvedor.

\subsection{Objetivos}

O intuito deste trabalho é de otimizar parametricamente as longarinas no que se refere à sua absorção de energia específica, testando diferentes longarinas de mesmo material sob uma mesma carga dinâmica, análoga àquelas realizadas pela New Car Assesment Program (NCAP). A longarina, mostrada na Figura 1, será representada por um cone cilíndrico, com uma combinação de dimensões única, variando-se entre as mesmas o comprimento longitudinal, o diâmetro da seção transversal, espessura da chapa e o ângulo longitudinal. Os ensaios são realizados exclusivamente pelo método dos elementos finitos.

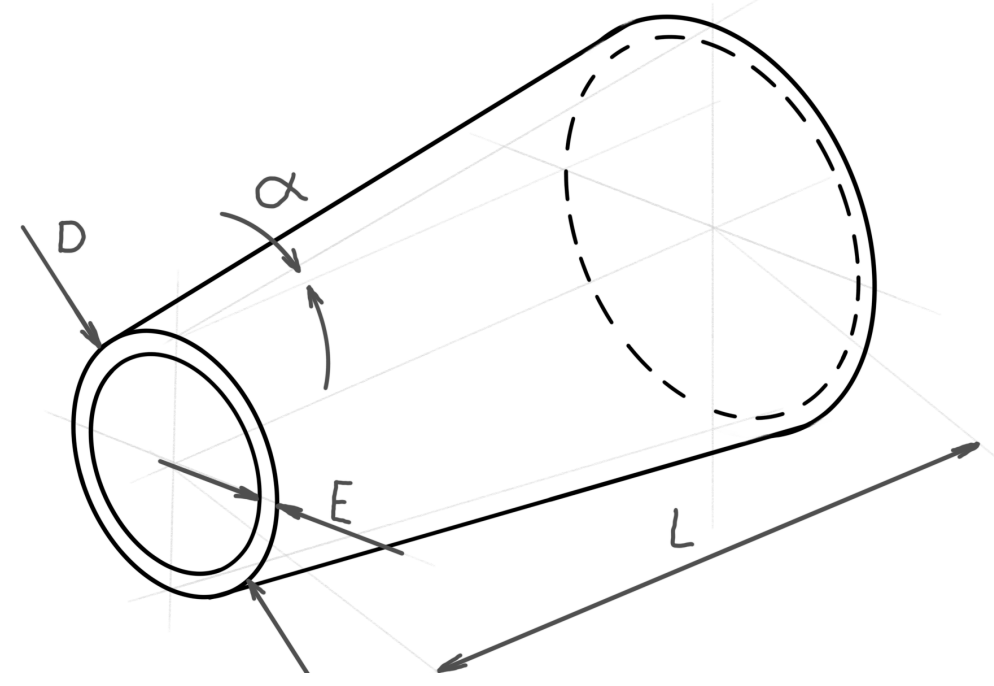

Figura 1: Representação da longarina estudada.

São utilizados três diferentes algoritmos de otimização, explicados no capítulo de revisão bibliográfica, sendo eles: um algoritmo genético, um algoritmo baseado em gradiente e um algoritmo baseado nas direções conjugadas de Powell. Serão comparadas suas respectivas soluções (pontos ótimos), assim como a capacidade para convergência e número de iterações. Será analisado também, além dos resultados obtidos através do uso de um 
algoritmo de otimização, o ganho de desempenho para cada um dos algoritmos quando aliados a algum tipo de metamodelo.

As simulações em elementos finitos são conduzidas através do software Abaqus, enquanto as etapas de planejamento de experimentos, metamodelagem e otimização são feitas com o software modeFRONTIER. A linguagem MATLAB é utilizada para automatizar os experimentos e permitir a correta comunicação entre os programas. A máquina que executa os experimentos possui um processador AMD Ryzen ${ }^{\mathrm{TM}} 7$ 1700X com 16 GB de memóriam RAM.

No final, com relação aos absorvedores de energia, são comparadas as diferentes características geométricas e suas respectivas métricas de desempenho, discorrendo-se as vantagens e desvantagens de cada configuração.

\subsection{Organização do Trabalho}

Para se alcançar os objetivos propostos no trabalho, o mesmo apresenta um capítulo de Revisão Bibliográfica; Metodologia; Resultados e Discussão; Conclusão; Referências.

A Revisão Bibliográfica possui a função de contextualizar o problema a ser resolvido e as ferramentas utilizadas para superá-lo, iniciando-se com a Seção 2.1, onde discorrem-se algumas das lesões, oriundas de acidentes de automóveis, geradas aos ocupantes, expondo também as métricas criadas para estimar o grau de severidade delas. Em seguida, na Seção 2.2, são apresentadas características que um veículo automotor deve possuir para evitar ou mitigar lesões aos ocupantes, caso o carro colida. A Seção 2.3 aborda os mecanismos físicos utilizados para transformar energia cinética em energia de deformação, protegendo pessoas e bens materiais de impactos. Ao longo da Seção 2.4, são explicados métodos que geram os projetos iniciais, dos quais serão posteriormente analisados e otimizados. Já na Seção 2.5, discorre-se sobre os modelos de regressão de fenômenos, chamados metamodelos, através de conceitos, aplicações e exemplos dos tipos mais usados dentro do contexto de absorção de energia. Por último, na Seção 2.6, são explorados métodos de otimização, cuja função é de procurar soluções de máximo desempenho, dentro de restrições pré-estabelecidas.

Durante a Metodologia, são mostrados os parâmetros e ferramentas utilizados para a obtenção de resultados, justificando as escolhas. Na Seção 3.1, é discutida a parte experimental do processo, mostrando as configurações usadas no modelo em elementos finitos para a execução dos ensaios de impacto dinâmico nas longarinas. Logo após, na 
Seção 3.2, é apresentada a maneira com que foi feita a comunicação entre a geração dos ensaios (software de elementos finitos) com o software de planejamento e otimização de experimentos, automatizando o procedimento. No decorrer da Seção 3.3, é demostrada a estratégia usada para analisar e otimizar os projetos, definindo objetivos e restrições. Por fim, na Seção 3.4, é explicado o procedimento de como são produzidos os modelos de regressão, além das diferenças entre a otimização direta apresentada na Seção 3.3 e uma otimização obtida a partir de um metamodelo.

No capítulo de Resultados e Discussão, são expostos os resultados provenientes da metodologia utilizada, mostrando vantagens e desvantagens de cada configuração de método, assim como contratempos encontrados. O trabalho segue para o capítulo de Considerações Finais, onde são listados os principais entendimentos dos resultados obtidos, acompanhado pela sugestão de Trabalhos Futuros. O trabalho então se encerra com as Referências, onde é enumerado o material utilizado para aquisição de informações e justificativas durante o trabalho.

Vale notar que o trabalho possui algumas animações, diferenciadas a partir do início do título de determinadas figuras. Para que as animações sejam executadas, é necessário um leitor de PDF capaz de reproduzir animações em JavaScript. Softwares testados capazes de executar essas animações incluem o Adobe Acrobat Reader DC 2020 e o Foxit Reader 10.1. 


\section{REVISÃO BIBLIOGRÁFICA}

\subsection{Tolerância do corpo humano ao impacto}

Durante uma colisão de automóvel, as lesões causadas nos ocupantes podem ser resultado dos seguintes fenômenos [9]:

- Intrusão no habitáculo.

- Impacto com um componente interno do veículo (impacto secundário).

- Ejeção do automóvel.

- Desaceleração intensa.

A grande força de impacto causada pela colisão de um automóvel é capaz de gerar desacelerações intensas, que por sua vez podem gerar lesões severas a determinados órgãos e regiões do corpo, especialmente lesões relacionadas ao cérebro, uma vez que sistemas de retenção passiva, como o cinto de segurança, são incapazes de fornecer retenção à cabeça [10].

Tratando-se de acidentes de trânsito, lesões na cabeça são identificadas como o tipo de trauma mais debilitante, uma vez que são de difícil tratamento e frequentemente resultam em sequelas a longo prazo, gerando um grande custo para a sociedade, seja por morte prematura, ou perda de produtividade [10].

Pesquisas na biomecânica buscam estabelecer associações entre lesões na cabeça humana e suas condições externas. Uma dessas relações é a Curva de Tolerância de Wayne State (em inglês, Wayne State Tolerance Curve), em que determina-se qual nível de aceleração necessário para provocar uma lesão craniana. Leva em consideração a aceleração e a duração do pulso de aceleração, como mostrado na Figura 2.

A curva de tolerância da Figura 2 serviu como base para índices que determinam a gravidade de lesões provocadas por acelerações, dentre eles, destaca-se o Índice de 


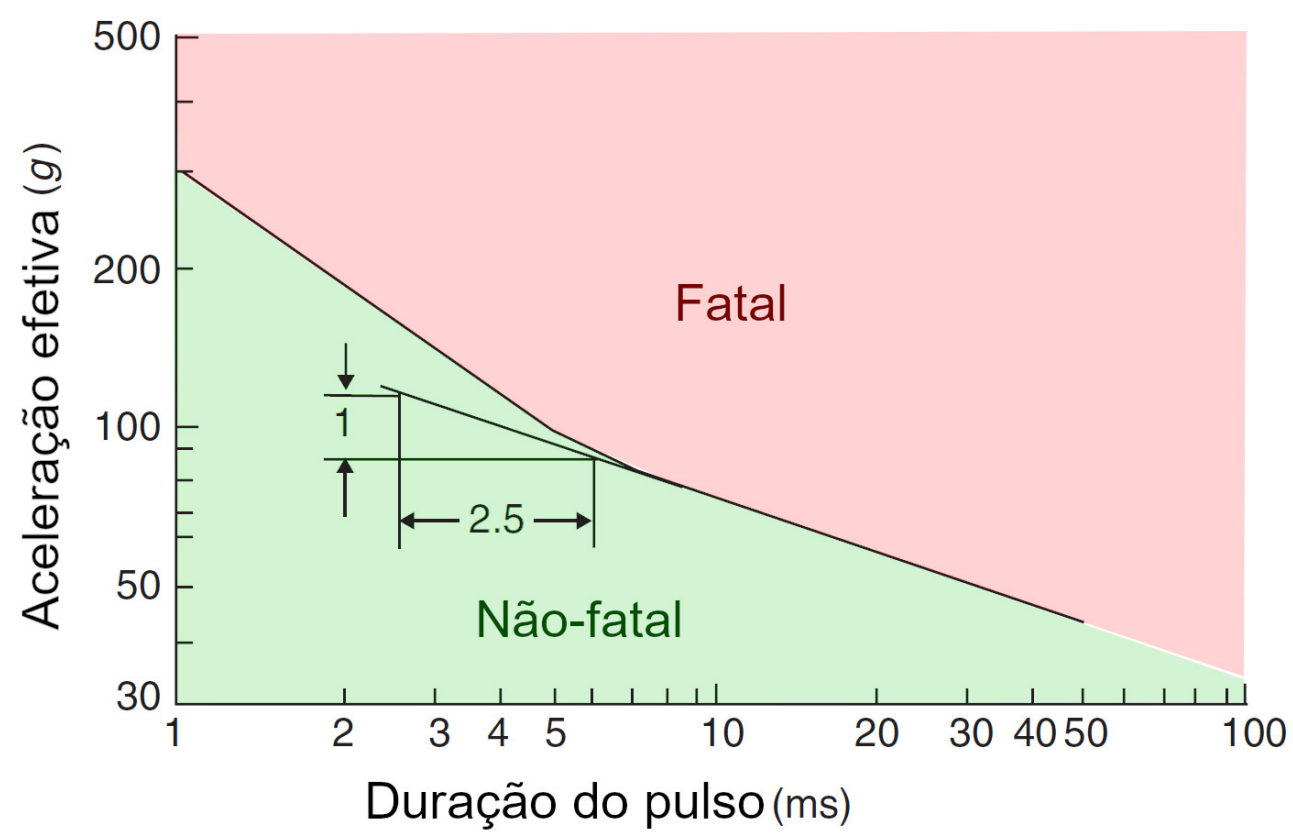

Figura 2: Curva de Tolerância de Wayne State (Adaptado pelo autor de Lu e Yu [10]).

Severidade de Gadd (GSI, do inglês Gadd Severity Index), mostrado na Equação 2.1.

$$
G S I=\int_{0}^{T} a^{2,5} d t<1000
$$

onde $a$ é a aceleração em $g, t$ representa o tempo em milissegundos, $T$ simboliza o tempo total do pulso de aceleração e o valor de 1000 descreve o limite para que ocorra uma lesão séria na cabeça. Dada a equação ser oriunda de uma aproximação da Curva de Tolerância de Wayne State, a fórmula é válida apenas para intervalos entre 0,25 e 50 ms.

Posteriormente, o GSI foi substituído pelo Critério de Traumatismo Craniano (HIC, do inglês Head Injury Criterion), mostrado na Equação 2.2, que é uma metodologia utilizada até os dias atuais para estimar a segurança de automóveis [10,11].

$$
H I C=\left(t_{2}-t_{1}\right)\left(\frac{1}{t_{2}-t_{1}} \int_{t_{1}}^{t_{2}} a(t) d t\right)^{2,5}
$$

onde $t_{2}$ e $t_{1}$ são respectivamente o tempo final e tempo inicial do pulso analisado e $a(t)$ a aceleração do corpo em função do tempo.

Vale notar que o HIC ainda possui algumas limitações, dentre elas, deficiência na assimilação de acelerações angulares e de formato da curva aceleração [11]. No entanto, mesmo com a existência de outros critérios, nenhum deles tem uma aceitação tão ampla quanto o HIC $[10,12]$. 
Durante o estudo de danos físicos causados aos ocupantes em um acidente, outras partes do corpo, além da cabeça, merecem atenção, exigindo modelos específicos para a análise de cada região.

O Critério de Lesão no Peito (em inglês, Chest Injury Criterion) é uma fórmula simples, ainda que válida. Parte da correlação que a severidade da lesão no peito é proporcional ao valor de deformação compressiva imposta. É o produto entre a velocidade torácica e a compressão torácica, ambos sendo parâmetros relativos [10].

Outra métrica importante para prever lesões é o Índice de Trauma Torácico (TTI, do inglês Thoracic Trauma Index), que estima danos causados a órgãos presentes na caixa torácica, como fígado, rins e baço. Sua fórmula é expressa pela Equação 2.3:

$$
T T I \equiv 0,5\left(G_{r}+G_{l s}\right)<100
$$

onde $G_{r}$ é o pico de aceleração da costela e $G_{l s}$ o pico de aceleração da parte inferior da coluna, ambos expressos em $g$. O índice TTI abaixo de 100 representa que a lesão provocada pela aceleração não é suficiente para provocar uma fatalidade [10].

A obtenção de estimativas de lesões corporais em acidentes é possível graças ao uso de manequins de testes de colisão (ou ainda em inglês, dummies). Os dummies são equipamentos que emulam as propriedades mecânicas, dinâmicas e geométricas do corpo humano. Permitem também a instrumentação e repetibilidade dos testes de colisão, possibilitando estabelecer uma padronização dos testes [13]. Existem diferentes tipos de manequins, adequados para testes de colisões específicos ou ainda representando seres humanos de diferentes faixas etárias e padrões físicos, como exposto com mais profundidade por Seiffert [13]. Vale notar ainda que atualmente, a confecção de dummies numéricos tem sido utilizada para complementar os estudos na área [14].

Independentemente da região do corpo investigada, os índices de estimativa de lesão levam em consideração as propriedades dinâmicas do sistema observado, como velocidade e aceleração. Visto que, durante um impacto, a desaceleração da cabine do automóvel afeta diretamente o comportamento dinâmico do corpo do ocupante, cria-se a necessidade de um estudo aprofundado sobre segurança automotiva. Dessa forma, um veículo seguro deve evitar a invasão da cabine de ocupantes, utilizar-se de meios para evitar grandes desacelerações no habitáculo e fornecer equipamentos de retenção apropriados. 


\subsection{Desempenho ao impacto}

Tendo em vista que carros mais seguros possuem uma influência considerável tanto na prevenção de acidentes, quanto na contenção de lesões dos ocupantes [2], a segurança veicular ganhou mais atenção nos últimos anos, resultando em alterações na legislação brasileira de trânsito e em uma maior divulgação de programas de avaliação de segurança automotiva, como por exemplo o Latin New Car Assesment Programme (Latin NCAP), fundado em 2010 [15].

No caso da legislação, foi feita uma alteração no Código de Trânsito Brasileiro em 2009, tornando obrigatório que veículos fabricados a partir de 2014 sejam munidos de equipamentos suplementares de retenção (Air bags) e sistema antitravamento dos freios (ABS, do inglês Antilock Brake System) [16], visando respectivamente aumentar o nível de proteção oferecido e reduzir a quantidade de acidentes.

O desempenho ao impacto de um automóvel refere-se à capacidade de proteção aos ocupantes no momento em que o carro é submetido a elevadas acelerações [17]. Para atingir tal objetivo, a estrutura de um automóvel deve atender a múltiplos objetivos, dentre eles:

- Zonas deformáveis responsáveis pela absorção de energia de impacto.

- No caso de um acidente, a não intrusão de regiões do carro (como teto, portas e colunas) no habitáculo.

- Um teto resistente para o caso de um capotamento.

- Sistemas de retenção aos ocupantes para aumento de proteção.

Vale notar, que além dos itens citados acima, os automóveis também devem atender a propriedades mecânicas que influenciam no seu uso diário, como por exemplo:

- Rigidez suficiente para a boa dirigibilidade do veículo.

- Correta filtração de vibrações externas com relação à cabine.

- Resistência a intempéries em geral.

O corpo estrutural de um veículo, também chamado de Body in White, geralmente é composto de tubos de aço com paredes finas, podendo também utilizar-se de alumínio 


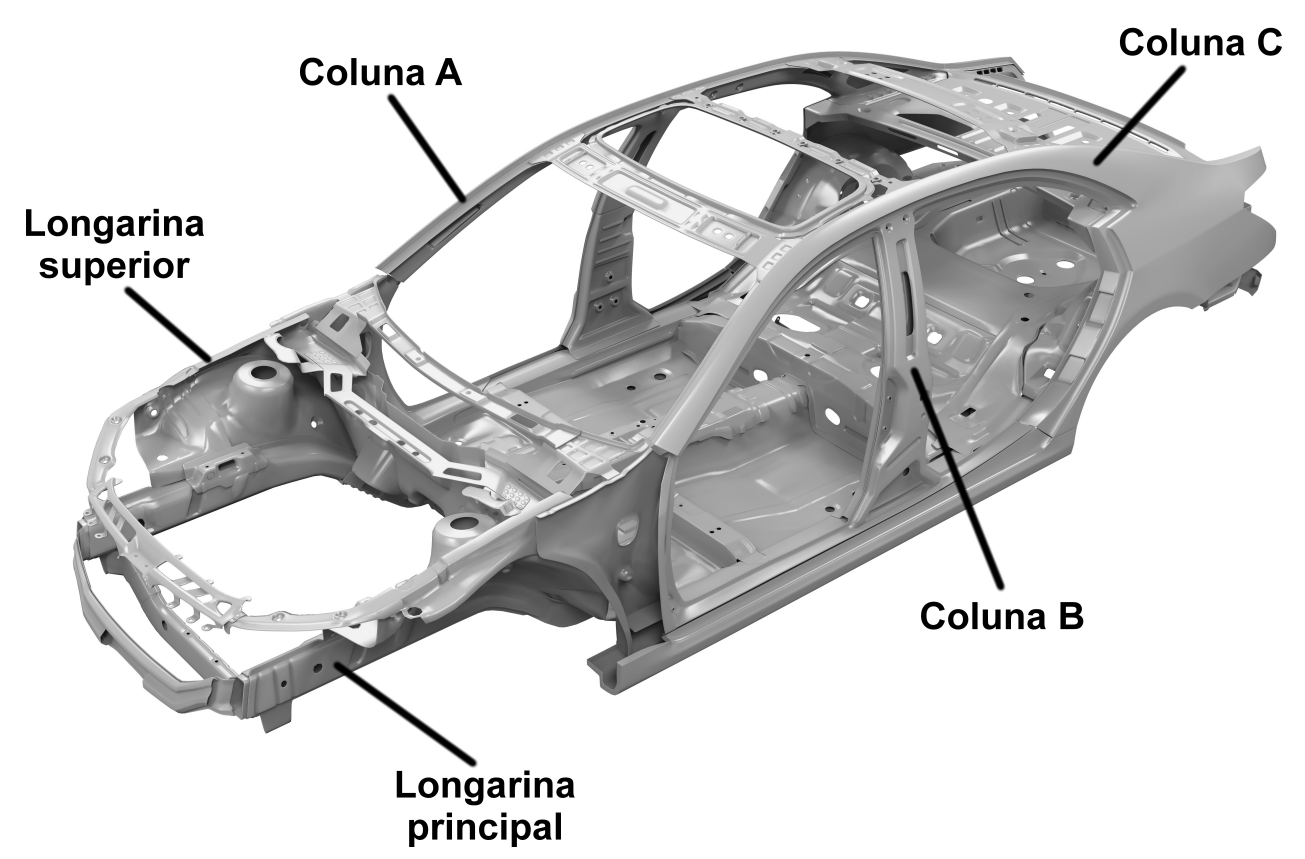

Figura 3: Corpo estrutural do tipo monobloco (Adaptado de (C) nerthuz / Adobe Stock).

ou compósitos [18]. O tipo mais comum de estrutura para automóveis de passeio é o monobloco, como exposto na Figura 3.

Os tubos e chapas que compõe o Body in White possuem diferentes funções dependendo de sua localização, como ilustrado pela Figura 4, e por isso, esse dispõe de diferentes propriedades mecânicas. Regiões próximas às extremidades da estrutura, como as longarinas, possuem uma ductilidade maior, pois são projetadas para converter energia cinética em energia de deformação permanente, reduzindo o pico de desaceleração imposto aos ocupantes em caso de um acidente. Por outro lado, regiões que envolvem o habitáculo, como o teto e as colunas A,B e C, são elaborados para apresentar alta resistência e pouca ductilidade, evitando que a estrutura do carro invada a área dos ocupantes [19].

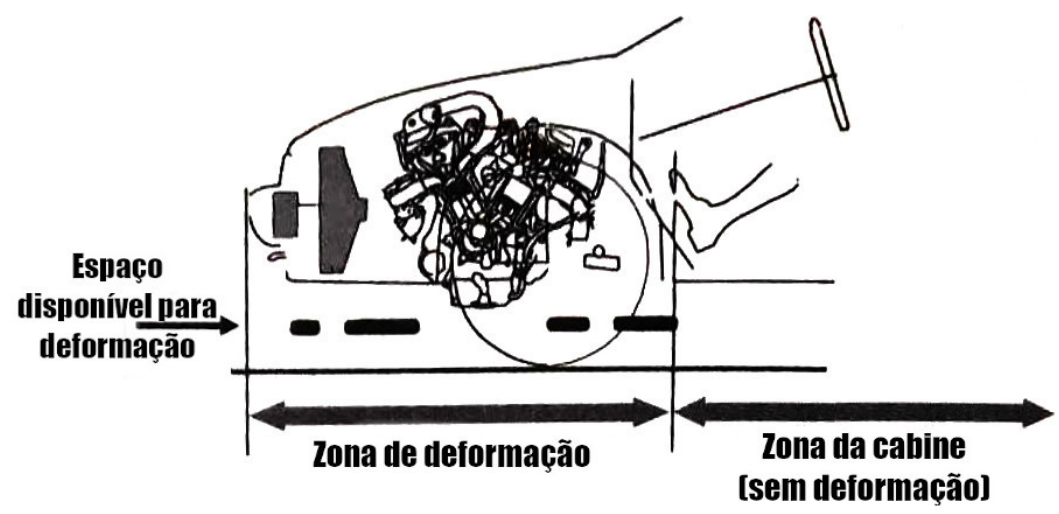

Figura 4: Zona de impacto e cabine (Adaptado pelo autor de Malen [20]). 
Dentre os componentes da zona de impacto, vale destacar que a longarina principal é responsável por absorver cerca de $50 \%$ da energia de impacto, enquanto a longarina superior e quadro inferior absorvem aproximadamente $20 \%$ cada e o capô, $10 \%$ [20], como ilustrado pela Figura 5.

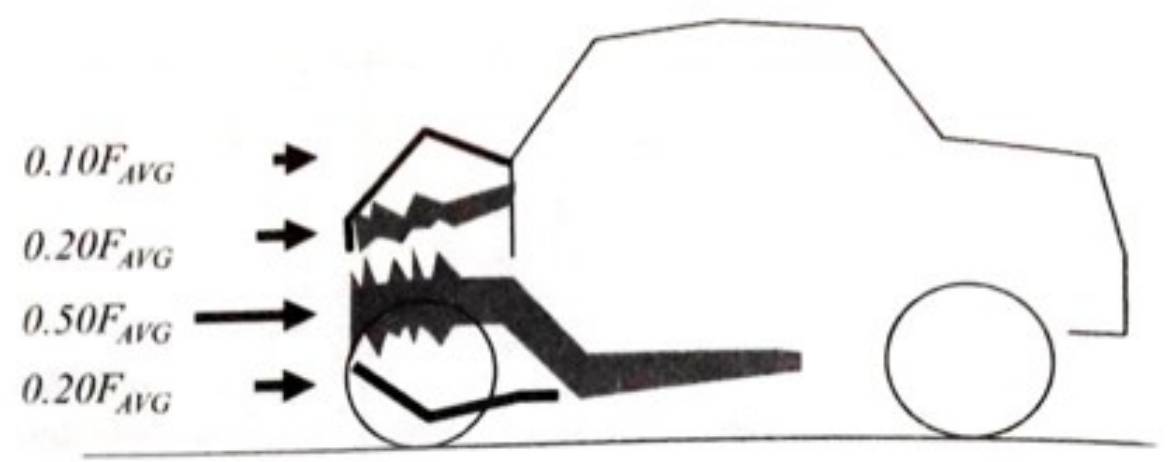

Figura 5: Distribuição da absorção de energia de impacto em um carro (Malen [20]).

Ao dimensionar a estrutura de um carro, deve-se levar em conta que um acidente real de trânsito pode se manifestar de formas variadas. O veículo pode colidir com obstáculos de características dispares, como massa, rigidez e geometria. A colisão também pode ocorrer em diferentes velocidades e iniciar-se em regiões distintas do automóvel, como por exemplo a região frontal, lateral ou traseira.

Um exemplo de teste de impacto é a colisão total frontal realizado pelo NCAP dos Estados Unidos. Nele, um carro movendo a $56 \mathrm{~km} / \mathrm{h}$ colide com uma barreira rígida com largura equivalente à largura do automóvel [21]. Dentro do automóvel, insere-se um ou mais dummies, que podem representar um motorista, passageiros adultos ou eventualmente crianças. Ao final da colisão, analisa-se a integridade dos manequins.

A reconstrução de um acidente é capaz de fornecer informações importantes sobre o desempenho ao impacto de um veículo. No entanto, esses testes não concedem informações quantitativas necessárias para projetar um carro, como pulso de desaceleração, cargas e cinemáticas nos ocupantes. Para que os requisitos de segurança sejam atingidos, o projetista necessita de uma combinação de testes padronizados em laboratório, avaliações em campo de testes e análises [18].

Para atender aos requisitos de segurança, o desenvolvimento de automóveis tornouse uma mistura de testes e de modelos matemáticos. Quanto mais avançado o estágio do projeto, mais complexo e robusto deverá ser o método [18]. Destacam-se entre eles, modelos massa-mola e em elementos finitos. 
Introduzido na década de 1970, o modelo massa-mola é empregado até hoje durante os estágios iniciais de um projeto estrutural de um automóvel [18]. É usado para estimar o pulso de desaceleração que a estrutura transfere ao ocupante no caso de um impacto. Para isso, os componentes da zona de deformação do carro são representados, de forma simplificada, por um sistema unidimensional composto por massas, molas e, por vezes, amortecedores. A Figura 6 ilustra o modelo massa-mola proposto por Kamal [22].

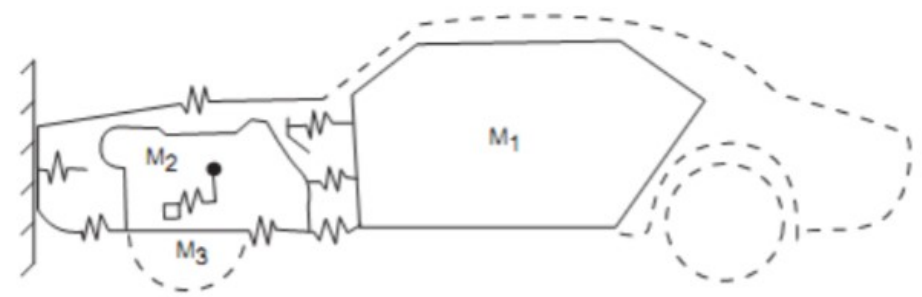

Modelo de simulação Modelo elástico do da estrutura frontal corpo do veículo

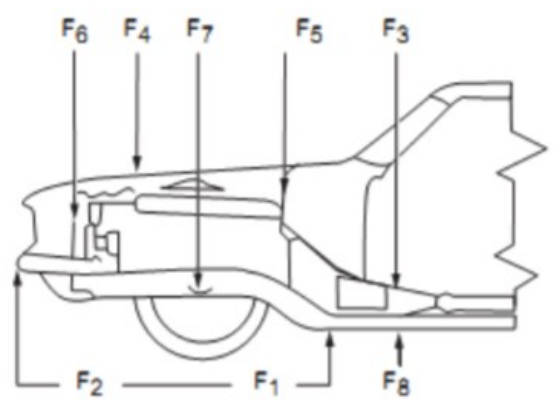

$F_{1}=$ Longarina

$F_{2}=$ Estrutura Frontal

$F_{3}=$ Transmissão

$\mathrm{F}_{4}=$ Chapa Metálica

$\mathrm{F}_{5}=$ Parede Corta Fogo

$F_{6}=$ Radiador, Ventilador $\mathbf{e}$ Grade

$F_{7}=$ Coxins do Motor

$F_{8}=$ Coxim da Transmissão

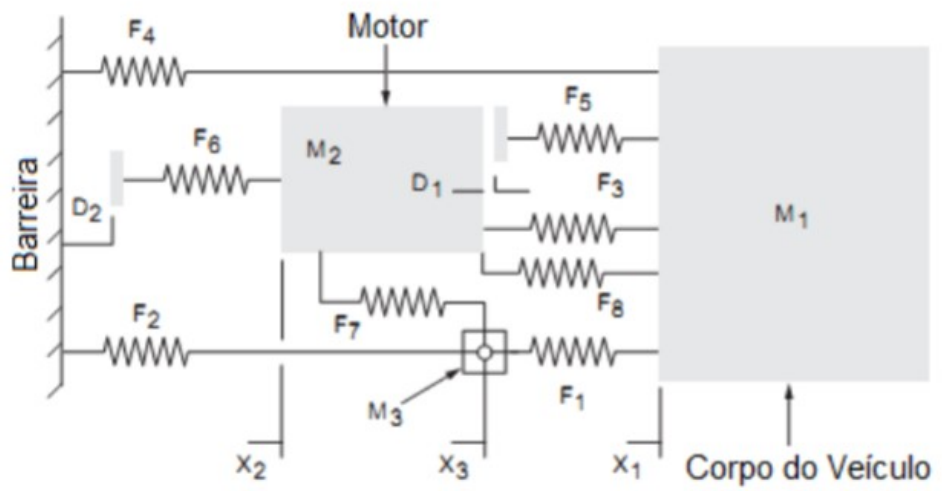

Figura 6: Modelo massa-mola de um automóvel proposto por Kamal (Adaptado por Lima [23] de Bois [18]).

No caso do modelo de Kamal, tem-se massas (motor e corpo do veículo), molas lineares, molas não-lineares e molas torcionais. Outros modelos podem constituir-se de diferentes composições, como por exemplo, representar a massa do radiador ou possuir 
um amortecedor associado à mola para representar a plasticidade da peça [18, 24,25].

Os modelos massa-mola, abreviados como LMS (do inglês, Lumped Mass-Spring), podem apresentar resultados próximos à situação real, sendo particularmente úteis para estudos paramétricos durante os estágios iniciais do projeto, uma vez que tal ferramenta possui custo computacional baixo e dispensa a confecção de uma geometria para a análise.

Por outro lado, para tornar-se eficaz, um modelo LMS necessita de uma investigação prévia das propriedades mecânicas dos componentes do carro, cuja obtenção exige o uso de outros métodos, como ensaios de campo ou simulações pelo método dos elementos finitos. Vale notar também que, caso o conjunto estrutural do carro possua uma geometria mais complexa, da qual justifique a análise do comportamento em duas ou três dimensões, os modelos LMS têm sua eficácia reduzida, já que esses, geralmente, estão limitados a apenas uma dimensão $[8,18]$.

A adoção do uso do método dos elementos finitos em projetos estruturais automotivos iniciou-se na década de 1980, tornando-se mais popular conforme o avanço do poder computacional ao longo dos anos. Por conta da alta complexidade dos fenômenos físicos presentes em um impacto de automóvel, técnicas numéricas se mostram mais práticas quando comparadas a modelos analíticos [18].

Quando bem caracterizado, o modelo em elementos finitos pode apresentar resultados próximos aos do acontecimento real, como mostra a Figura 7, tendo potencial de reduzir o número de testes de campo realizados.

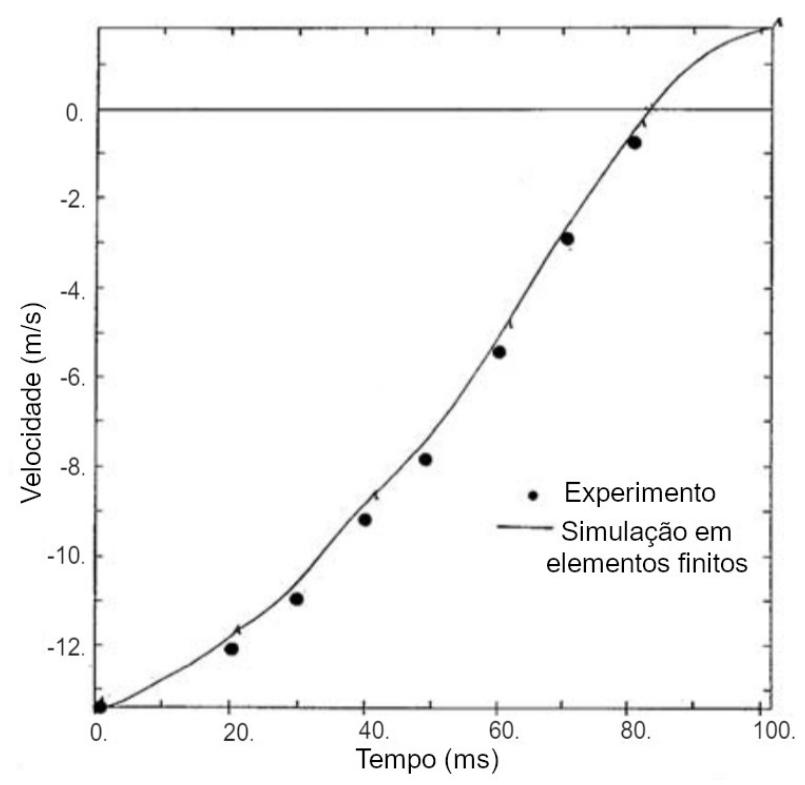

Figura 7: Velocidade do balancim traseiro de um automóvel durante um impacto (Bois $[18])$. 
No caso da Figura 7, mostram-se resultados gerados pelo impacto de um carro, com velocidade inicial de $13,4 \mathrm{~m} / \mathrm{s}$, em uma barreira rígida, comparando um ensaio real e uma simulação em elementos finitos. A geometria em elementos finitos, antes e depois do impacto, pode ser visualizada na Figura 8.

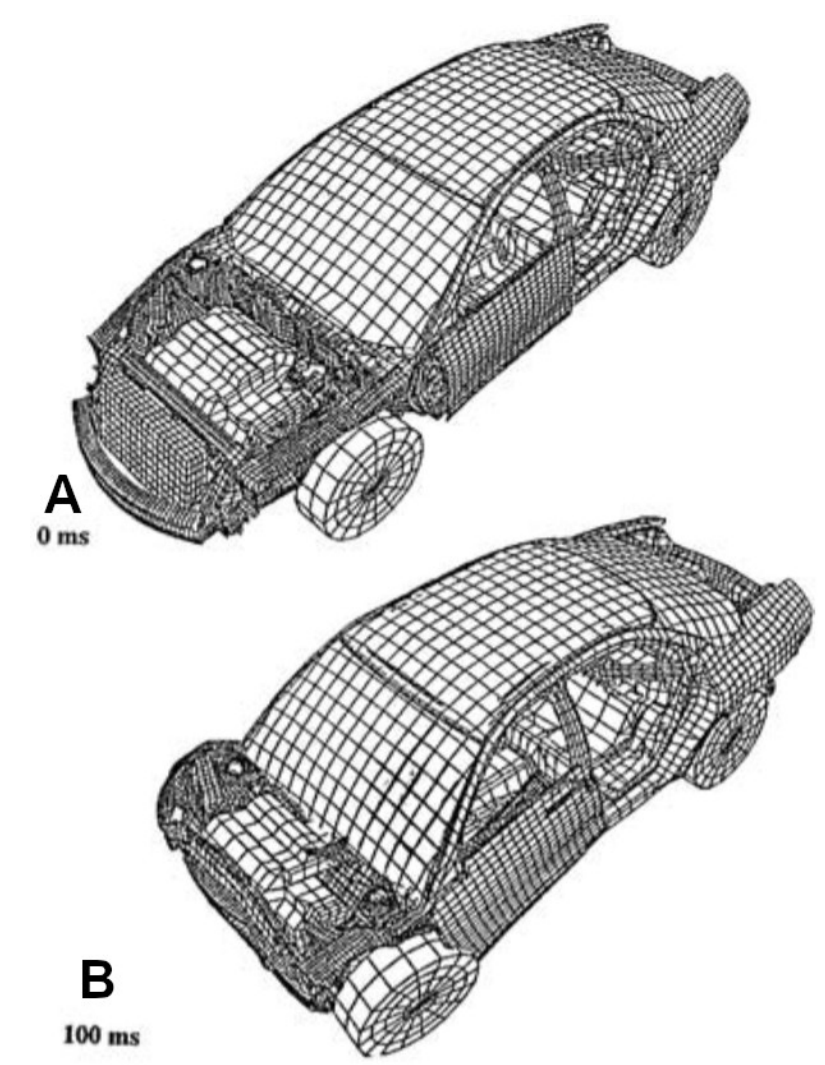

Figura 8: Geometria de um automóvel em elementos finitos, antes (A) e após 100 ms de impacto (B) (Adaptado de Bois [18]).

Vale notar que, como limitação, o modelo em elementos finitos necessita que o projetista já tenha estabelecido uma geometria, uma vez que ela deverá ser reproduzida de forma fiel dentro da simulação numérica. Ressalta-se ainda que ensaios por MEF não substituem as etapas finais de validação e certificação de um protótipo, tornando necessária a realização do teste de impacto com o protótipo real.

Por outro lado, atualmente, as simulações numéricas são responsáveis por eliminar rapidamente projetos com alta probabilidade de não satisfazer determinados critérios de desempenho. Através de estudo paramétricos feitos com MEF, é possível desenvolver protótipos com grandes chances de validação, reduzindo de forma drástica o tempo de desenvolvimento ou de melhoria de um produto $[8,18]$. 


\subsection{Absorção de energia}

Estruturas convencionais, de um modo geral, são dimensionadas para trabalhar dentro de seu regime elástico, em que suas causas de falha, usualmente, resumem-se a fadiga, corrosão ou degradação do material. A mesma lógica não vale para o dimensionamento de estruturas de absorção de energia. Para o último caso, busca-se saber como será sua falha e deformação ao receber uma carga de impacto intensa. Para tal, deve-se levar em consideração fenômenos como: mudanças de geometria, efeitos de taxa de deformação, mudanças na tensão de escoamento e interações entre diferentes modos de deformação [10].

Para atender aos requisitos de desempenho, a maioria dos projetos de absorção de energia é composta por materiais dúcteis. Ligas de alumínio e aços de baixo carbono estão entre os mais usados. Espumas poliméricas e materiais compósitos também tem aplicação usual, principalmente onde se almeja redução de peso [10,26].

O uso de absorvedores de energia não se limita apenas a estruturas automotivas, está presente também em aplicações cuja função é de proteger pessoas e bens materiais de impactos. Pode-se citar exemplos distintos, como muretas metálicas (ou em inglês, guard rails), capacetes e coletes à prova de bala.

Apesar de o projeto poder variar substancialmente de uma aplicação para outra, todo absorvedor de energia é confeccionado para dissipar energia cinética de forma controlada. Para alcançar esse objetivo, são considerados alguns princípios fundamentais durante a concepção desses componentes [10], listados abaixo:

- Conversão irreversível de energia: a energia cinética deve, em sua maior parte, ser transformada para algum meio de dissipação irreversível, como dissipação plástica, energia de deformação viscosa, atrito ou fratura. Caso a energia da carga dinâmica seja convertida em energia elástica, ao final da deformação elástica, a carga dinâmica seria reintroduzida ao meio, causando acelerações e danos subsequentes.

- Restrição da força de reação: o pico da força de reação deve ficar abaixo de um limite considerado como seguro para sua aplicação. Um absorvedor de energia deve atuar como um limitador de carga e deve, idealmente, possuir uma força de reação constante durante o processo de deformação.

- Curso de deslocamento longo: o componente deve ter um deslocamento suficientemente longo para absorver a energia de impacto. Como a energia absorvida é produto da força de reação pelo deslocamento, um curso maior requer uma força de 
reação menor para absorver o impacto, reduzindo danos e lesões.

- Modo de deformação repetível e estável: a maneira como a estrutura se deforma deve ser consistente, garantindo confiabilidade ao sistema. Vale notar que cargas externas de impacto possuem incertezas em sua magnitude, formato de pulso, direção e distribuição. Um absorvedor de energia deve possuir baixa sensibilidade às incertezas externas, o que assegura sua capacidade em absorver energia de modo repetível.

- Alta absorção de energia específica: o elemento deve conter uma alta capacidade de absorção de energia por unidade de massa. Essa propriedade é especialmente importante na aplicação em veículos automotores, uma vez que o aumento de massa em um veículo implica no aumento de consumo de combustível e emissão de poluentes.

- Baixo custo e fácil instalação: o ciclo de vida de um absorvedor de energia deve ser economicamente viável. Devido à competitividade de mercado, o desenvolvimento de produtos está, na maioria das vezes, limitado ao custo. Ressalta-se ainda que, uma vez deformados, os absorvedores de energia não podem ser utilizados novamente.

Estudos contemporâneos na área de absorção de energia propõem ganhos de desempenho a partir de diferentes abordagens. A aplicação de materiais compósitos e espumas metálicas mostrou-se eficiente, principalmente em aplicações onde busca-se redução de massa, como na indústria aeroespacial [27].

Vale citar também o uso de materiais auxéticos, também conhecidos como metamateriais, que possuem características ausentes nos materiais e estruturas convencionais. Possuem boas propriedades de absorção de energia e ganharam viabilidade com a popularização de métodos de manufatura aditiva [28].

A partir de análises experimentais, Li e You [29] investigaram o desempenho de tubos com seção transversal côncava, associados com iniciadores de falha. Tal escolha de geometria permitiu um ganho considerável de absorção de energia específica.

Há também absorvedores de energia com geometria conhecida como origami. Análoga às dobraduras em papel, essa configuração possui irregularidades geométricas intencionais, ilustradas na Figura 9, que influenciam no modo de falha do componente. Esse tipo de estrutura permitiu ganhos na absorção de energia específica e redução na força de reação máxima $[30,31]$. 


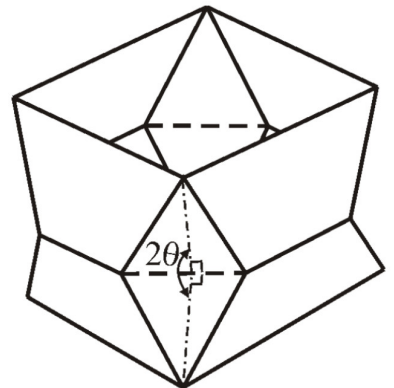

(a)

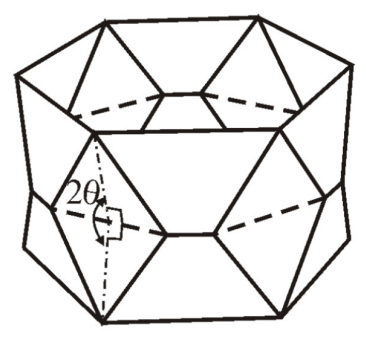

(b)

Figura 9: (a) Tubo de origami retangular, (b) tubo de origami hexagonal (Adaptado de Ma [32]).

Como mencionado na Seção 2.2, na Figura 5, um absorvedor de energia notável, foco deste trabalho, é a longarina principal do automóvel. Em carros de passeio, ela se apresenta como um tubo metálico de paredes finas. Esse tipo de construção é justificado pela simplicidade, alta capacidade de absorver energia e custo de fabricação e montagem relativamente baixo $[20,33]$. Pode apresentar seção transversal circular ou ainda poligonal, como mostra a Figura 10. O resultado base para a comparação é o teste dinâmico no tubo de seção quadrada, com o valor de 100\%. Em outras palavras, um valor maior que $100 \%$ representa um aumento na força de reação média, quando comparado ao teste dinâmico no tubo de seção quadrada.

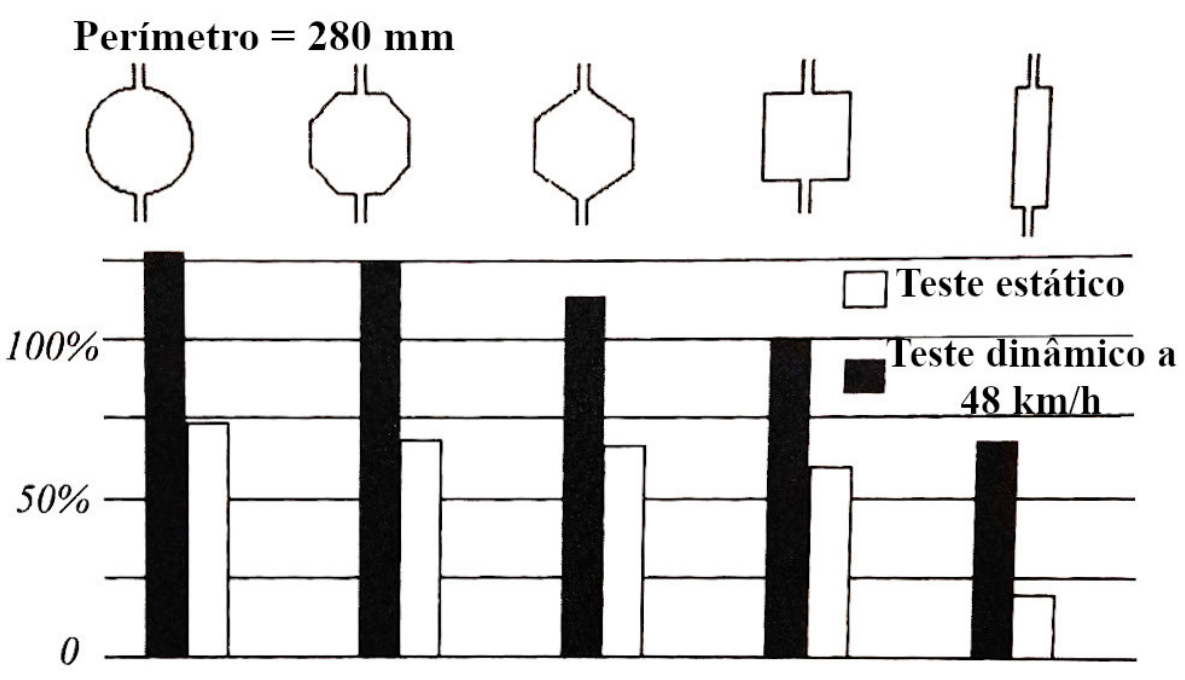

Figura 10: Força de reação média de tubos com mesmo perímetro e geometrias transversais díspares (Adaptado de Malen [20]).

A Figura 10 exibe uma comparação entre diferentes seções transversais de tubos de paredes finas, apresentando a força de reação média obtida para o teste estático e o teste dinâmico. 
Cabe ressaltar a importância da força de reação média de um absorvedor de energia, uma vez que ela indica a capacidade de absorção de energia por unidade de comprimento. A Figura 11 ajuda a ilustrar a ideia, lembrando que a energia absorvida resulta da área abaixo do gráfico.

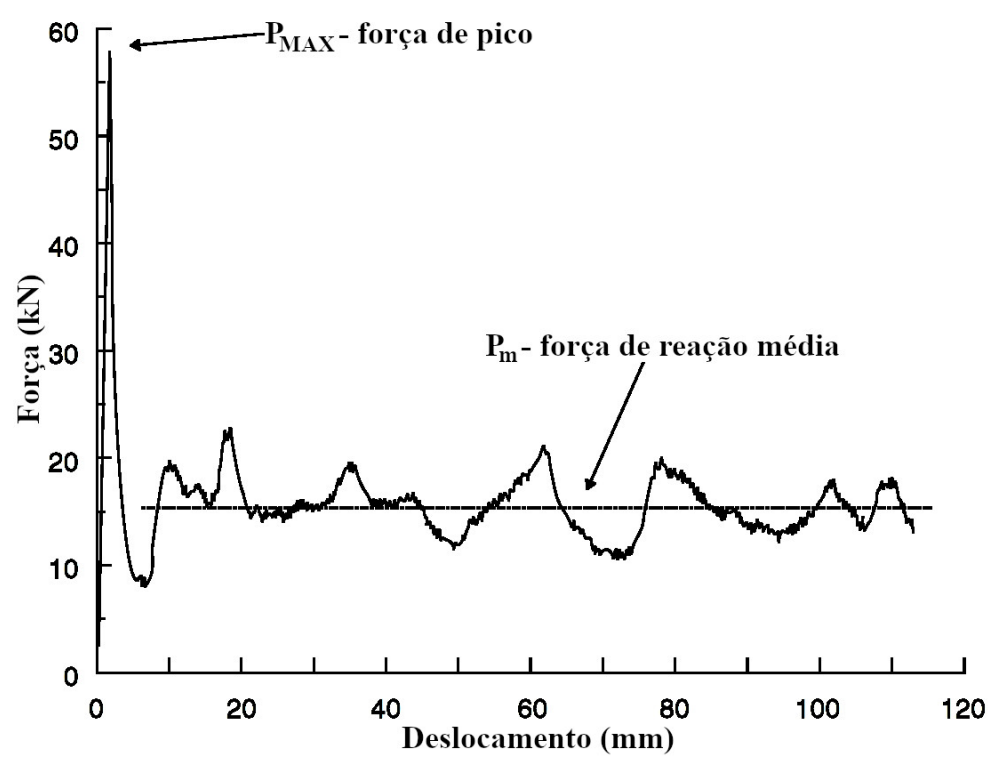

Figura 11: Gráfico de força por deslocamento típico de um tubo de paredes finas (Adaptado de Jones [34]).

A Figura 11 mostra o comportamento de falha típico de um tubo de paredes finas. O primeiro pico de força caracteriza o esforço necessário para iniciar a deformação no tubo. Os picos e variações de força subsequentes retratam um fenômeno chamado de flambagem progressiva, em que são formadas dobras ao longo da seção longitudinal do tubo $[10,34,35]$.

A razão entre a força média e a de pico é chamada de eficiência da força de esmagamento, ou ainda de uniformidade de carga [32], que quanto mais próxima de 100\%, melhor. Uma eficiência maior corresponde a menos mudanças de aceleração [33]. Vale ressaltar que o resultado do gráfico de força por deslocamento depende simultaneamente da carga externa atuante e das características de projeto do absorvedor de energia.

O modo de falha do componente varia de acordo com seu dimensionamento e geometria. Para o caso de um tubo circular de paredes finas, destacam-se o modo axissimétrico (também chamado de modo anel) e o modo assimétrico (também conhecido como modo diamante), como ilustrado pela Figura 12. 


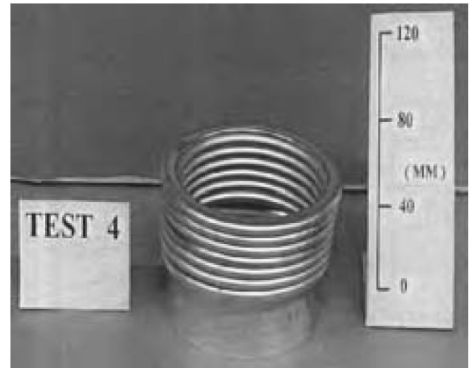

(a)

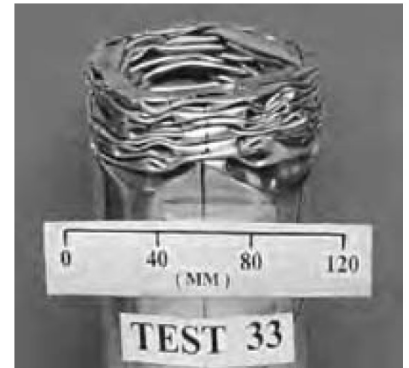

(b)

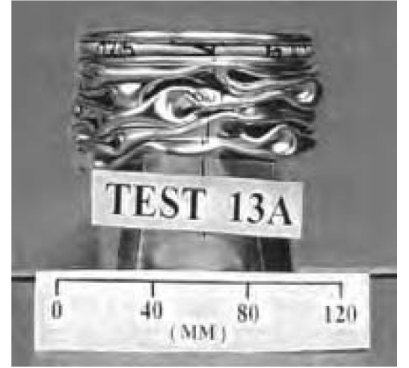

(c)

Figura 12: Modos de falha de absorvedores de energia sob cargas axiais. Modo anel em (a); modo diamante em (b) e modo misto em (c) ( $\mathrm{Lu}$ e Yu [10]).

O modo misto é uma combinação entre o modo axissimétrico e o assimétrico. No caso da Figura 12 (c), a falha do absorvedor iniciou com o modo anel e depois passou para o modo diamante. O tubo pode falhar também por flambagem global, o que é indesejado para a aplicação, uma vez que a maior parte da energia absorvida provém da formação de dobras no tubo $[10,34]$. A Figura 13 exemplifica a relação entre o dimensionamento e o modo de falha de absorvedores de energia.

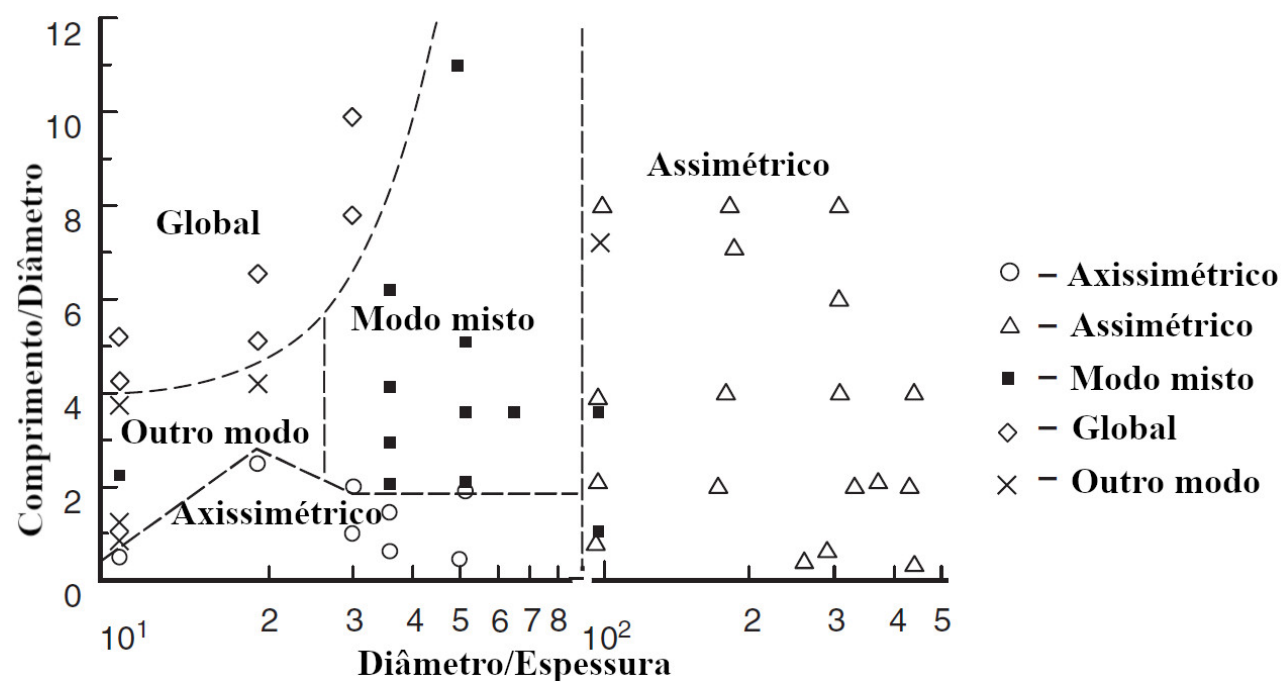

Figura 13: Modos de falha em tubos circulares de alumínio e com paredes finas (Adaptado pelo Autor de Guillow et al. [36]).

As informações ilustradas pela Figura 13 foram obtidas de maneira experimental, a partir de tubos circulares de alumínio 6060-T5 com diferentes medidas. Guillow et al. [36] discutem tais resultados com maior profundidade. O modo de falha também é diretamente afetado pela velocidade de impacto e o material do absorvedor [35,37], conforme mostra a Figura 14. 


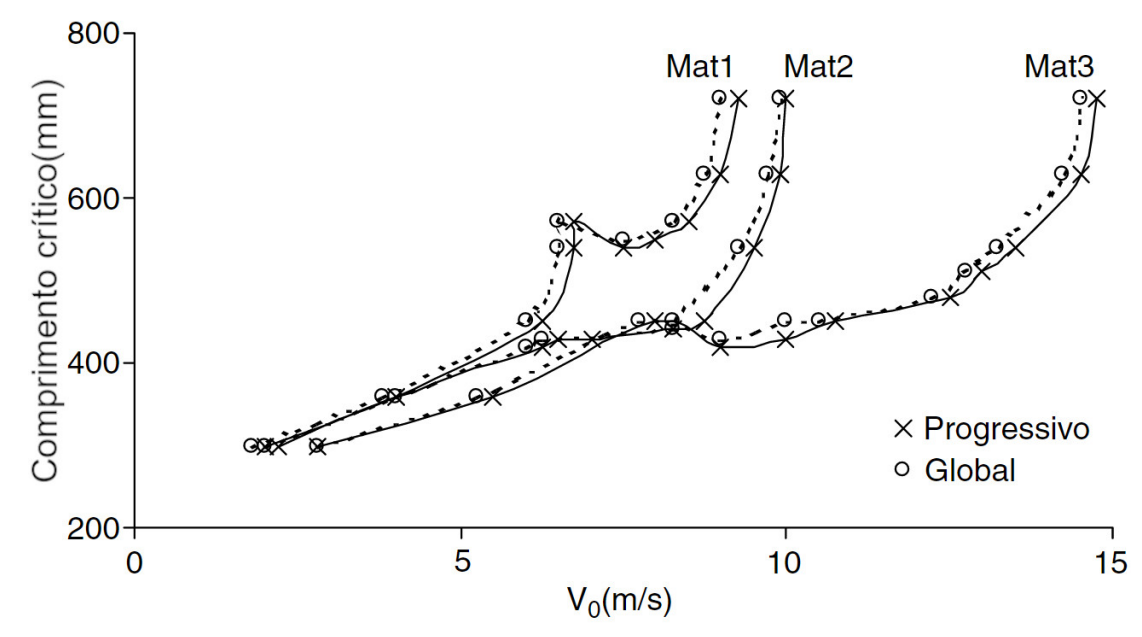

Figura 14: Modos de falha em absorvedores de energia com diferentes materiais (Adaptado pelo Autor de Karagiozova e Alves [37]).

O comprimento crítico é a dimensão em que a falha está na transição entre a flambagem global e a flambagem progressiva, onde a última contempla os modos mais compactos, como axissimétrico, assimétrico ou misto. Os resultados da Figura 14 foram obtidos numericamente a partir de três modelos diferentes de material. No caso, quanto maior a velocidade de impacto, maior pode ser o comprimento do tubo, sem que o mesmo falhe por flambagem global.

Por conta da simplicidade geométrica, o modo de falha axissimétrico possui um modelo matemático mais robusto [10]. O cálculo de dissipação de energia para uma carga axial é feito com base na energia necessária para formar as chamadas rótulas plásticas, como mostra a Figura 15.

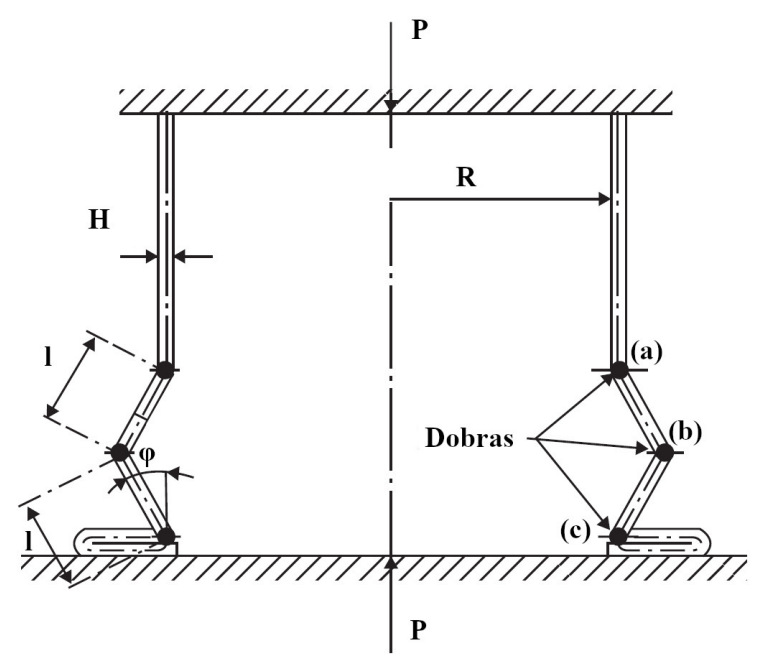

Figura 15: Formação de rótulas plásticas axissimétricas em tubo circular (Adaptado pelo Autor de Jones [34]). 
A energia plástica absorvida pelas duas articulações estacionárias, representadas por (a) e (c) na Figura 15, durante a formação de uma dobra é representada por,

$$
D_{1}=2 \times 2 \pi R M_{0} \pi / 2
$$

onde $R$ é o raio do tubo e $M_{0}$ é o momento, por unidade de comprimento, de colapso plástico para a seção transversal, descrito como,

$$
M_{0}=\left(2 \sigma_{0} / \sqrt{3}\right) H^{2} / 4
$$

onde $\sigma_{0}$ é a tensão de escoamento do material e $H$ a espessura do tubo.

A articulação (b) move da posição $R$ para $R+l$, apresentando uma absorção de energia conforme a alteração do ângulo $\phi$. A variação de energia é dada por,

$$
d D_{2}=2 \pi(R+l \operatorname{sen}(\phi)) M_{0}(2 d \phi)
$$

Integrando a Equação 2.6 em função de $d \phi$ de 0 para $\pi / 2$, tem-se:

$$
D_{2}=4 \pi M_{0}(R \pi / 2+l)
$$

Tem-se ainda a energia necessária para mover a seção entre (a) e (b) e a seção entre (b) e (c), descrita como,

$$
d D_{3}=\sigma_{0} d \epsilon_{\theta} 2 l H 2 \pi R
$$

onde $d \epsilon_{\theta}$ é o incremento de deformação de engenharia, expresso por:

$$
d \epsilon_{\theta}=l \cos (\phi) d \phi / 2 R
$$

Inserindo a Equação 2.9 dentro da Equação 2.8 e a integrando em função de $d \phi$ de 0 a $\pi / 2$, gera-se:

$$
D_{3}=2 \sigma_{0} l^{2} H \pi
$$

A energia total absorvida por cada dobra de um tubo circular é dada por $D_{T}=$ 
$D_{1}+D_{2}+D_{3}$, forma-se:

$$
D_{T}=2 \pi \sigma_{0} H^{2}(\pi R+l) / \sqrt{3}+2 \pi \sigma_{0} l^{2} H
$$

Levando em conta a conservação de energia, a energia absorvida $D_{T}$ pode ser igualada ao trabalho necessário para formar uma dobra completa, gerando,

$$
P_{m} 2 l=2 \pi \sigma_{0} H\left\{H(\pi R+l) / \sqrt{3}+l^{2}\right\}
$$

onde $P_{m}$ é a força externa média e $2 l$ o comprimento total da dobra. O comprimento $l$ é inicialmente desconhecido, porém pode ser obtido ao minimizar a força axial de esmagamento $d P_{m} / d l=0[34]$, resultando em:

$$
l=\sqrt{\frac{\pi R H}{\sqrt{3}}}
$$

Ao substituir a Equação 2.13 na Equação 2.12 e rearranjá-la, faz-se:

$$
P_{m} / M_{0}=4(3)^{1 / 4} \pi^{3 / 2}(R / H)^{1 / 2}+2 \pi
$$

Lembrando que a Equação 2.14 foi feita levando em conta dobras exclusivamente externas ao diâmetro do tubo. Repetindo o processo para articulações que se movem de $R$ para $R-l$ e alterando a Equação 2.6, obtém-se a seguinte equação para dobras internas ao diâmetro,

$$
P_{m} / M_{0}=4(3)^{1 / 4} \pi^{3 / 2}(R / H)^{1 / 2}-2 \pi
$$

Assumindo que as articulações móveis (b) da Figura 15 podem ser tanto internas quanto externas ao diâmetro original do tubo, usa-se um valor médio entre a Equação 2.14 e a Equação 2.15,

$$
P_{m}=2(\pi H)^{3 / 2} R^{1 / 2} \sigma_{0} / 3^{1 / 4}
$$

que oferece uma boa aproximação dos resultados reais de falha por modo axissimétrico [34].

Ressaltando que a Equação 2.16 vale apenas para o modo anel de falha. Jones [34] explora a formulação desse tipo de falha com maior profundidade, discutindo inclusive 
efeitos da taxa de deformação.

Já os modelos matemáticos do modo diamante são baseados em relações geométricas dos lóbulos triangulares formados pela falha [38-40], como exemplificado pela Figura 16. Vale notar que não há um modelo teórico definitivo para definir a energia absorvida pela falha assimétrica, sendo que cada fórmula apresenta seus prós e contras [10].

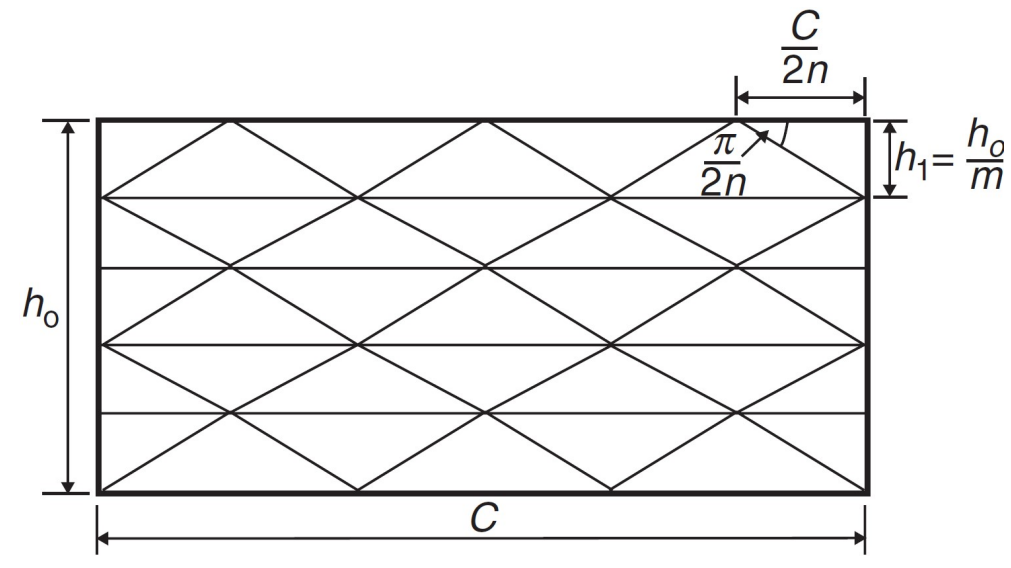

Figura 16: Lóbulos triangulares do modo de falha assimétrico (Adaptado pelo Autor de $\mathrm{Lu} \mathrm{e} \mathrm{Yu}[10])$.

Em 1960, Pugsley e Macaulay [40] propuseram a equação a seguir para estimar a força média do absorvedor de energia que falha de forma assimétrica:

$$
P_{m}=\sigma_{0} \pi H(10 H+0,26 R)
$$

Já em 1977, Johnson et al. [38] propuseram:

$$
\frac{P_{m}}{2 \pi M_{0}} \approx 1+n \operatorname{cosec}\left(\frac{\pi}{2 n}\right)+n \operatorname{cotan}\left(\frac{\pi}{2 n}\right)
$$

onde $n$ é o número de lóbulos circunferenciais, do qual não há método determinado para prever seu valor [10].

Vale citar também o trabalho de Singace [39], que desenvolveu a seguinte equação para prever a força do modo diamante:

$$
\frac{P_{m}}{M_{0}}=-\frac{\pi}{3} n+\frac{2 \pi^{2}}{n} \tan \left(\frac{\pi}{2 n}\right) \frac{2 R}{H}
$$

Seja pelo modo anel ou diamante, a energia total absorvida é dada por, 


$$
E_{T}=P_{m} \Delta
$$

onde $\Delta$ é o deslocamento axial máximo do absorvedor de energia, que depende diretamente do comprimento do tubo.

É importante que o absorvedor de energia possua um comprimento longo suficiente para permitir a formação de lóbulos necessários para absorver toda a energia de impacto. Caso contrário, o componente atingirá um fim de curso, o que aumentará sua rigidez abruptamente, consequentemente gerando uma grande força de reação ao fim de sua deformação, como exemplificado na Figura 17.

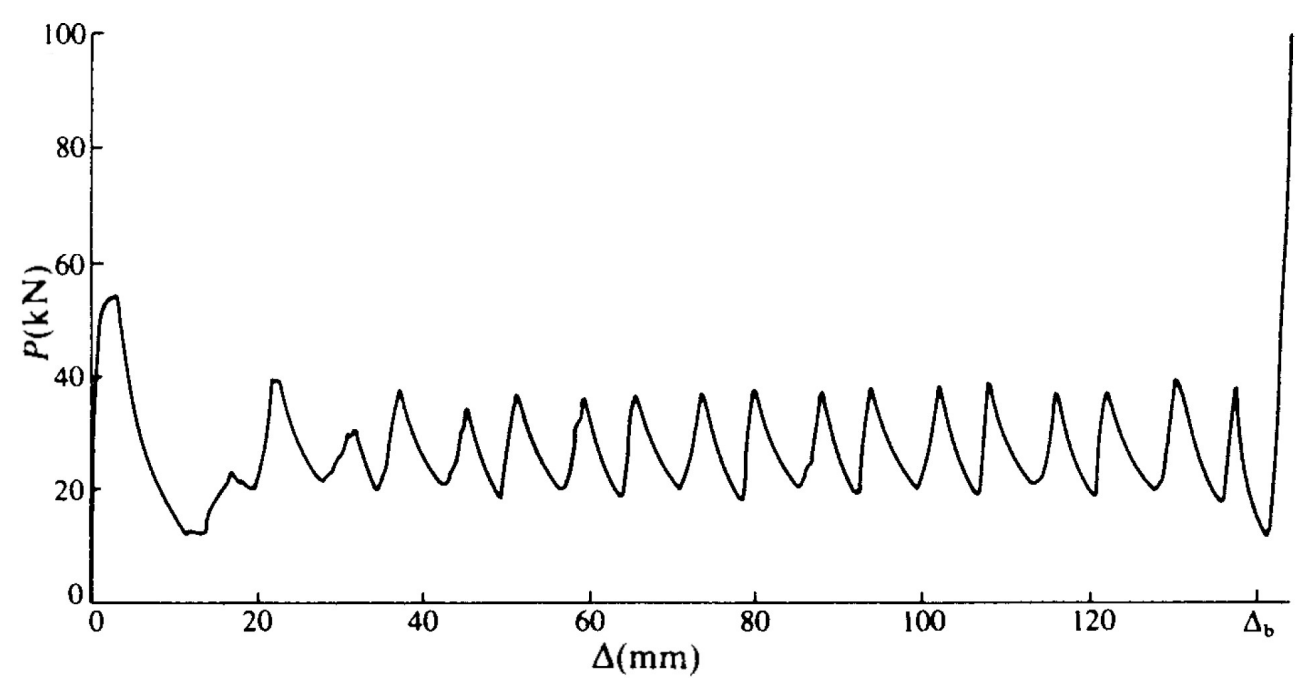

Figura 17: Comportamento do fim de curso de um tubo circular (Adaptado de Jones [34]).

Dado os parâmetros a serem considerados no cálculo da energia total absorvida (Equação 2.20), a estimativa de força média (Equações 2.16 à 2.19, dependendo do fenômeno ou modelo) e o momento de colapso plástico (Equação 2.5), nota-se que a absorção total de energia depende diretamente do comprimento, espessura e raio da longarina, justificando a escolha desses parâmetros para a otimização.

\subsection{Planejamento de experimentos (DoE)}

O grande custo computacional de uma simulação de impacto veicular acaba por limitar o número de experimentos a serem realizados, requerendo que a seleção das amostras dos valores dos parâmetros seja cuidadosamente planejada. Tanto a criação de projetos iniciais, quanto a construção de um metamodelo se dá a partir de um grupo de dados de entrada de projeto e seus respectivos valores de resposta. A metodologia que descreve o 
preenchimento de dados dentro do espaço de projeto, minimizando o número de amostras ao mesmo tempo em que fornece os melhores resultados possíveis, é denominado projeto de experimentos (DoE, do inglês, Design of Experiments) [23].

No estudo em questão, a seleção da melhor forma de gerenciar os experimentos é de suma importância, uma vez que seus respectivos resultados serão utilizados para a geração de projetos iniciais e a criação de metamodelos. De acordo com Queipo et al. [41], o erro sistemático entre o metamodelo e o modelo original pode ser reduzido a partir do uso de um DoE que distribua os pontos amostrais uniformemente no espaço do projeto. No caso de otimizações que dispensam o uso de um metamodelo, o DoE também é responsável por gerar projetos que possuam características diversas entre si, permitindo que o algoritmo de otimização explore diferentes combinações dentro do espaço estudado.

Vale notar ainda que há uma diferença crucial entre os planejamentos de experimentos clássicos e aqueles voltados para simulações computacionais. No primeiro caso, busca-se reduzir a variância gerada por eventos aleatórios dentro do processo físico. Para isso, um DoE clássico gera experimentos replicados, já que um mesmo experimento pode gerar resultados ligeiramente distintos. Além disso, deve possuir uma tendência de gerar projetos próximos aos limites do espaço analisado, buscando agrupar os resultados [42, 43].

No contexto de simulações computacionais, os resultados possuem caráter determinístico, ou seja, desde que seja usado um mesmo método, um experimento específico deverá apresentar sempre o mesmo resultado. Tal característica isenta o uso de replicações e agrupamento de testes. Chamado de projeto de experimento de preenchimento do espaço, do inglês "space-filling design", esse tipo de classe de DoE busca distribuir os pontos de maneira uniforme ao longo do espaço do estudo, favorecendo pontos na parte interna do espaço de estudo. Sob a condição de o estudo ser determinístico, um space-filling design tem a capacidade de reduzir o erro de um modelo de regressão gerado, conforme ilustrado na Figura 18. 


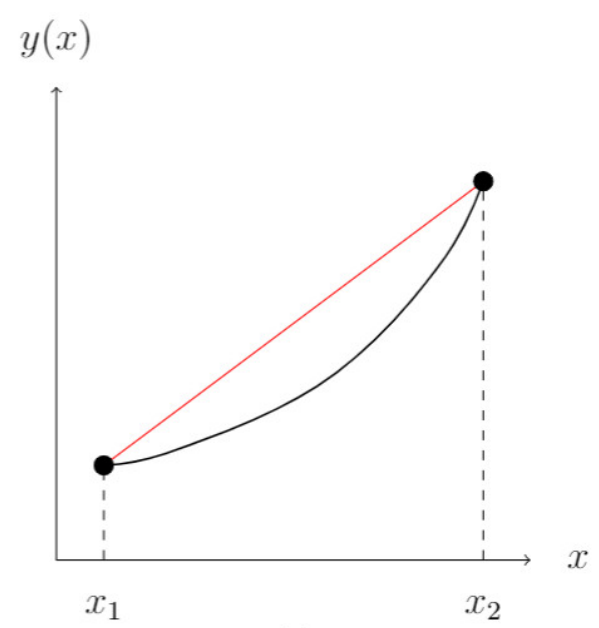

(a)

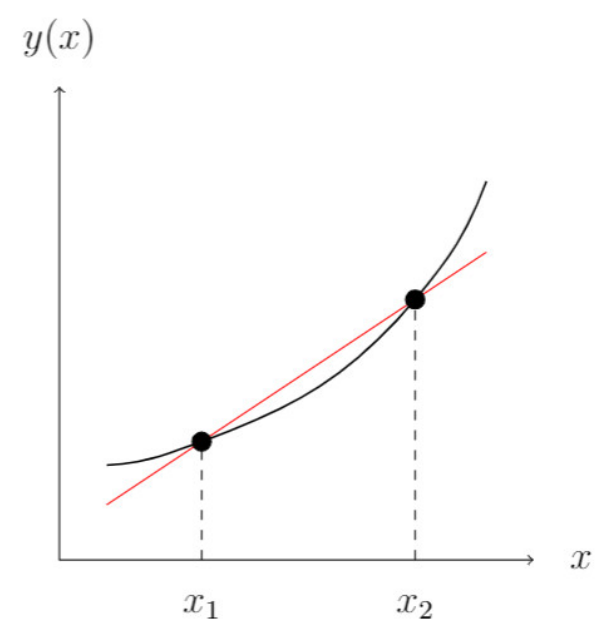

(b)

Figura 18: Interpolação (em vermelho) de um fenômeno determinístico (em preto) através de um DoE clássico (a) e um DoE de preenchimento de espaço (b) (Adaptado pelo Autor de Nesbakken [42]).

Dentre as técnicas de preenchimento de espaço, vale destacar o Hipercubo Latino e o Sobol.

Proposta por McKay et al. em 1979, a amostragem por Hipercubo Latino (LHS, do inglês Latin Hypercube Sampling) tem como objetivo gerar amostras esparsas, possibilitando a obtenção de uma distribuição mais uniforme [44,45].

O conceito do algoritmo LHS embasa-se na definição do "quadrado latino", em que há uma grade quadrada $n \times \mathrm{x} n$ contendo os pontos amostrais, onde os valores aparecem exclusivamente uma vez em cada linha e coluna, conforme exemplificado na Figura 19.

Durante a construção de uma amostra do tipo LHS de tamanho $n$ e dimensão $k$, realiza-se um particionamento do intervalo de cada variável $k \mathrm{em} n$ subintervalos espaçados 

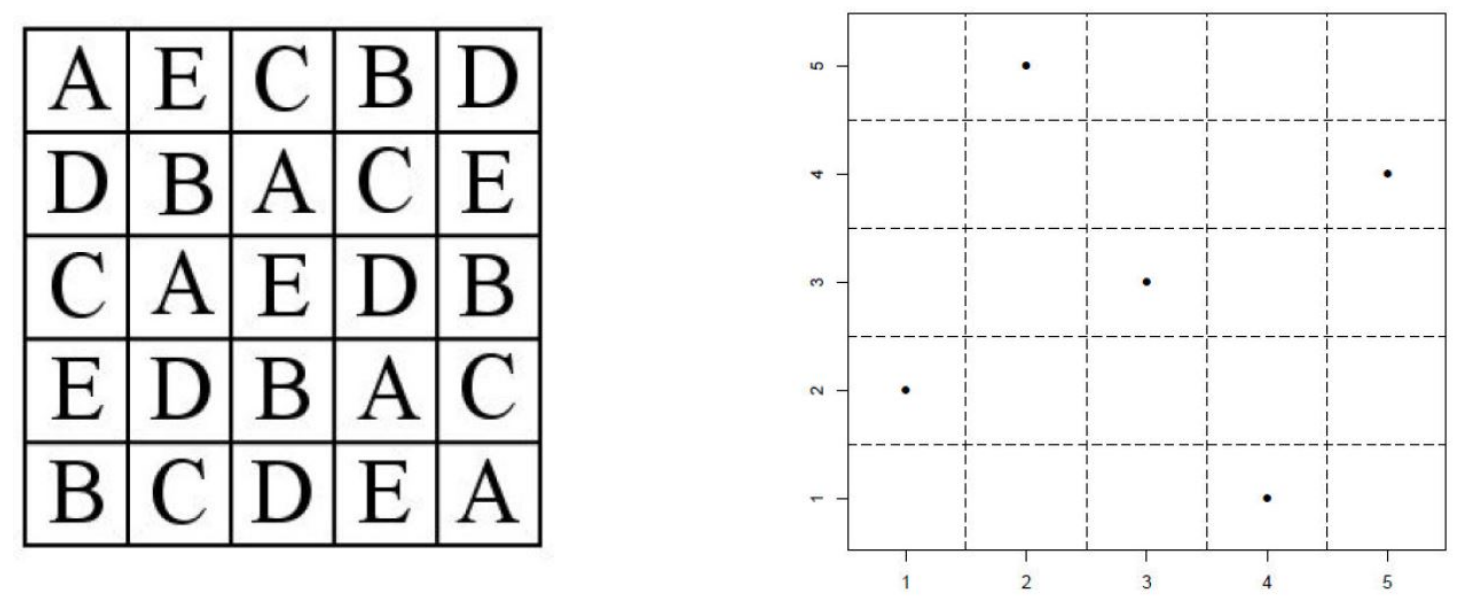

Figura 19: Quadrado latino à esquerda e à direita uma amostra de quadrado latino baseado na letra E (Nesbakken [42]).

igualmente. O espaço das variáveis é então dividido em um total de regiões $n^{k}$ de mesma probabilidade. Em seguida é realizada uma permutação aleatória dos valores de 1 até $n$ para cada variável $k$ e combina-se as colunas para obter uma matriz $n \times k$, representando uma amostra por hipercubo latino [23,42], como demonstrado pelas Equações de 2.21 à 2.23:

$$
x_{i j}=\frac{\boldsymbol{\pi}_{i j}-\boldsymbol{U}_{i j}}{n}, \quad \text { para } 1 \leq i \leq n, 1 \leq j \leq k
$$

onde cada $\boldsymbol{\pi}_{. j}$ é uma permutação aleatória de números inteiros de 1 até $n$, e cada $\boldsymbol{U}_{i j}$ é um valor aleatório retirado da distribuição uniforme $U[0,1]$. O subscrito $j$ representa o índice da dimensão, enquanto $i$ representa o índice do número de experimentos [42].

Para um espaço amostral com 6 projetos e 2 dimensões tem-se:

$$
\boldsymbol{\pi}_{.1}=\left[\begin{array}{l}
5 \\
2 \\
4 \\
6 \\
3 \\
1
\end{array}\right], \quad \boldsymbol{\pi}_{.2}=\left[\begin{array}{l}
2 \\
1 \\
6 \\
4 \\
5 \\
3
\end{array}\right], \quad \boldsymbol{U}=\left[\begin{array}{ll}
0,576 & 0,175 \\
0,240 & 0,374 \\
0,620 & 0,147 \\
0,294 & 0,837 \\
0,877 & 0,616 \\
0,865 & 0,018
\end{array}\right]
$$

onde os vetores $\boldsymbol{\pi}_{.1}$ e $\boldsymbol{\pi}_{.2}$ são permutações aleatórias da sequência $[1,2,3,4,5,6]$ e a matriz $U$ resultado de 12 números aleatórios entre 0 e 1.

A partir da Equação 2.22, gera-se o planejamento de experimentos mostrado na 
Equação 2.23:

$$
\frac{1}{n}(\boldsymbol{\pi}-\boldsymbol{U})=\frac{1}{n}\left(\left[\begin{array}{ll}
5 & 2 \\
2 & 1 \\
4 & 4 \\
6 & 4 \\
3 & 5 \\
1 & 3
\end{array}\right]-\left[\begin{array}{ll}
0,576 & 0,175 \\
0,240 & 0,374 \\
0,620 & 0,147 \\
0,294 & 0,837 \\
0,877 & 0,616 \\
0,865 & 0,018
\end{array}\right]\right)=\left[\begin{array}{ll}
0,737 & 0,287 \\
0,304 & 0,027 \\
0,626 & 0,853 \\
0,937 & 0,563 \\
0,396 & 0,689 \\
0,142 & 0,496
\end{array}\right]
$$

Visualmente, o resultado da Equação 2.23 geraria a distribuição ilustrada pela Figura 20:

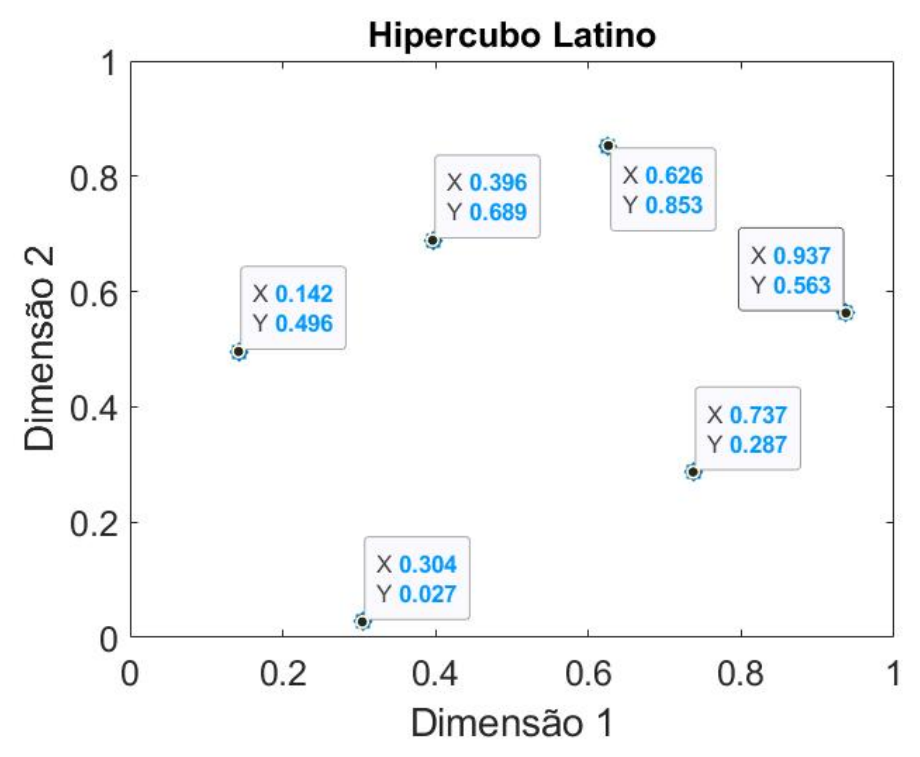

Figura 20: Distribuição de valores entre 0 e 1 gerados por Hipercubo Latino.

onde os números da primeira coluna estão representados no Eixo X, enquanto os valores da segunda coluna são retratados no Eixo Y.

Vale ressaltar que o LHS possui um comportamento estocástico, ou seja, caso o valor que comande a permutação (chamado de seed) do vetor $\pi_{. j}$ seja alterado, esse algoritmo de DoE irá gerar distribuições distintas a cada execução, mesmo que os outros parâmetros permaneçam iguais.

Introduzida pelo matemático Ilya Meyerovich Sobol, a sequência de Sobol é um algoritmo de DoE determinístico que emula o comportamento de um planejamento de experimentos do tipo aleatório. Tem como principal função gerar pontos que maximizem as suas distâncias, reduzindo o efeito de agrupamento [46, 47].

O algoritmo de Sobol é gerado a partir de um polinômio primitivo de grau $q$ associado 
a um corpo de Galois de ordem 2 [48], também representado pela notação GF(2) (do inglês, Galois Field), como representado na Equação 2.24.

$$
P_{q}=x^{q}+a_{1} x^{q-1}+a_{2} x^{q-2}+\ldots+a_{q-1} x+1
$$

onde $a$ representa o corpo de Galois, podendo assumir o valor de 0 ou de 1 .

A Tabela 1 mostra alguns exemplos de polinômios primitivos $P_{q}$ para GF(2).

\begin{tabular}{|c|c|}
\hline Grau & Polinômio primitivo \\
\hline 1 & $1+x$ \\
\hline 2 & $1+x+x^{2}$ \\
\hline 3 & $1+x+x^{3}, 1+x^{2}+x^{3}$ \\
\hline 4 & $1+x+x^{4}, 1+x^{3}+x^{4}$ \\
\hline 5 & $\begin{array}{l}1+x^{2}+x^{5}, 1+x+x^{2}+x^{3}+x^{5}, 1+x^{3}+x^{5}, \\
1+x+x^{3}+x^{4}+x^{5}, 1+x^{2}+x^{3}+x^{4}+x^{5}, 1+x+x^{2}+x^{4}+x^{5}\end{array}$ \\
\hline
\end{tabular}

Tabela 1: Exemplos de polinômios primitivos para GF(2).

Os valores de $a$ são definidos ao selecionar o grau do polinômio primitivo. Quando feito, dá-se sequência à equação recursiva [49], descrita por:

$$
M_{i}=2 a_{1} M_{i-1} \oplus 2^{2} a_{2} M_{i-2} \oplus \ldots \oplus 2^{q-1} a_{q-1} M_{i-q+1} \oplus 2^{q} M_{i-q} \oplus M_{i-q}
$$

onde $\oplus$ representa o operador "Ou exclusivo" (XOR, do inglês Exclusive Or), $M$ denota um conjunto de números de inicialização para compor a sequência aleatória de Sobol. $M_{i}$ deve atender dois critérios, sendo eles: ser um número inteiro ímpar e ser menor que seu respectivo $2^{i}$, ou seja, $M_{3}<2^{3}[50]$.

Os primeiros $q$ valores de $M$ são gerados aleatoriamente, enquanto os outros valores de $M$ são calculados com base na Equação 2.25. Por exemplo, para um polinômio primitivo equivalente a $x^{3}+x+1(q=3), a_{1}=0$ e $a_{2}=1$. A equação recursiva terá o seguinte formato:

$$
M_{i}=4 M_{i-2} \oplus 8 M_{i-3} \oplus M_{i-3}
$$

Assume-se então valores aleatórios, seguindo os critérios de geração de $M_{i}$, para os três primeiros valores de $\mathrm{M}$, resultando em $M_{1}=1, M_{2}=3$ e $M_{3}=7$. Os próximos valores de $\mathrm{M}$ são gerados a partir da equação recursiva, resultando em: 


$$
\begin{aligned}
& M_{4}=12 \oplus 8 \oplus 1=5 \\
& M_{5}=28 \oplus 24 \oplus 3=7, \text { e assim sucessivamente. }
\end{aligned}
$$

Em seguida, após gerar o conjunto de $M_{i}$, é computado o chamado número de direção, calculado para cada $M_{i}$, conforme:

$$
V_{i}=\frac{M_{i}}{2^{i}}
$$

Dando sequência ao exemplo, tem-se $V_{1}=0,5, V_{2}=0,75, V_{3}=0,875, V_{4}=0,3125$ e $V_{5}=0,21875$.

A seguir, é calculado o Código Gray, que é um sistema de código binário que gera valores sucessivos que diferem de um bit. É utilizado para gerar sequências únicas aos números vizinhos e prevenir valores ambíguos durante a execução do algoritmo de Sobol [51]. É descrito por:

$$
G_{c}(i)=i \oplus\left[\frac{i}{2}\right]
$$

Seguindo o exemplo, retira-se: $G(1)=1, G(2)=3, G(3)=2, G(4)=6, G(5)=7$. onde [ ] delimita a parte inteira de um número real.

A sequência de Sobol é calculada de acordo com a Equação 2.30.

$$
x_{i}=G_{1} V_{1} \oplus G_{2} V_{2} \oplus G_{3} V_{3} \oplus \ldots
$$

onde $G$ é o número binário correspondente do código de Gray.

No exemplo, são obtidos os seguintes valores: $x_{1}=0,5, x_{2}=0,25, x_{3}=0,75, x_{4}=$ $0,125, x_{5}=0,4375$.

Para gerar a sequência em um número maior de dimensões, basta selecionar outro polinômio primitivo e repetir todo o processo. Por isso, ao utilizar a sequência de Sobol, recomenda-se trabalhar com 10 dimensões ou menos [47].

A Figura 21 mostra, visualmente, um exemplo de uma sequência de Sobol gerada a partir de 6 experimentos e 2 dimensões, análogo ao apresentado na Figura 20. 


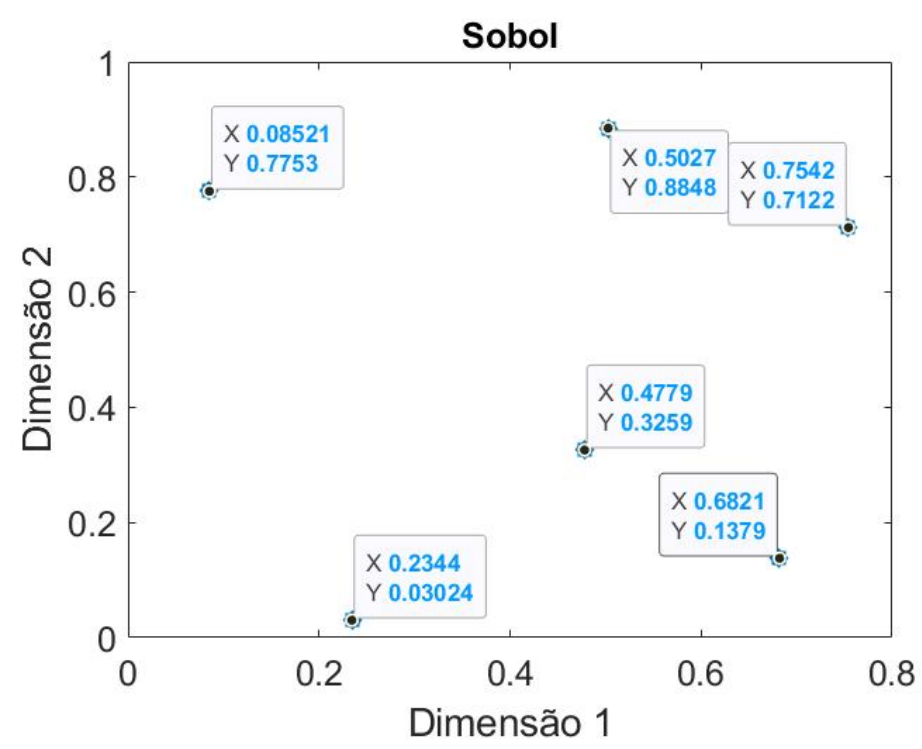

Figura 21: Distribuição de valores entre 0 e 1 gerados por Sobol.

\subsection{Metamodelamento}

A otimização é uma ferramenta imprescindível quando se quer acelerar o desenvolvimento de um produto e reduzir o custo de sua produção [8]. No entanto, a complexidade dos fenômenos físicos presentes em um impacto de automóvel acaba por dificultar a aplicação de otimização. A inviabilidade da adoção de um modelo analítico para este tipo de estudo acaba por gerar a necessidade da adoção de códigos computacionais complexos, que por sua vez fornecem apenas resultados pontuais entre os dados de entrada e saída, obstando a análise do problema como um todo.

Apesar do constante avanço tecnológico no que se refere à velocidade de processamento de computadores, o tempo necessário para a conclusão de simulações numéricas de maior complexidade (como uma situação dinâmica e não linear) representa um obstáculo para estudos que requerem múltiplos ensaios, dentre eles, estudos de otimização [23]. Neste caso específico, uma estratégia válida é a utilização de um modelo simplificado, chamado metamodelo, que descreva de forma contínua e aproximada o fenômeno estudado, com o objetivo de reduzir o número de testes necessários.

O metamodelo pode ser definido como um recurso matemático que retorna, de maneira aproximada, a relação entre os dados de entrada e saída de um modelo mais complexo. O intuito principal é de substituir um método experimental de alto custo por uma função matemática simplificada. A criação do metamodelo consiste em calcular determinados valores utilizando-se do método original, como por exemplo uma simulação por elementos finitos, e posteriormente aplicando-se mecanismos de regressão, gerando uma curva ou 
superfície de resposta que passa de maneira ótima pelos pontos calculados anteriormente [23], conforme ilustrado na Figura 22. A natureza mais simples de um metamodelo ainda permite a utilização de diferentes técnicas de otimização [23].

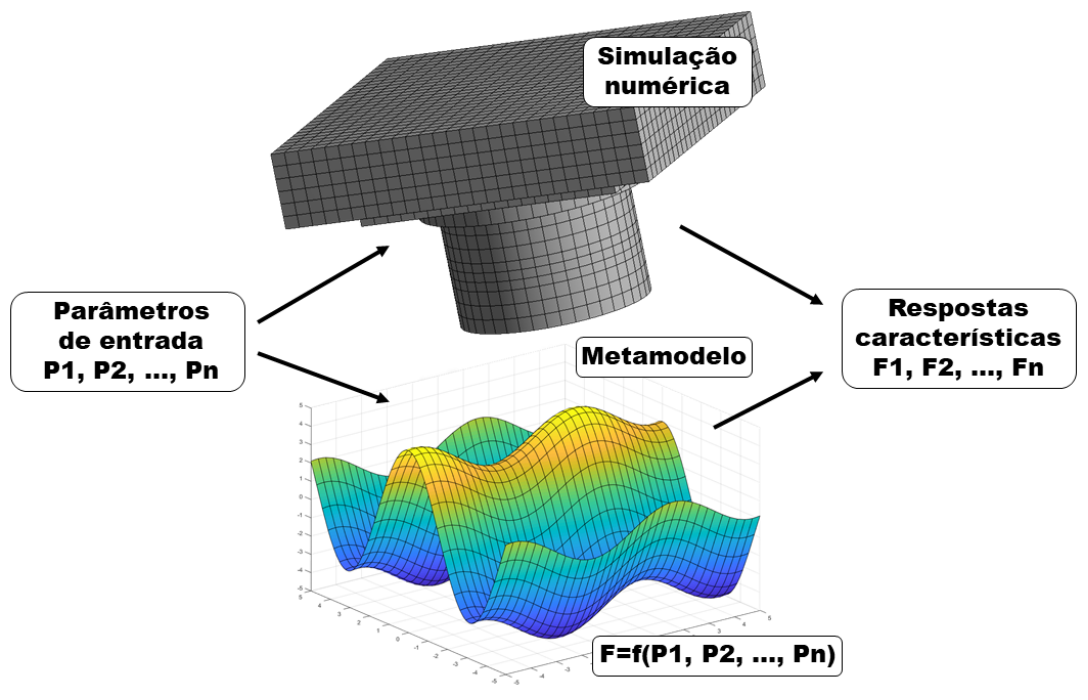

Figura 22: Esquema de metamodelo em conjunto com simulação computacional.

Para que ocorra uma aderência mais precisa entre o modelo gerado e o fenômeno estudado, é necessário realizar um número mínimo de experimentos, experimentos que devem originar de pontos distintos e bem distribuídos, como exemplificado na Figura 23. Para isto é importante utilizar-se de técnicas de planejamento de experimento (DoE), responsáveis por designar a quantidade de experimentos necessários e sua distribuição para atingir a acurácia requerida entre o fenômeno e o metamodelo. Quando bem implementado, o DoE minimiza o número necessário de dados coletados e maximiza a quantidade de informação obtida [8].
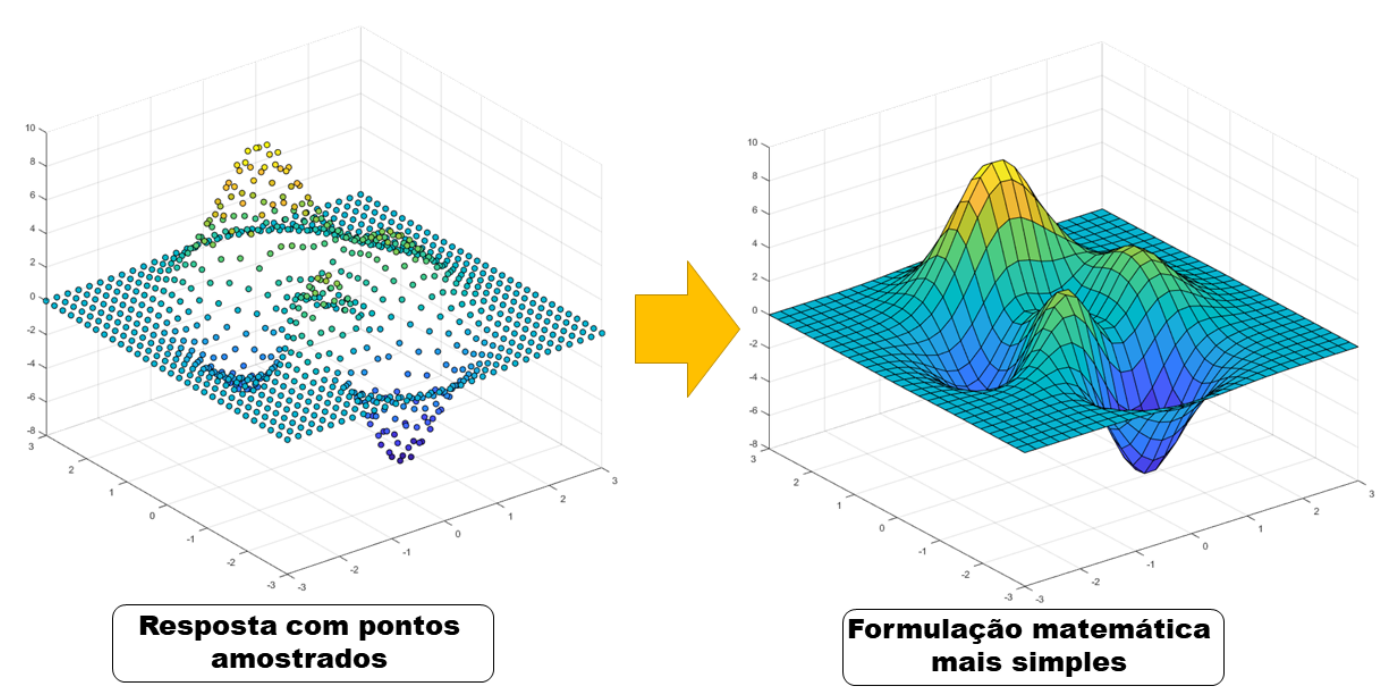

Figura 23: Metamodelo a partir de pontos amostrais. 


\subsubsection{Determinação de metamodelo}

Finalizado o processo de projeto de experimentos, resta definir o modelo de aproximação e ajuste apropriado ao fenômeno em estudo. Dada a complexidade envolvida em um impacto de um automóvel, há uma dificuldade em definir qual tipo de metamodelo é capaz de fornecer o melhor ajuste para análise em questão. Deste modo, são expostas as quatro técnicas de construção de metamodelos mais utilizadas [23]:

- Método Polinomial

- Funções de Base Radial, ou RBF do inglês Radial Basis Functions

- Kriging

- Redes Neurais Artificiais, RNA ou ainda ANN do inglês Artificial Neural Network

\subsubsection{Método Polinomial}

O método polinomial consiste em aproximar o modelo inicial por uma função polinomial explícita, utilizando o método dos mínimos quadrados a fim de minimizar o erro $\epsilon(x)$ na equação 2.31, que representa a diferença entre o modelo real $y(x)$ e o modelo aproximado $\hat{y}(x)$, onde $x$ representa uma variável das respectivas funções. Reescrevendo:

$$
\epsilon(x)=y(x)-\hat{y}(x)
$$

Como são realizados $n$ experimentos e com $m$ variáveis, há a necessidade de utilizar uma matriz modelo $\chi$ de dimensões $n \times m$, gerando a seguinte superfície de resposta:

$$
\hat{y}(x)=\chi b
$$

onde $\chi$ é a matriz de funções base e $b$ são os coeficientes desconhecidos. Por sua vez, o vetor dos coeficientes desconhecidos pode ser determinado através do método dos mínimos quadrados:

$$
b=\left(\chi^{T} \chi\right)^{-1} \chi^{T} y
$$

Para a geração da superfície de resposta podem ser utilizadas, por exemplo, funções lineares, funções cúbicas ou especiais como função base. Um exemplo de função que pode 
ser utilizada é o modelo quadrático com iteração, mostrado na equação 2.34. Esta função é utilizada em casos em que não se sabe a princípio o tipo de função [23].

$$
\hat{y}_{n}=b_{0}+\sum_{i=1}^{m} b_{i} x_{n i}+\sum_{i=1}^{m} b_{i i} x_{n i}^{2}+\sum_{i=1}^{m-1} \sum_{j=i+1}^{m} b_{i j} x_{n i} x_{n j}
$$

onde $\hat{y}_{n}$ é a função aproximada de um respectivo experimento, $b$ o coeficiente desconhecido para cada experimento e variável e $x$ o valor de cada variável de projeto.

\subsubsection{Funções de Base Radial (RBF)}

O método RBF utiliza-se de uma série de funções básicas que são simétricas e centralizadas em cada ponto amostral [52]. A aproximação obtida a partir de uma RBF apresenta a forma mostrada na equação 2.35 .

$$
\hat{y}=\sum_{i=1}^{n} \lambda_{i} \phi\left(\left\|x-x_{i}\right\|\right)
$$

onde $n$ é o número de pontos de amostragem, $x$ é o vetor das variáveis de projeto, $x_{i}$ é o vetor das variáveis no $i$-ésimo ponto de amostragem, $\left\|x-x_{i}\right\|$ é a distância Euclidiana, $\phi$ é a função de base e $\lambda_{i}$ é um coeficiente de ponderação desconhecido. Portanto, uma RBF é uma combinação linear de $n$ funções de base com coeficientes de ponderação. Dentre os exemplos de funções base, tem-se [53]:

Linear:

$$
\phi(r)=r
$$

Cúbica:

$$
\phi(r)=r^{3}
$$

Spline de placa fina:

$$
\phi(r)=r^{2} \ln (r)
$$

Gaussiana:

$$
\phi(r)=e^{-r^{2} / 2 c^{2}}
$$

Multiquadrática:

$$
\phi(r)=\left(r^{2}+c^{2}\right)^{1 / 2}
$$


onde $c$ é um parâmetro de forma que controla a suavidade da função e $r$ a variável do polinômio.

Substituindo $x$ na equação 2.35 , tem-se:

$$
\begin{array}{r}
\hat{y}_{1}=\sum_{i=1}^{n} \lambda_{i} \phi\left(\left\|x_{1}-x_{i}\right\|\right) \\
\hat{y}_{2}=\sum_{i=1}^{n} \lambda_{i} \phi\left(\left\|x_{2}-x_{i}\right\|\right) \\
\ldots \\
\hat{y}_{n}=\sum_{i=1}^{n} \lambda_{i} \phi\left(\left\|x_{n}-x_{i}\right\|\right)
\end{array}
$$

Os pesos ideais para $\lambda$ podem ainda ser obtidos por meio do método dos mínimos quadrados:

$$
\lambda=\left(A^{T} A\right)^{-1} A^{T}
$$

onda A é a matriz de interpolação simétrica que avalia as distâncias entre todos os pontos.

\subsubsection{Kriging}

O método Kriging consiste em estimar o valor de uma função em pontos não amostrados como a soma de um modelo de regressão com um modelo aleatório de variações locais [41,54], conforme:

$$
y(x)=\sum_{i=1}^{k} \beta_{i} f_{i}(x)+Z(x)=f^{T} \beta+Z
$$

onde $k$ é a quantidade de funções de base polinomiais, $f(x)$ é o vetor das funções de regressão, $\beta$ é o vetor dos coeficientes desconhecidos e $Z$ é uma função aleatória com média zero, variância e covariância diferentes de zero, representando desvios locais com relação à curva de tendência formada pelas funções de regressão [23,41], conforme a Figura 24.

A covariância é dada por:

$$
\operatorname{Cov}\left[Z\left(x_{n}\right), Z\left(x_{m}\right)\right]=V^{2} R\left[R\left(\theta_{j}, x_{n}, x_{m}\right)\right]
$$




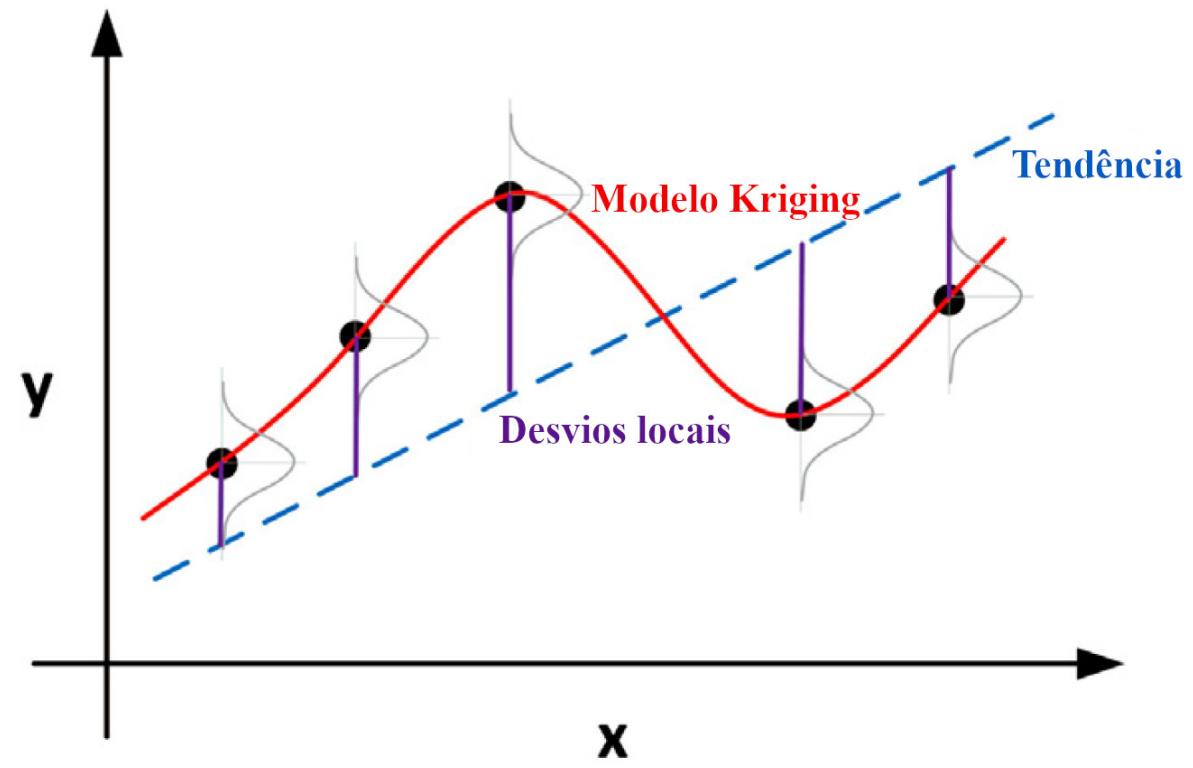

Figura 24: Exemplo genérico de regressão por Kriging (Adaptado pelo Autor de Liu [54]).

onde $R$ é a variância do processo, $\boldsymbol{R}$ é a função espacial de correlação, $\theta$ é o parâmetro da função de correlação, $\mathrm{x}_{\mathrm{n}}$ e $\mathrm{x}_{\mathrm{m}}$ são dois conjuntos de valores das amostras $n$ e $m$ [23]. No modelo de Kriging um ponto desconhecido pode ser descrito como:

$$
\hat{y}(x)=f^{T}(x) \beta+r^{T}(x) \boldsymbol{R}^{-1}(y-F \beta)
$$

onde $y$ é o valor das respostas para as amostras conhecidas, $r(x)$ é um vetor de funções de correlação entre o ponto desconhecido e o ponto de amostragem $n, F$ é um vetor que corresponde a uma das linhas da matriz modelo $\chi$ de dimensões $n \times m$, apresentada no modelo polinomial, e $\beta$ é um vetor dos coeficientes de regressão estimados, obtido pelo método dos mínimos quadrados [23], representado a seguir:

$$
\beta=\left(F^{T} R^{-1} F\right)^{-1} F^{T} R^{-1} y
$$

\subsubsection{Redes Neurais Artificiais (RNA)}

Inspiradas pelas funções dos neurônios no cérebro, as redes neurais artificiais são frequentemente utilizadas como uma alternativa às técnicas de regressão não-lineares padrões e análises de agrupamento [55].

A unidade básica que compõe uma rede neural artificial é chamada de neurônio, ou ainda de nó. Cada neurônio, ou grupo de neurônios, é organizado conforme sua função, da qual compõe uma diferente camada. Todo nó possui pelo menos uma ligação com outro 
nó, chamada de sinapse, que é responsável por transferir informações de uma camada a outra, além de ponderar o valor dessas informações [55-57].

Em termos matemáticos, as RNAs consistem de um conjunto de funções base com parâmetros livres, das quais podem adotar diferentes formatos, como sigmoides, por exemplo. Tais parâmetros livres são chamados de funções de ativação e representam a influência que cada dado de entrada possui no resultado final do processo. O funcionamento de uma RNA embasa-se em ajustar as funções de ativação, de maneira iterativa, de modo a minimizar o erro associado ao processo de regressão $[55,57]$.

A RNA pode ainda adotar formatos, estruturas e notações distintas. A categoria mais utilizada é a rede neural sem realimentação (ou ainda em inglês, feedforward). Nela, as informações percorrem uma única direção e os nós são conectados exclusivamente com nós de camadas distintas. Um exemplo dessa construção pode ser visto na Figura 25.

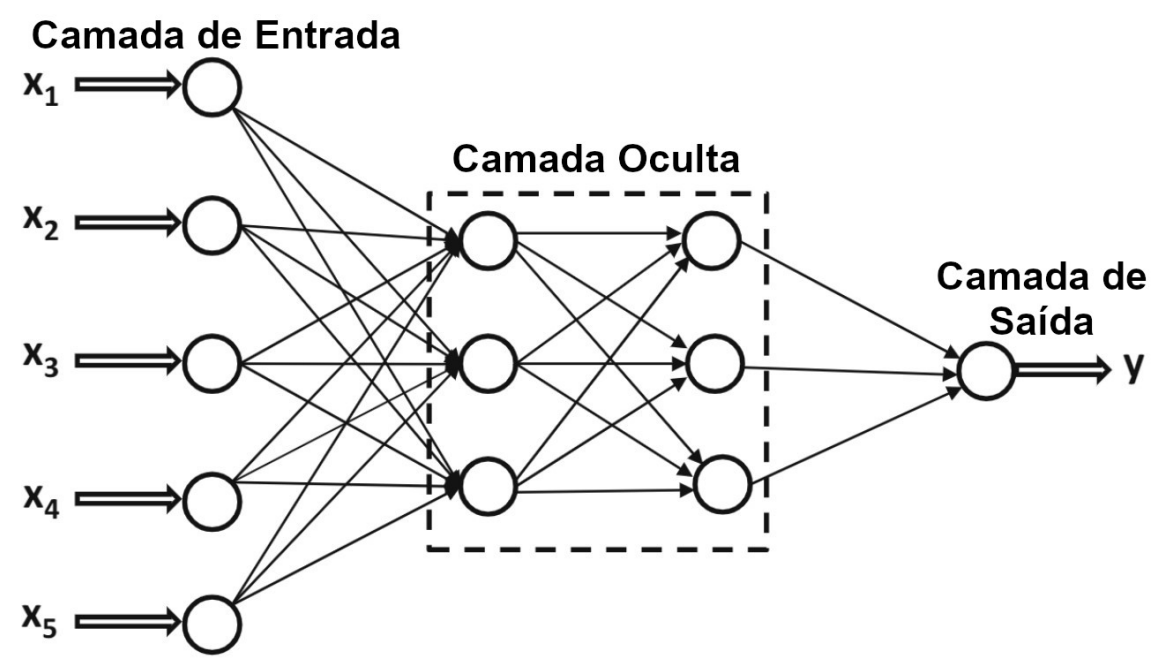

Figura 25: Exemplo de rede neural sem alimentação (Adaptado pelo Autor de Aggarwal $[56])$.

Note que em uma rede sem realimentação, há três tipos de camadas, sendo:

- Camada de entrada: representa as informações que entram na RNA, como por exemplo os parâmetros de experimento. Os neurônios dessa camada são os únicos que não executam cálculos [56].

- Camada oculta: possui neurônios que auxiliam na convergência das informações de saída. Apresenta esse nome pois o usuário não possui acesso aos cálculos realizados nessa camada [56].

- Camada de saída: é composta pelos neurônios que definem a resposta da rede neural, ou seja, o valor de saída que o RNA prevê para os valores de entrada inseridos. 
O processo em que o valor previsto pela RNA se aproxima cada vez mais do valor real é chamado de aprendizagem, ou treinamento. No caso de redes sem realimentação, o processo de aprendizagem é feito por um algoritmo com o nome de backpropagation, da qual apresenta duas etapas principais:

- Para frente: as informações de entrada são alimentadas na rede, utilizando um conjunto de pesos iniciais para cada valor, que são computadas ao longo de toda a cadeia de neurônios, gerando um valor de saída. Compara-se o resultado obtido com o real, gerando a função erro.

- Para trás: a partir do valor real, procura-se minimizar o erro. Para tal, busca-se encontrar o gradiente do erro em função de cada peso utilizado nas sinapses dos nós.

O treinamento é feito de forma iterativa até que se obtenha um mínimo global (ou mínimo local) para a função de erro. O funcionamento das redes neurais, assim como as equações que regem cada uma de suas etapas, são discutidas com mais profundidade na obra de Aggarwal [56].

\subsubsection{Validação de Metamodelo}

A precisão de um metamodelo pode ser verificada por sua capacidade de prever um conjunto de dados de validação, ou seja, um conjunto de pontos que não fizeram parte do conjunto de dados usados para o ajuste do modelo de aproximação [53]. Para a avaliação são utilizadas métricas baseadas em técnicas de análises estatísticas, como por exemplo: coeficiente de determinação $\left(\mathrm{R}^{2}\right)$, somatório quadrático de erros (MSE ou SSE), variância (SST), máximo erro absoluto (MAE), raiz do erro quadrático médio (RMSE), dentre outros [23], sendo representados por:

$$
R^{2}=1-\frac{S S E}{S S T}
$$

onde SSE é o somatório quadrático de erros e SST a variância, sendo calculados respectivamente por:

$$
\begin{aligned}
& S S E=\sum_{i=1}^{n}\left(f_{i}-f_{i}^{\prime}\right)^{2} \\
& S S T=\sum_{i=1}^{n}\left(f_{i}-\bar{f}_{i}\right)^{2}
\end{aligned}
$$


onde $f_{i}$ é o valor verdadeiro, $f_{i}^{\prime}$ o valor estimado pelo metamodelo e $\bar{f}_{i}$ o valor médio da sequência de $f_{i}$.

O máximo erro absoluto descreve o maior erro encontrado entre um valor verdadeiro e um estimado:

$$
M A E=\max \left|f_{i}-f_{i}^{\prime}\right|
$$

A raiz do erro quadrático médio corresponde a:

$$
R M S E=\sqrt{\frac{\sum_{i=1}^{n}\left(f_{i}-f_{i}^{\prime}\right)^{2}}{n}}
$$

Quando as métricas comuns se tornam impraticáveis devido ao seu custo para determinado estudo, pode-se utilizar outras técnicas de validação como validação cruzada (do inglês cross-validation) e a técnica conhecida no inglês como bootstrapping error assesment, conforme exposto por Forrester e Keane [53] e Queipo et al. [41].

No caso da validação cruzada, os dados do modelo são divididos em $n$ subconjuntos aproximadamente iguais. O modelo aproximado é então construído $n$ vezes, removendo a cada etapa um dos subconjuntos e reajustando o modelo conforme os dados restantes. Em cada estágio, os dados removidos são estimados novamente pelo modelo e então é realizado o cálculo do erro entre o valor exato e previsto do conjunto retirado. Após a conclusão do processo, o erro da validação cruzada pode ser calculado pelo somatório quadrático de erros [58].

\subsection{Otimização}

Durante o desenvolvimento de um projeto, almeja-se atingir o máximo desempenho possível em determinada categoria (ou categorias) dentro de restrições práticas. Uma ferramenta apropriada para chegar a tal objetivo é a otimização.

Segundo Messac [59], a otimização matemática é o processo de maximizar e/ou minimizar um ou mais objetivos, sem violar certas restrições de projeto, que regula um grupo de parâmetros variáveis que influenciam tanto os objetivos quanto as restrições de projeto. É um método sistemático de analisar diversas possibilidades possíveis dentro do objeto de estudo.

De modo geral o ato de projetar é um método que inclui a análise e a otimização como 
sub-processos [59]. A etapa de projeto preliminar consiste em definir os objetivos, restrições e variáveis de projeto; analisar o comportamento do projeto e aplicar a otimização, como mostra a Figura 26.

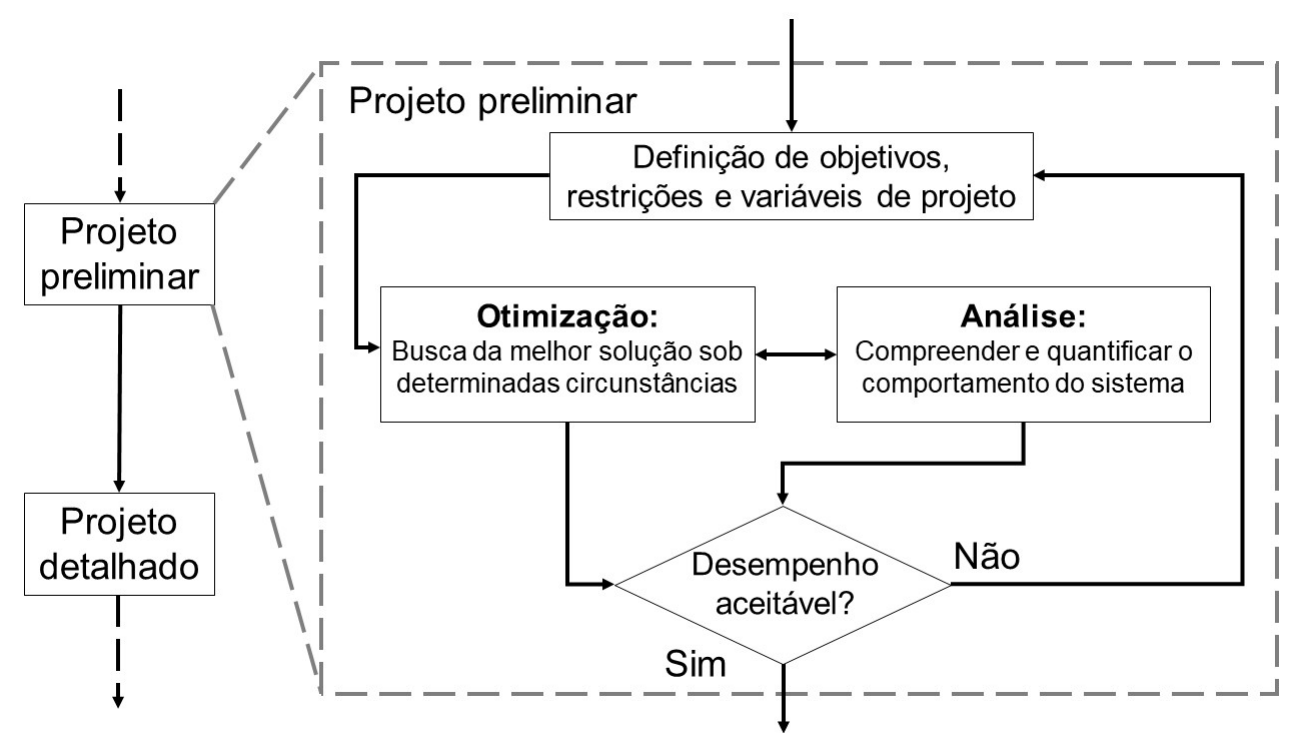

Figura 26: Relação entre projeto, análise e otimização (Adaptado de Messac [59]).

Para atingir resultados significativos através da otimização e tendo em vista a interdependência do projeto, análise e otimização, é necessário possuir uma formulação bem planejada sobre o problema em questão.

Um exemplo básico de otimização pode ser dado por:

$$
\min _{x} J(x)
$$

sujeito a:

$$
\begin{gathered}
g(x)=0 \\
h(x) \geq 0 \\
x_{l} \leq x \leq x_{u}
\end{gathered}
$$

onde $J(x)$ representa a função objetivo a ser minimizada que acarretará em um melhor comportamento para o sistema. As funções $g(x)$ e $h(x)$ representam restrições de comportamento, que garantem que as variáveis de projeto sejam factíveis, como por exemplo 
uma massa positiva. Por fim, $x_{l}$ e $x_{u}$ são as restrições laterais e representam os limites a serem trabalhados com a variável de projeto $x$.

Ao longo do trabalho, utilizam-se diferentes tipos de algoritmos, com o intuito de comparar e definir um método, ou combinação de métodos, mais apropriado para a análise e otimização de um absorvedor de energia ao impacto, processo este que envolve fenômenos físicos complexos e um custo computacional relativamente alto.

\subsubsection{Programação Sequencial Quadrática de Filtro Adaptativo}

A Programação Sequencial Quadrática de Filtro Adaptativo (AFSQP, do inglês Adaptative Filter Sequential Quadratic Programming) é um algoritmo de otimização baseado em gradientes desenvolvido para problemas com possíveis restrições e objetivo único [60]. O custo computacional oriundo do cálculo de gradientes é compensado pela possibilidade de se atingir taxas de convergência melhores, dependendo das hipóteses do problema [60].

Proveniente da Programação Quadrática Sequencial, o AFSQP aproxima a formulação do problema localmente por um modelo quadrático. A parte linear é construída a partir dos gradientes calculados, enquanto as derivadas de segunda ordem são aproximadas pela fórmula de Broyden-Fletcher-Goldfarb-Shanno e dispensam computação adicional. As restrições do problema são avaliadas a partir da aplicação de métodos de Multiplicadores de Lagrange. O problema local é resolvido pela sub-rotina de modelo quadrático e então o procedimento repete-se a partir do próximo ponto.

Dado um problema de otimização genérico, descrito pelas equações de 2.52 à 2.54, supondo que $x^{*}$ seja o vetor solução e que $\lambda^{*}=\left(\lambda_{e q}^{*}, \lambda_{i n}^{*}\right)$ seja um vetor auxiliar, responsável por transformar inequações em equações, têm-se:

$$
\begin{gathered}
\nabla f\left(x^{*}\right)+\lambda_{e q}^{*} \nabla g\left(x^{*}\right)+\lambda_{i n}^{*} \nabla h\left(x^{*}\right)=0 \\
g\left(x^{*}\right)=0 \\
h\left(x^{*}\right) \geq 0 \\
\left\langle\lambda_{i n}^{*}, h\left(x^{*}\right)\right\rangle=0 \quad \operatorname{com} \lambda_{i n}^{*} \geq 0 .
\end{gathered}
$$


O conjunto de equações de 2.56 até 2.59 descreve as condições de Karush-KuhnTucker, ou ainda sistema KKT, que garantem que o resultado gerado por $x^{*}$ é um mínimo local. Vale ressaltar que o sistema KKT não garante que o ponto encontrado seja um mínimo global, a menos que uma hipótese mais rigorosa seja satisfeita, como por exemplo, garantir que o problema analisado seja convexo. A solução do sistema é encontrada ao resolver, iterativamente, um problema de otimização quadrática de restrições lineares [60].

A função descrita por $L(x, \lambda)=f(x)+\lambda_{e q} g(x)+\lambda_{i n} h(x)$ é chamada de função Lagrangeana. Dada uma iteração $\left(x^{(k)}, \lambda^{(k)}\right)$, considera-se o seguinte problema para um vetor desconhecido $d$ :

$$
\begin{gathered}
\min \frac{1}{2}\left\langle d, \nabla_{x}^{2} L\left(x^{(k)}, \lambda^{(k)}\right) \cdot d\right\rangle+\nabla f\left(x^{(k)}\right) \cdot d \\
\nabla g\left(x^{(k)}\right)^{T} \cdot d+g\left(x^{(k)}\right)=0 \\
\nabla h\left(x^{(k)}\right)^{T} \cdot d+h\left(x^{(k)}\right) \geq 0
\end{gathered}
$$

As equações de 2.60 à 2.62 são chamadas de problema de Programação Quadrática, ou problema QP (do inglês Quadratic Programming).

O próximo ponto de iteração será $x^{(k+1)}=x^{(k)}+d$. O novo ponto de aproximação dos multiplicadores de Lagrange $\lambda^{(k+1)}$ é o vetor de multiplicadores associados ao subproblema QP por suas equações KKT.

A escolha de um modelo quadrático impõe duas características principais. Caso haja apenas restrições de igualdade, uma iteração de SQP equivale a um passo do método de Newton aplicado ao sistema KKT. Caso haja também restrições de desigualdade, o algoritmo mantém consistência numérica, o que não ocorre para uma expansão de Taylor simples. Portanto, basta assegurar estabilidade para obter uma convergência do problema. Quanto menos restrições de desigualdade impostas, mais a taxa de convergência do SQP se aproxima daquela apresentada pelo método de Newton. A aplicação de um filtro é feita para que se alcance essa condição [60].

O filtro adaptativo é usado para auxiliar na convergência, levando em conta todos os pontos já encontrados na otimização e comparando os novos pontos com os anteriores. O ponto novo é considerado apenas se o mesmo supera os pontos anteriores no valor da função objetivo e no cumprimento das restrições estabelecidas. 
Um passo do método de Newton $x^{(k+1)}=x^{(k)}+d$ induz a uma taxa de convergência local quadrática (a melhor taxa de convergência possível, como ilustrado na Figura 27). No entanto, quando distante da solução, pode introduzir instabilidades no algoritmo. Como, a princípio, não se sabe a distância entre uma iteração e a solução, faz-se necessária a adição de um critério que avalie o passo de uma iteração e, eventualmente, modifique o valor desse passo [60].
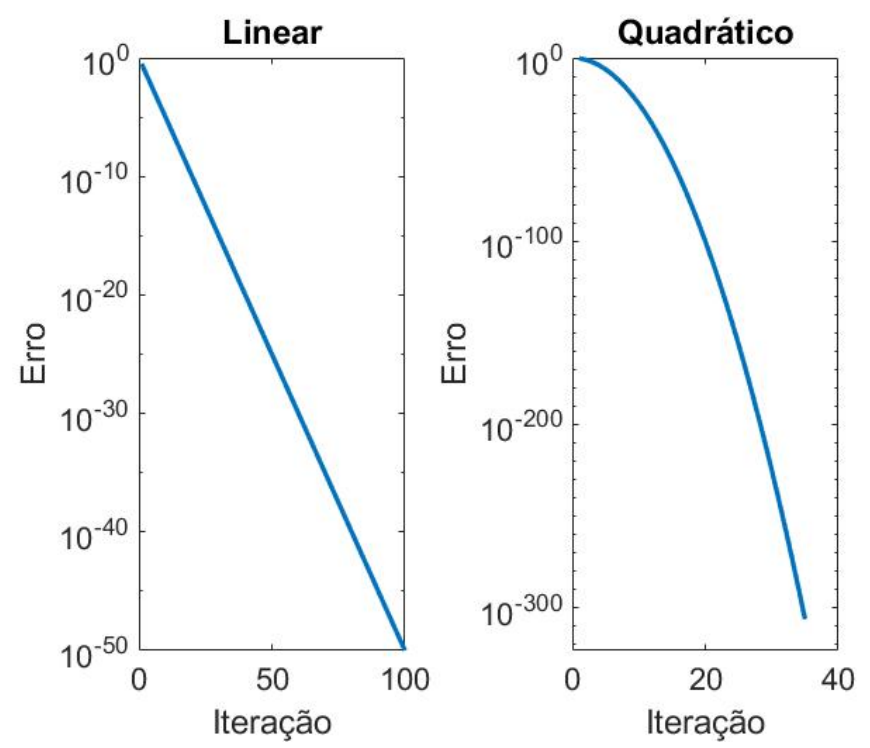

Figura 27: Taxa de convergência linear contra taxa de convergência quadrática.

Dentre os parâmetros definidos pelo usuário, ao utilizar o algoritmo AFSQP no software modeFRONTIER, destacam-se:

- Tipo de diferença finita: permite definir o cálculo das derivadas pelo método das diferenças progressivas ou pelo método das diferenças centrais. Para $n$ variáveis, o primeiro requer $n+1$ operações para a obtenção do gradiente. Já o segundo, mais preciso, requer $2 n+1$ operações.

- Perturbação relativa de diferença finita: define a fração da variável, utilizada para perturbar o ponto inicial e computar as derivadas.

- Política de diferença mínima de diferença finita: permite escolher entre dois métodos que definem a perturbação mínima dos parâmetros:

- Perturbação mínima constante: define um valor fixo utilizado para perturbar o ponto inicial. O passo de perturbação é definido entre a perturbação relativa de diferença finita (valor máximo) e este valor como o mínimo. 
- Perturbação mínima da faixa percentual: assim como a perturbação mínima constante, define um valor mínimo de perturbação. Desta vez, é definida como: Perturbação Mínima $=($ Limite Superior - Limite Superior $) \cdot($ Perturbação mínima da faixa percentual).

\subsubsection{Direções Conjugadas de Powell}

Proposto por Michael James David Powell, o método das direções conjugadas de Powell é um algoritmo de otimização de objetivo único. É uma ferramenta que não calcula derivadas. Para encontrar o mínimo (ou máximo) local, o método de Powell baseia-se em um conjunto de direções conjugadas, ou seja, a direção do vetor de otimização não interfere na direção do vetor da próxima iteração, prevenindo um ciclo infinito durante a busca pelo ponto ótimo. O fato de dispensar o cálculo de derivadas faz deste recurso útil para funções contínuas complexas, especialmente quando não há uma função matemática que descreva o fenômeno.

Para esse algoritmo, a função a ser otimizada é aproximada localmente por uma função quadrática descrita por:

$$
f(\mathbf{x})=\mathbf{x}^{\mathbf{T}} \mathbf{A} \mathbf{x}+\mathbf{b} \mathbf{x}+\mathbf{c}
$$

onde $A, b$ e $c$ são matrizes que compõe a função.

Dadas direções u e q, elas serão linearmente independentes se:

$$
\mathbf{u}^{\mathbf{T}} \mathbf{A q}=0
$$

Dá-se $\mathbf{u}_{\mathbf{1}}, \mathbf{u}_{\mathbf{2}}, \ldots, \mathbf{u}_{\mathbf{m}}$, para $m \leq n$, sendo $m$ o número de dimensões do espaço (quantidade de variáveis), $n$ o número de direções e $\mathbf{u}_{\mathbf{i}}$ direções mutuamente conjugadas. Ao minimizar a função objetivo para cada direção $\mathbf{u}_{\mathbf{i}}$, o valor mínimo da função $f(\mathbf{x})$ pode ser encontrado ao percorrer, no máximo, $m$ passos. A comprovação desse teorema é aprofundada na obra de Powell [61].

Um exemplo mais visual do funcionamento do algoritmo pode ser visto nas Figuras 28 e 29 . 


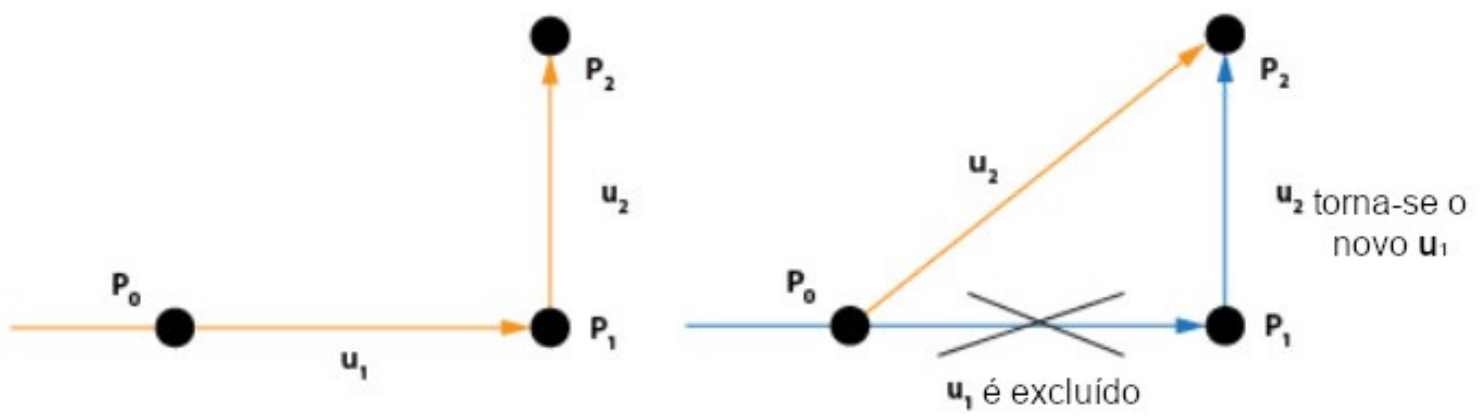

Figura 28: Exemplo de funcionamento do algoritmo de Powell (Adaptado de [47]).

A partir do ponto $P_{0}$, a função objetivo move-se até o valor mínimo da direção $u_{1}$, chegando ao ponto $P_{1}$. Em seguida, a função desloca-se para o mínimo da direção $u_{2}$, no ponto $P_{2}$. Ainda na Figura 28, o primeiro deslocamento $u_{1}$ é suprimido, enquanto o vetor $u_{2}$ torna-se o vetor inicial $\left(u_{1}\right)$ para a próxima iteração. Um novo vetor é criado ligando o ponto inicial $P_{0}$ ao último ponto $P_{2}$, tornando-se o vetor $u_{2}$ para a iteração seguinte.

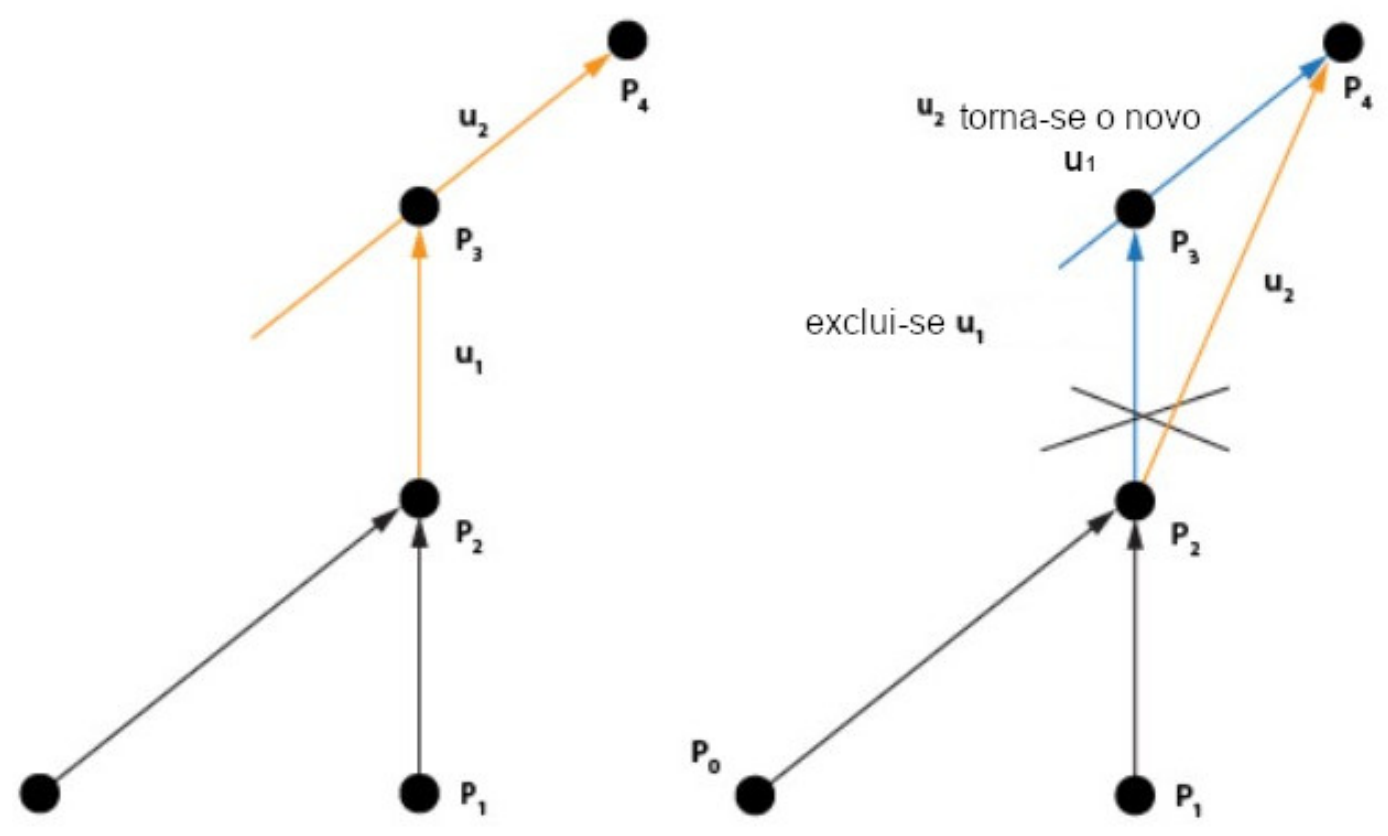

Figura 29: Continuação funcionamento do algoritmo de Powell (Adaptado de [47]).

A partir do ponto $P_{2}$, encontra-se o novo mínimo na nova direção $u_{1}$ (ponto $P_{3}$ ) e posteriormente o mínimo na nova direção $u_{2}$, gerando o ponto $P_{4}$. O processo exposto nas Figuras 28 e 29 é repetido até que se atinja convergência ou um número máximo de interações [47].

Originalmente, o método de Powell é incapaz de lidar com restrições. Para tal, o algoritmo é modificado para que possa penalizar projetos que infrinjam os limites preesta- 
belecidos ao problema. Sua implementação varia conforme o software comercial utilizado, explicado na Seção 2.6.4.

Por fim, os parâmetros do algoritmo que o software modeFRONTIER permite alterar são:

- Fração de avaliações permitidas para cada ponto de DoE: uma vez que o algoritmo de Powell necessita de apenas um ponto inicial, este parâmetro define a porcentagem de projetos de DoE serão utilizados como pontos iniciais. Um valor de 1 representa que $100 \%$ dos projetos gerados por DoE serão utilizados como pontos iniciais.

- Tamanho inicial dos vetores de procura normalizados: estabelece o tamanho inicial do vetor de busca, que decresce conforme o algoritmo se aproxima da convergência. Quanto maior o vetor, mais rápida a convergência pode se tornar, porém aumenta a chance de o algoritmo ultrapassar os limites da área de análise, aumentando sua imprecisão.

- Tamanho final dos vetores de procura normalizados: estipula, através do tamanho do vetor, o critério para a convergência da otimização. Quanto maior, mais rápida será a convergência, porém maior será a probabilidade de o valor encontrado ser sub-ótimo.

\subsubsection{Algoritmo Genético Multi-Objetivo II}

Inspirados da Teoria da Evolução, os algoritmos genéticos utilizam operações que emulam determinados mecanismos da genética, gerando um novo projeto a partir de informações provenientes de outros dois projetos anteriores. As operações mais usadas são:

- Cross-Over Clássico: As propriedades de dois projetos são inseridas, de maneira aleatória, em um novo projeto, buscando gerar um projeto com desempenho superior aos dos anteriores. Quanto maior a probabilidade de ocorrência do cross-over clássico, maior será a robustez da análise, porém a convergência será mais lenta.

- Cross-Over Direcional: Assume que uma direção de melhoria pode ser detectada através da inspeção do desempenho de projetos de uma mesma geração. Comparase três indivíduos de uma mesma geração, selecionados estocasticamente, então o próximo indivíduo é gerado a partir das propriedades provenientes dos projetos anteriores, esperando-se obter uma melhor performance. 
- Mutação: As propriedades da próxima geração são alteradas aleatoriamente, inibindo uma convergência prematura do problema.

- Seleção: O projeto de uma geração é copiado para a próxima geração sem qualquer modificação.

- Taxa de mutação de cadeia de DNA: define a porcentagem em que os parâmetros de projeto são alterados pelo operador de Mutação.

Abreviado como MOGA-II, do inglês Multi-Objective Genetic Algorithm II é um algoritmo proprietário, que distingue-se de um algoritmo genético multi-objetivo genérico por utilizar-se de um operador de elitismo, em que soluções que apresentem um desempenho superior são preservadas ao longo das iterações, evitando convergências prematuras [62].

O algoritmo parte de um conjunto de projetos iniciais definido pelo DoE, classificado aqui como população inicial. A partir dos operadores enumerados no início desta seção, gera-se um novo conjunto de projetos, de mesma quantidade, denominado como geração. Para cada nova geração, é computada a capacidade individual de cada projeto de atender às funções objetivos e restrições. Em seguida, os projetos considerados favoráveis são armazenados dentro de um "conjunto de elite" [62]. A Figura 30 ajuda a ilustrar tal procedimento.

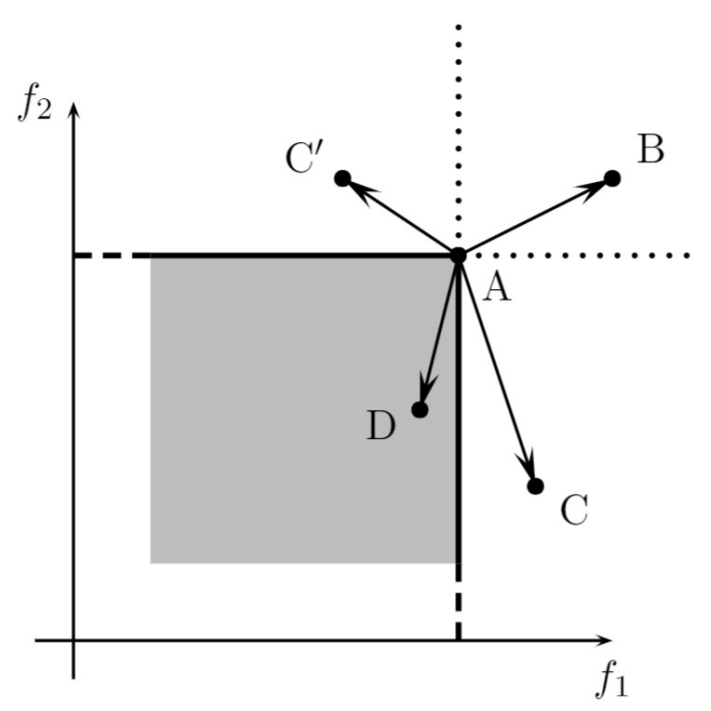

Figura 30: Avaliação de desempenho de projetos no MOGA-II [62].

onde A, B, C, C' e D são projetos, enquanto $f_{1}$ e $f_{2}$ são funções objetivas distintas. Nesse caso, "A" é um projeto inicial que pode gerar 4 novos projetos B, C, C' e D. No entanto, o projeto "D" possui desempenho inferior ao "A" em ambas as funções objetivo, logo é considerado como um projeto não favorável. Já os pontos B, C e C' superam A em pelo 
menos uma das funções objetivo. Apesar de "B" representar a melhor combinação de $f_{1}$ e $f_{2}$, os pontos $\mathrm{C}$ e C' também são mantidos no conjunto de elite com a finalidade de aumentar a variedade de projetos viáveis.

Vale notar que o número de projetos dentro de um conjunto de elite não pode ultrapassar o número de projetos que compõe a população (no caso, tamanho definido pelo DoE), para tal, projetos replicados ou não favoráveis são removidos. Caso o tamanho do conjunto continue maior que o da população, projetos são removidos aleatoriamente até que a quantidade se iguale.

Por fim, é estabelecida uma nova geração de projetos com atributos baseados na geração anterior e no conjunto de elite definido. O procedimento repete-se até que se atinja o número máximo de gerações estipulado pelo usuário.

\subsubsection{Restrições}

Originalmente, algoritmos heurísticos de otimização não possuem um método nativo de lidar com restrições de um problema, como é o caso do algoritmo de Powell e o MOGAII. Em ambos os casos, para avaliar as restrições, o software modeFRONTIER utiliza um método chamado de política de penalidade (ou em inglês, penalty policy).

O funcionamento de uma política de penalidade consiste, basicamente, em transformar um problema de otimização com restrições em um problema de otimização sem restrições e em seguida, adicionar (para um problema de minimização) ou remover (para um problema de maximização) da função objetivo um valor proporcional ao quanto a restrição foi violada [47].

O fator ou proporção em que a penalidade de restrições interfere no resultado da função objetivo é calculado automaticamente a cada interação do algoritmo. Um fator muito grande reduziria a capacidade de o software distinguir entre uma violação de restrição pequena e uma violação grande, fazendo com que o algoritmo ignore projetos próximos à região de restrição. Por outro lado, um fator muito pequeno aumentaria o número de iterações necessárias para se alcançar um resultado ótimo. A Figura 31 ilustra a ideia. 


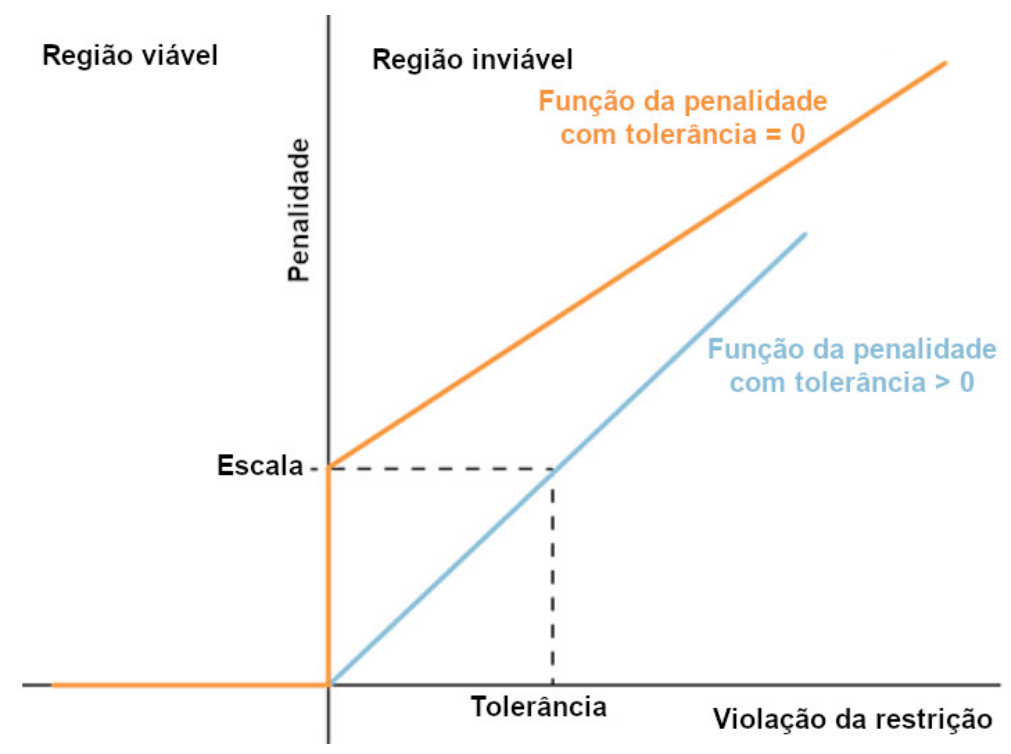

Figura 31: Gráfico da política de penalização (Adaptado pelo autor de [47]).

A Figura 31 mostra dois exemplos de penalidade. Em ambos os casos, o valor da penalidade aumenta conforme o projeto adentra a região inviável do problema. Na curva em laranja, onde a tolerância é igual a zero, a penalidade é aplicada na função objetivo assim que se atinge o limiar da restrição, com $Y(0) \neq 0$. Já a curva com tolerância maior que zero, em azul, a penalidade é inserida somente após infringir a restrição, com $Y(0)=0$, representando uma leniência maior para projetos com uma violação menor de restrição.

Definidas as teorias e ferramentas que regem os experimentos, dá-se sequência à metodologia, que explica a maneira como os métodos foram usados e seus respectivos porquês. 


\section{METODOLOGIA}

\subsection{Modelo em Elementos Finitos}

Para a simulação dinâmica utilizou-se o software comercial Abaqus 6.13-1, desde a criação da geometria, passando pela geração da malha, até o processamento propriamente dito.

Pelo fato do absorvedor de energia possuir uma espessura fina, quando comparada com suas outras dimensões, ele foi criado utilizando elementos de casca retangulares e lineares.

Foram criadas duas chapas com elementos rígidos, sendo uma fixa engastada no absorvedor e outra móvel, representando o impacto do veículo na barreira rígida. A segunda chapa possui velocidade de $15,6 \mathrm{~m} / \mathrm{s}$, que é a velocidade utilizada para os testes da New Car Assessment Program (NCAP) e uma massa equivalente de $275 \mathrm{~kg}$, representando 1/4 da massa total de um carro compacto genérico, ou seja, $50 \%$ de energia cinética absorvida pelas longarinas, sendo que os veículos de passeio possuem 2 longarinas principais. A chapa estática ainda foi usada para retirar informações com relação à força de reação da longarina, enquanto a chapa móvel foi utilizada para saber o deslocamento da extremidade do absorvedor. A montagem pode ser visualizada na Figura 32.

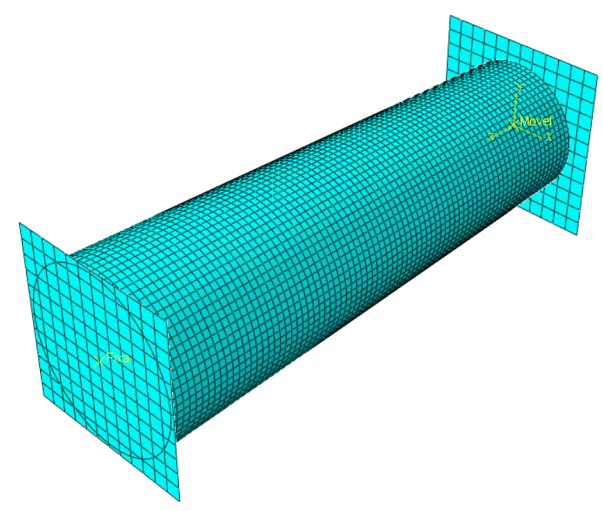

Figura 32: Sistema absorvedor barreira em elementos finitos. 
A princípio, durante a criação das malhas, optou-se por utilizar elementos de integração reduzida, no caso S4R, com a finalidade de evitar travamento volumétrico dos elementos durante a deformação do sistema, como recomendado por Tarlochan et al. [33]. No entanto, nas circunstâncias deste trabalho, o controle do fenômeno de ampulheta (chamado no Abaqus de Enhancement-based hourglass control) não foi o suficiente para evitar modos de deformação artificial de energia zero, causando a presença de uma grande taxa de energia artificial, como exposto na Figura 33.

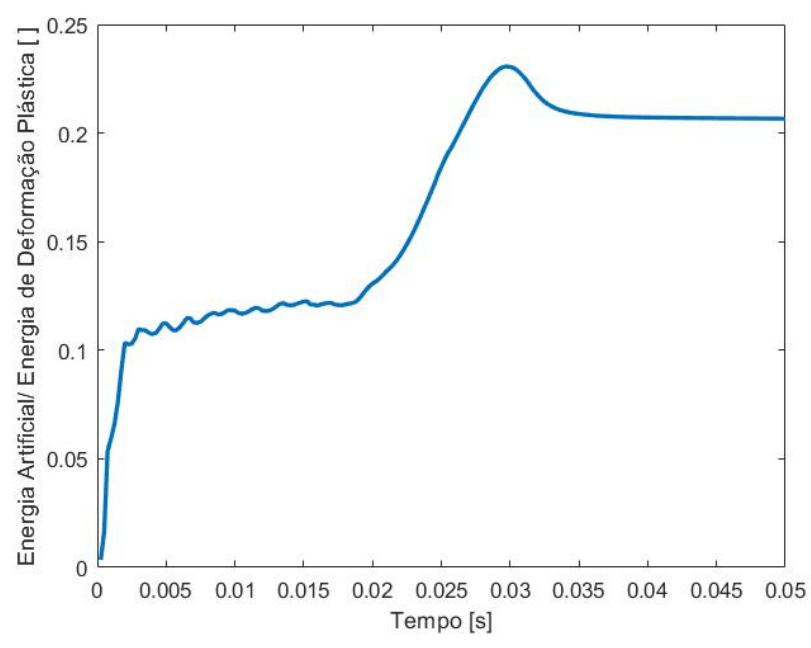

Figura 33: Fração da energia artificial pela energia de deformação plástica, em função do tempo.

A Figura 33 foi baseada em um projeto com $400 \mathrm{~mm}$ de comprimento, $30 \mathrm{~mm}$ de diâmetro, $0^{\circ}$ de ângulo longitudinal e $1 \mathrm{~mm}$ de espessura. Em seu modelo numérico foram utilizados 5 pontos de integração de Simpson ao longo de sua espessura. O aumento de pontos de integração (tanto por Simpson, quanto por Gauss) não foi o suficiente para deixar a fração de energia artificial abaixo de 10\%, tornando necessária a adoção de elementos de integração completa (S4) para o trabalho.

Definido o tipo de integração utilizado nos elementos, alterou-se também o número de pontos de integração ao longo da espessura para 3 pontos de Gauss, que no caso foi a configuração que apresentou a melhor relação entre precisão e custo computacional, quando aliada a elementos de integração completa. Por conta disto, tal configuração foi utilizada para os resultados finais deste trabalho.

A fração de energia artificial para a nova configuração pode ser visualizada na Figura 34 .

Vale ressaltar que a energia artificial não foi extinta com o uso da integração completa. Também não foi observado travamento volumétrico (em inglês, volumetric locking) para 


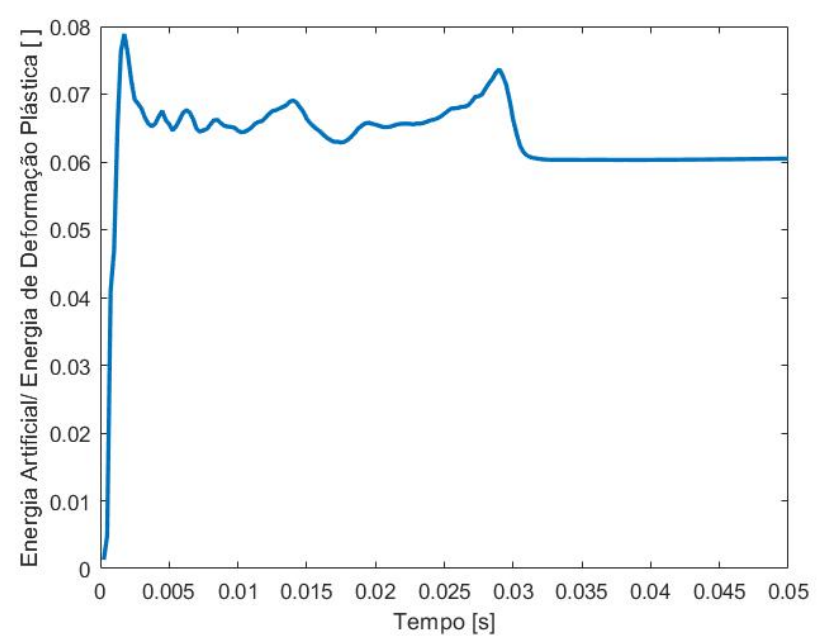

Figura 34: Projeto da Figura 33 com integração completa e 3 pontos de integração por Gauss.

projetos devidamente dimensionados, justificando o uso de elementos S4.

O material para o absorvedor de energia foi utilizado o aço estrutural A36, apresentando as propriedades expostas na Tabela 2. Por conta de o fenômeno de impacto gerar grandes deformações e uma taxa de deformação elevada, foi considerado o modelo de material de Johnson Cook.

Tabela 2: Propriedades do aço A36 (Adaptado de Tarlochan et al. [33]).

\begin{tabular}{|l|l|l|}
\hline Sigla & Valor & Descrição \\
\hline$\rho$ & $7850 \mathrm{~kg} / \mathrm{m}^{3}$ & Densidade \\
\hline $\mathrm{E}$ & $200 \mathrm{GPa}$ & Módulo elástico \\
\hline$\nu$ & 0,26 & Coeficiente de Poisson \\
\hline $\mathrm{A}$ & $146,7 \mathrm{MPa}$ & Tensão de escoamento referência \\
\hline $\mathrm{B}$ & $896,9 \mathrm{MPa}$ & Termo de encruamento \\
\hline $\mathrm{n}$ & 0,32 & Expoente de deformação plástica \\
\hline $\mathrm{m}$ & 0,323 & Expoente de dependência de temperatura \\
\hline $\mathrm{C}$ & 0,033 & Coef. de dependência da taxa de deformação \\
\hline$\varepsilon_{0}$ & $1,0 \mathrm{~s}^{-1}$ & Taxa de deformação referência \\
\hline $\mathrm{T}_{\mathrm{M}}$ & $1773 \mathrm{~K}$ & Temperatura de fusão \\
\hline
\end{tabular}

Com relação ao contato, utilizou-se a opção de contato geral, com um coeficiente de atrito de 0,2 para o comportamento tangencial e a opção "Hard' Contact" para o comportamento de contato normal.

Para a malha, utilizaram-se elementos de $5 \mathrm{~mm}$ para a parte deformável (tubo) e elementos de $10 \mathrm{~mm}$ para as partes indeformáveis (placas). 
Anteriormente à etapa de simulação dinâmica, foi realizada uma simulação dos três primeiros modos de flambagem de cada um dos tubos simulados, como na Figura 35, com o objetivo de prever possíveis defeitos do tubo real, uma vez que tais defeitos influenciam diretamente no modo de falha do absorvedor sob uma carga dinâmica. Um tubo ausente de imperfeições, ou seja, simular diretamente a geometria criada no software, geraria um resultado mais suscetível a erros numéricos [35].

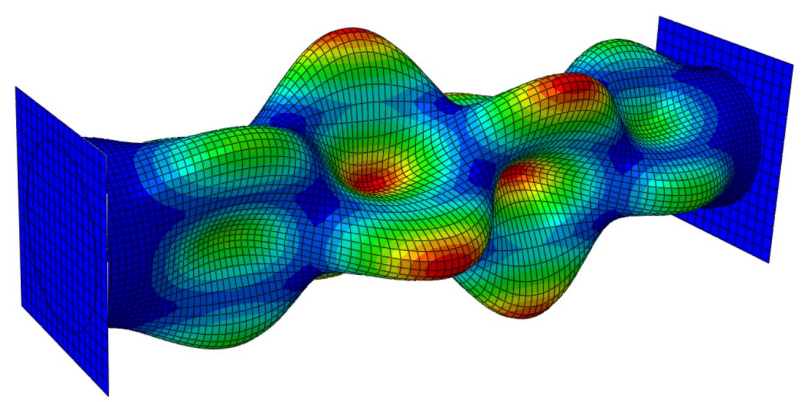

Figura 35: Distorções do primeiro modo de flambagem, ampliadas em 55 vezes [63].

Os modos de flambagem obtidos são então utilizados como defeitos nos tubos das simulações dinâmicas. As deformações foram normalizadas a partir de uma força de compressão de $1 \mathrm{~N}$.

A duração de todas as simulações de impacto foi de $50 \mathrm{~ms}$, tempo suficiente para o absorvedor de energia se deformar completamente independentemente da configuração. Para efeito de observação, as informações da simulação foram salvas em 500 intervalos, ou seja, a cada 0,100 ms. A Figura 36 mostra uma simulação de impacto em diferentes intervalos, em um tubo com dimensões geradas pelo algoritmo de planejamento de experimentos Sobol.

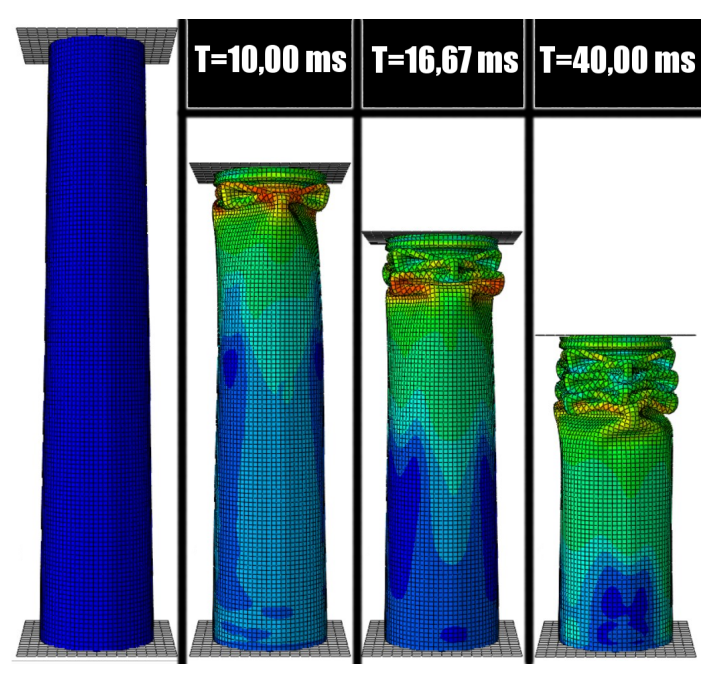

Figura 36: Exemplo de simulação dinâmica. 


\section{$3.2 \quad$ Scripting}

Entre a etapa de simulação pelo método dos elementos finitos (Abaqus) e a etapa de otimização (executada no software modeFRONTIER, explicado com maior profundidade no item 3.3), houve ainda uma etapa intermediária, responsável pela correta comunicação entre os dois softwares, além de permitir que simulações subsequentes ocorressem de forma autônoma, sem a intervenção do usuário.

A primeira fase constituiu-se em criar arquivos modelo para o software de elementos finitos, sendo eles:

- O primeiro, com dimensões genéricas para a simulação dos modos de vibrar.

- O segundo, com as mesmas dimensões do primeiro, com a simulação dinâmica.

- O terceiro, responsável pela extração e conversão das informações de saída, deixandoas legíveis para outros softwares.

Tal estágio consistiu em seguir o item 3.1 e converter os arquivos de extensão ".jnl” (Journal), gerados automaticamente pelo Abaqus ao criar um arquivo de simulação, para a extensão “.py" (Python), que no caso é a linguagem em que o Abaqus lê scripts.

O segundo passo baseou-se em criar um script na linguagem MATLAB capaz de alterar a geometria dos arquivos originais em Python. Além disso, o script altera outros parâmetros conforme o necessário. Como por exemplo, a montagem e a posição das placas e tubos para as novas dimensões, ou o nome do novo arquivo de defeitos (modo de vibrar) a ser lido pela respectiva simulação dinâmica.

O script então envia os novos arquivos ao Abaqus, que são executados de forma sequencial. Ao final da simulação dinâmica, o arquivo responsável pela extração de informações gera arquivos de texto com os dados solicitados, como por exemplo força de reação em função do tempo, que são interpretados por um segundo script em MATLAB e em seguida, transformados nas variáveis de saída requisitadas pelo modeFRONTIER. No caso, as variáveis de saída são: eficiência, força de pico, volume e energia absorvida. O processo de preparação pode ser visualizado na Figura 37.

O desenvolvimento de um script torna possível, além da automatização, criar adaptações que auxiliem na correta implementação da otimização.

Com o código pronto, basta dar sequência ao processo de otimização, ilustrado pela Figura 38. 


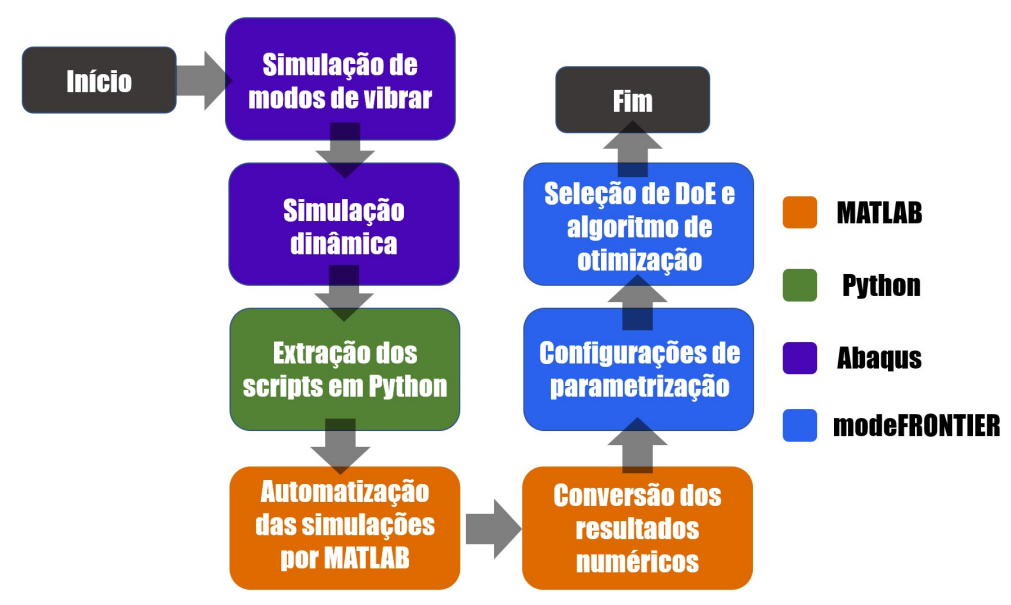

Figura 37: Fluxograma de preparação.

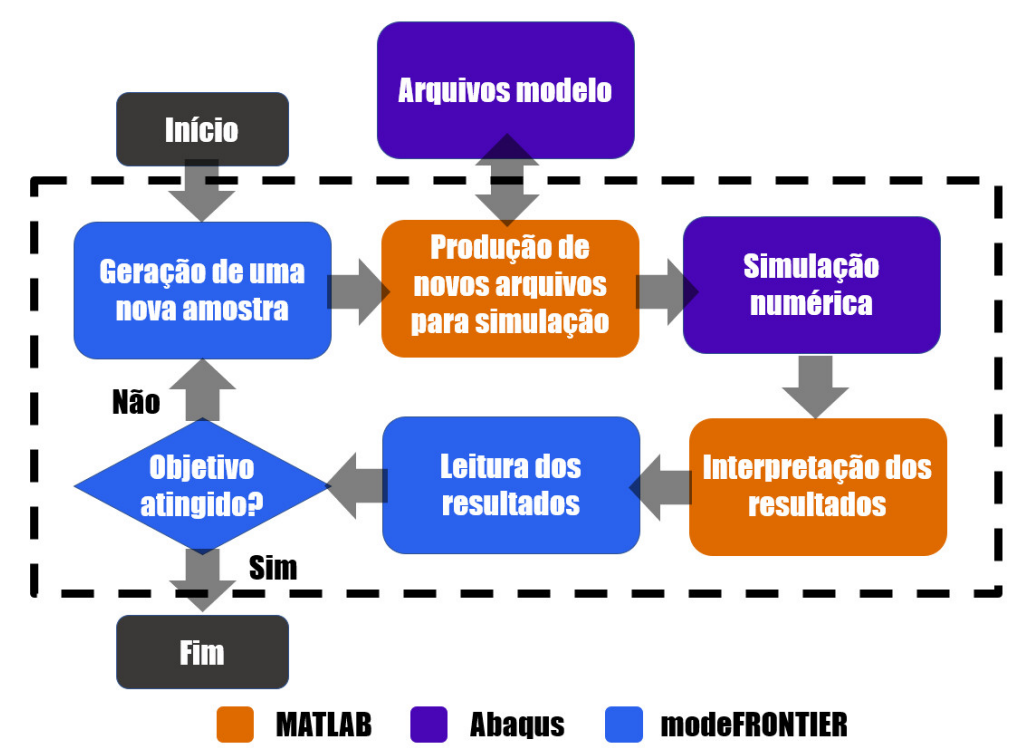

Figura 38: Fluxograma da otimização.

\subsection{Métodos de Otimização}

A etapa de otimização foi realizada utilizando o software modeFRONTIER 2018R2. O módulo utilizado para permitir a comunicação entre modeFRONTIER, Abaqus e Matlab foi o EasyDriver. Definida a lógica de otimização, foram seguidas as seguintes etapas:

- Definição das variáveis de entrada: são declarados quais parâmetros do componente serão explorados ao longo da otimização. No caso variou-se espessura, comprimento, raio e ângulo longitudinal do absorvedor. Ainda são determinados os limites inferiores e superiores das variáveis investigadas.

- Definição das variáveis de saída: são as informações a serem analisadas, neste caso, importadas do software de simulação. Neste trabalho analisou-se a eficiência, força 
de pico, volume e energia.

- Definição de objetivos: Estipula-se maximizar ou minimizar uma ou mais variáveis de saída ou até mesmo uma equação função das variáveis de saída. O objetivo deste trabalho foi o de maximizar a energia específica, ou seja, a razão entre a energia e o volume.

- Definição de restrições (opcional): são estabelecidas restrições, ou seja, valores que uma variável de entrada ou de saída não poderá ultrapassar. Foram exploradas diferentes restrições ao longo das otimizações e seus respectivos efeitos.

- Planejamento da otimização: estipula-se o tipo de planejamento de experimentos, a quantidade de pontos do planejamento, o algoritmo de otimização e suas configurações. Aqui foram utilizadas diferentes configurações, conforme a necessidade dos algoritmos descritos.

Um exemplo de um fluxo de trabalho utilizado pode ser visto na Figura 39:

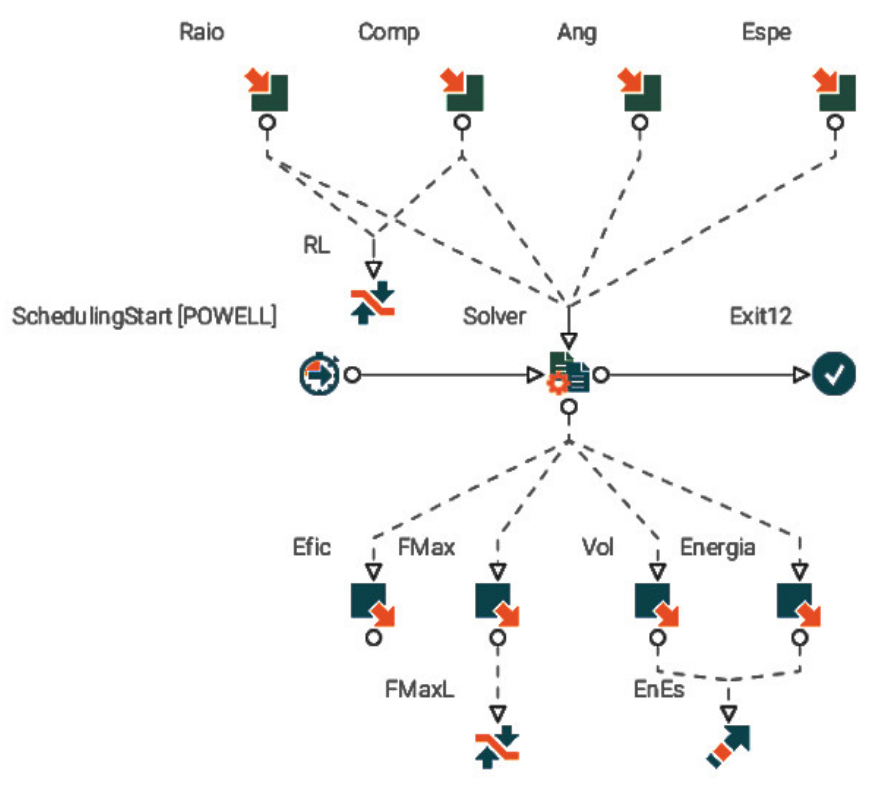

Figura 39: Exemplo de fluxo de trabalho.

Definido o fluxo de trabalho, é possível configurar o módulo EasyDriver, rotulado como "Solver" na Figura 39, configurando-se os seguintes parâmetros:

- Input Template: Responsável pela parametrização do problema. Estabelece uma relação entre as variáveis de entrada do fluxo de trabalho com o script original, alterando os respectivos valores na simulação numérica. 
- Edit Driver: define-se a linha de comando responsável por executar o script em determinado sistema operacional, no caso do Windows, uma linha de comando em batch.

- Output Template: É inserido um aquivo modelo que exemplifica como as informações de saída serão exibidas após o término da simulação, informações que são posteriormente associadas às variáveis de saída do fluxo de trabalho.

Utilizou-se uma restrição envolvendo as variáveis de entrada, limitando a razão do raio pelo comprimento do absorvedor de energia $(R / L)$ para valores acima de 0,07. Para o material e parâmetros de simulação utilizados, quando $R / L$ ficava abaixo de 0,07 , observou-se uma tendência de a longarina falhar por flambagem global ao invés de flambagem progressiva. O primeiro tipo de falha diminui substancialmente a quantidade de energia absorvida. Por isso, a coexistência desses dois fenômenos pode gerar uma maior complexidade no problema de otimização, uma vez que, nesse caso, dimensões semelhantes podem gerar respostas com maior discrepância, reduzindo a robustez do ensaio. Em outras palavras, essa restrição de entrada garante que os projetos gerados falhem apenas por flambagem progressiva. A diferença visual entre os dois modos pode ser visualizada na Figura 40.

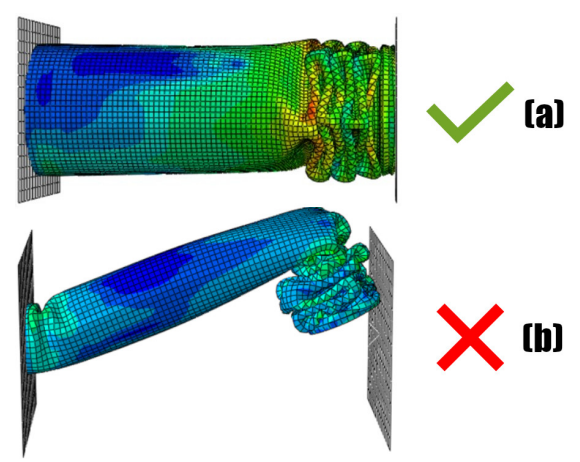

Figura 40: Comparação de flambagem progressiva em (a) e flambagem global em (b).

Já para os objetivos, foi definida uma restrição de força de pico de $250 \mathrm{kN}$. Tal limite permite que a longarina, ao ser otimizada, apresente um dimensionamento correto com relação a aceleração transferida para a cabine, uma vez que o pico de força na longarina influencia diretamente no pico de aceleração do habitáculo. O valor da força de pico foi retirado de trabalhos anteriores que envolvem o estudo em impactos de longarinas, como o de Tarlochan et al. [33].

O intervalo de valores usados como parâmetros de entrada para a otimização podem ser vistas na Tabela 3 . 
Tabela 3: Intervalo de valores utilizados.

\begin{tabular}{|l|l|l|}
\hline \multirow{2}{*}{ Propriedades } & \multicolumn{2}{|c|}{ Valores } \\
\cline { 2 - 3 } & Mínimo & Máximo \\
\hline Raio $[\mathrm{mm}]$ & 30 & 60 \\
\hline Comprimento $[\mathrm{mm}]$ & 200 & 600 \\
\hline Ângulo $\left[^{\circ}\right]$ & 0,0 & 2,0 \\
\hline Espessura $[\mathrm{mm}]$ & 1,0 & 5,0 \\
\hline
\end{tabular}

Definidos os limites superiores e inferiores dos parâmetros de entrada, usou-se um algoritmo de planejamento de experimento de preenchimento de espaço para a criação dos primeiros 10 projetos, respeitando as configurações determinadas. Para as otimizações diretas geradas por AFSQP e Powell, utilizou-se o algoritmo de Hipercubo Latino. Na otimização por MOGA-II, fez-se o uso do DoE de Sobol por questões de compatibilidade [64].

Por fim, para cada algoritmo de otimização, usou-se as seguintes configurações:

- AFSQP

- Derivadas aproximadas pelo método das diferenças progressivas

- Perturbação relativa de diferença finita: $10^{-3}$

- Política de diferença mínima de diferença finita: porcentagem do intervalo

- Perturbação mínima da faixa percentual: $10^{-4}$

- Precisão para definir convergência: $10^{-3}$

- Powell

- Fração de avaliações permitidas para cada ponto de DoE: 1,0

- Tamanho inicial dos vetores de procura normalizados: 0,25

- Tamanho final dos vetores de procura normalizados: $10^{-6}$

- MOGA-II

- Probabilidade de cross-over direcional: 0,5

- Probabilidade de seleção 0,05

- Probabilidade de mutação: 0,10

- Taxa de mutação de cadeia de DNA: 0,05 
- Elitismo habilitado

Por questões de custo computacional, todos os algoritmos foram limitados a gerar, no máximo, 1000 projetos cada.

\subsection{Metamodelamento}

O intuito principal em explorar o uso de metamodelos neste trabalho é de investigar, de forma paralela, as diferenças entre uma otimização direta contra uma otimização com o auxílio de metamodelos. Para tal, são desconsiderados os resultados gerados a partir da metodologia descrita na Seção 3.3, iniciando outro conjunto de otimizações a partir do zero, partindo do domínio de variáveis declarado pela Tabela 3.

Para a confecção dos modelos, é realizado um planejamento de experimentos de 200 pontos com o algoritmo Hipercubo Latino. Em seguida, após as simulações numéricas, é iniciado o processo de treinamento das superfícies de resposta. O objetivo é que o modelo matemático substitua os ensaios por completo, gerando a resposta de energia, volume e força máxima a partir dos parâmetros de entrada, como no exemplo da Figura 41.

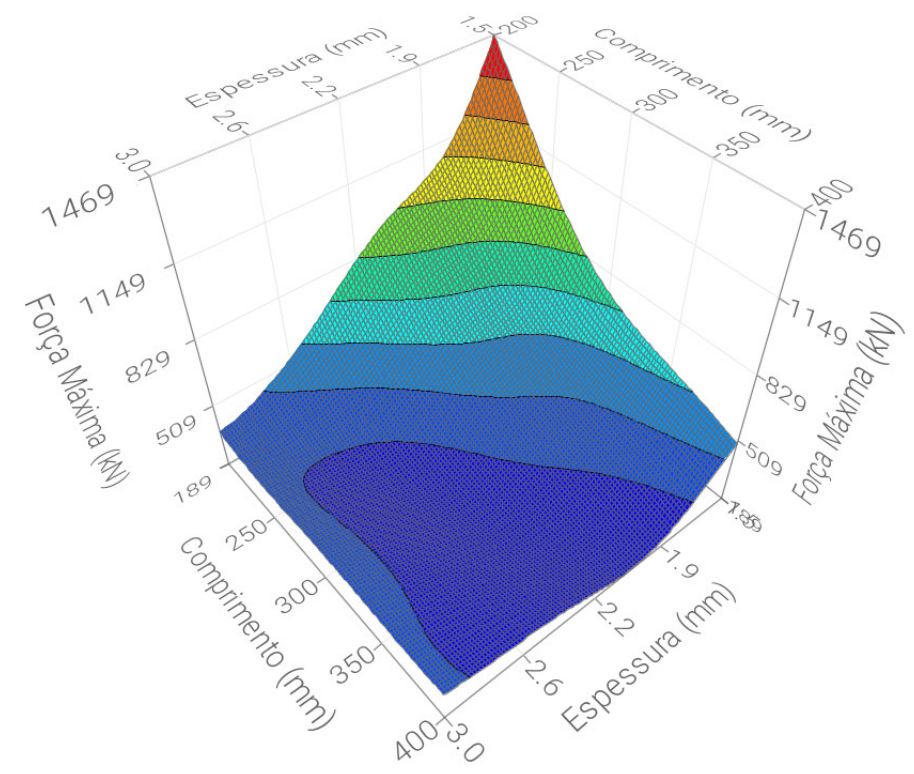

Figura 41: Exemplo de superfície de resposta

Os metamodelos utilizados são os descritos ao longo da Seção 2.5.1 ou derivados. Os tipos de funções e suas respectivas configurações são listadas abaixo:

- Polinomial SVD (do inglês, Singular Value Decomposition): foi utilizado o maior grau permitido pelo programa, no caso, grau 10. 
- RBF: usou-se Multiquadráticos de Hardy para prever a energia e o volume. Para a força de pico, foi escolhida a opção de Splines Poliarmônicas de Duchon.

- Kriging (abreviado como KR pelo software): definiu-se o variograma do tipo Exponencial para a prever a energia e Gaussiana para o cálculo da força de pico e volume.

- Kriging Anisotrópico (abreviado como AKR): é uma variação do algoritmo de Kriging em que é considerada anisotropia no fenômeno de estudo. Foram usadas as mesmas configurações feitas no Kriging.

- Redes Neurais: o número de camadas ocultas foi definido como automático.

Com a finalidade de testar a aderência de cada superfície, é feita uma primeira etapa de validação. Nela, uma quantidade definida de projetos do DoE é desconsiderada durante a criação do metamodelo. Posteriormente, esses mesmos projetos são usados para testar a acurácia dos modelos matemáticos criados. Optou-se por utilizar 10 projetos para a validação inicial, retirados de forma aleatória do DoE inicial, ou seja, os modelos são construídos a partir de 190 dos 200 pontos. No caso do software modeFRONTIER, essa fase retorna o coeficiente de determinação e as médias do erro absoluto e erro relativo. Seleciona-se a fórmula que possui as melhores métricas de aderência, ou seja, os melhores valores de regressão mostrados na Seção 2.5.2.

O metamodelo, uma vez definido, é explorado com um algoritmo de otimização. Nessa etapa, as respostas são apenas estimativas do acontecimento real, por isso, recebe o nome de otimização virtual. Nele, é encontrado pelo menos um ponto ótimo virtual, que por sua vez, pode estar aderente à realidade ou não.

O impacto de uma longarina é um fenômeno físico complexo com alto grau de nãolinearidade e, portanto, é esperado que o primeiro grupo de metamodelos não atinja uma precisão satisfatória. Para conferir uma maior aderência do modelo à ocorrência real, são realizados novos treinamentos para cada algoritmo, realizando alterações no DoE responsável por dar origem às superfícies de resposta. Como algoritmos de gradiente são notórios por trabalhar bem com metamodelos [8], o AFSQP é usado para o refinamento.

Encontrado um ponto ótimo virtual, inicia-se uma segunda validação. Nela, é feita uma simulação numérica com os mesmos parâmetros do projeto estimado, ou seja, comparase o valor previsto com o verdadeiro. Caso haja uma grande divergência, então o metamodelo não é suficientemente preciso para a região do ponto ótimo virtual, exigindo um refinamento. 
Os modelos de regressão possuem uma tendência de suavizar o comportamento de estudo, potencialmente ocultando o máximo local do problema. Para evitar essa ocorrência, os metamodelos são retreinados caso o ponto ótimo virtual gere um desempenho relativamente baixo, ou seja, um valor de saída insatisfatório. Esse procedimento é feito mesmo que o valor previsto esteja próximo do real.

O processo de refinamento é repetido toda vez em que o ponto ótimo obtido é insatisfatório ou haja uma grande discrepância entre o valor verdadeiro e o previsto, conforme ilustrado pela Figura 42.

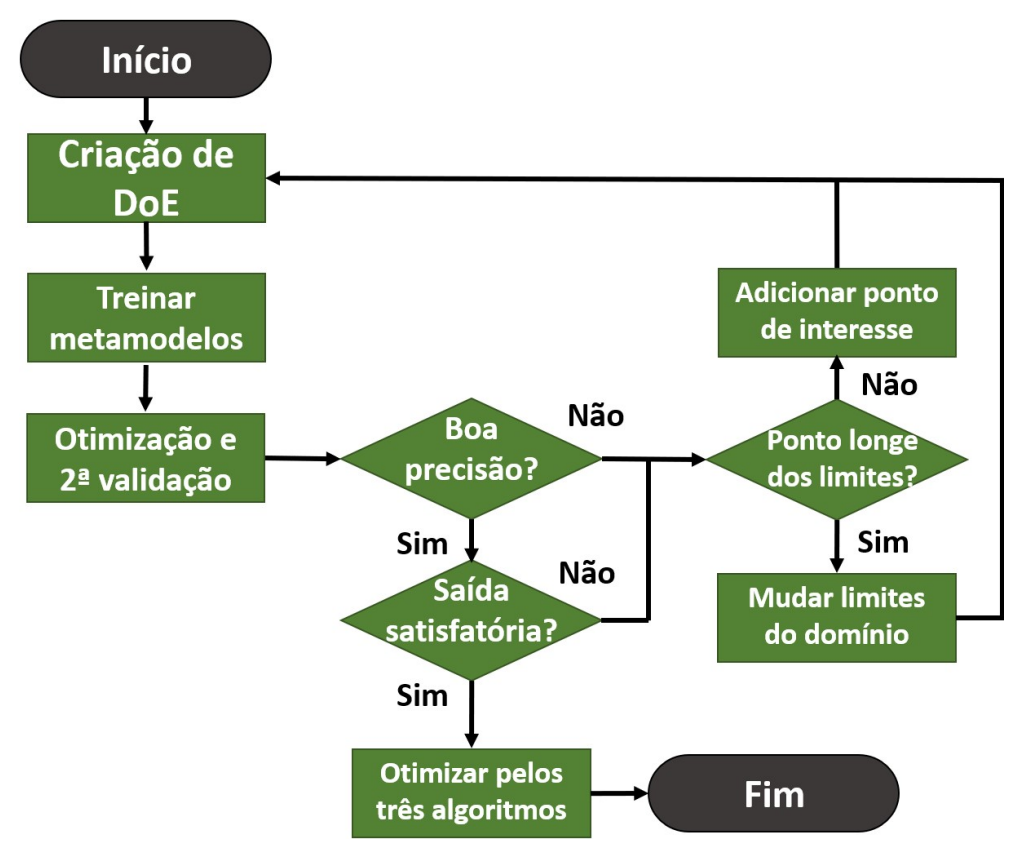

Figura 42: Refinamento do metamodelo

Vale notar que o tipo de modificação no DoE depende da posição do ponto de interesse dentro do domínio de estudo. Caso as variáveis de entrada dos projetos de interesse estejam muito distantes dos limites do domínio, então não é necessário estudar o domínio todo, mas sim a região que apresenta projetos com melhor desempenho. Nesse contexto, o refinamento do metamodelo é realizado de forma global, ou seja, cria-se um novo DoE com uma distância reduzida entre o limite superior e inferior.

Caso haja a necessidade de mais refinamentos, mesmo com um domínio de estudos enxuto, faz-se um refino local do metamodelo. Nesta circunstância, inserem-se, no último DoE gerado, os pontos reais gerados pela segunda etapa de validação. Esses projetos, também chamados de ponto de interesse, tendem a manifestar um desempenho superior aos espécimes anteriores, uma vez que foram obtidos de otimizações virtuais.

Ao final, ao definir um conjunto de metamodelos que satisfaça às necessidades do 
problema, o mesmo é usado para conduzir otimizações com os três algoritmos da Seção 2.6: AFSQP, Powell e MOGA-II.

Pelo fato de a superfície possuir um comportamento contínuo, a otimização com metamodelos permitiu que o algoritmo AFSQP trabalhasse com um maior grau de precisão, quando comparado ao parâmetros da Seção 3.3. As novas configurações para AFSQP estão listados a seguir:

- Derivadas aproximadas pelo método das diferenças progressivas

- Perturbação relativa de diferença finita: $10^{-5}$

- Política de diferença mínima de diferença finita: porcentagem do intervalo

- Perturbação mínima da faixa percentual: $10^{-6}$

- Precisão para definir convergência: $10^{-6}$

Os outros algoritmos mantiveram suas configurações iniciais. Como otimizações com metamodelos possuem um custo computacional baixo, o limite de iterações para este caso foi definido para $10^{4}$. 


\section{RESULTADOS E DISCUSSÃO}

\subsection{Análise Paramétrica}

Primeiramente, foi realizado um estudo paramétrico preliminar com relação às longarinas, tendo como objetivo entender como os parâmetros influenciam no desempenho dos absorvedores de energia. A primeira simulação, chamada de Projeto A, possui os valores médios da Tabela 3 como parâmetros, ou seja, os parâmetros da Tabela 4.

Tabela 4: Parâmetros geométricos do Projeto A.

\begin{tabular}{|l|c|}
\hline \multicolumn{2}{|c|}{ Projeto A } \\
\hline Raio & $45 \mathrm{~mm}$ \\
\hline Comprimento & $400 \mathrm{~mm}$ \\
\hline Ângulo & $1,0^{\circ}$ \\
\hline Espessura & $3,0 \mathrm{~mm}$ \\
\hline
\end{tabular}

O resultado da simulação em elementos finitos do Projeto A pode ser visualizado na Figura 43.

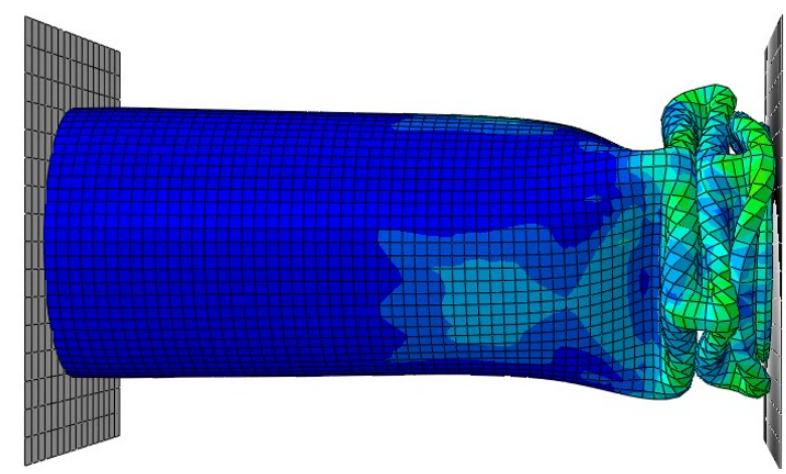

Figura 43: Animação de simulação de impacto do Projeto A.

A partir da Figura 43, é possível observar que há um volume considerável da longarina em que a deformação é muito pequena após o impacto, ou seja, parte do volume não é responsável por absorver energia, o que certamente prejudica a absorção de energia 
específica do projeto. Valores de saída de importância, como energia absorvida, força de pico e energia específica podem ser vistos na Tabela 5.

Tabela 5: Valores de saída do Projeto A.

\begin{tabular}{|l|c|}
\hline \multicolumn{2}{|c|}{ Projeto A } \\
\hline Energia absorvida & $30984 \mathrm{~J}$ \\
\hline Força de pico & $406072 \mathrm{~N}$ \\
\hline Energia específica & $0,08220 \mathrm{~J} / \mathrm{mm}^{3}$ \\
\hline Eficiência & $57,66 \%$ \\
\hline
\end{tabular}

O gráfico de força por deslocamento, da Figura 44, auxilia a entender as informações da Tabela 5 .

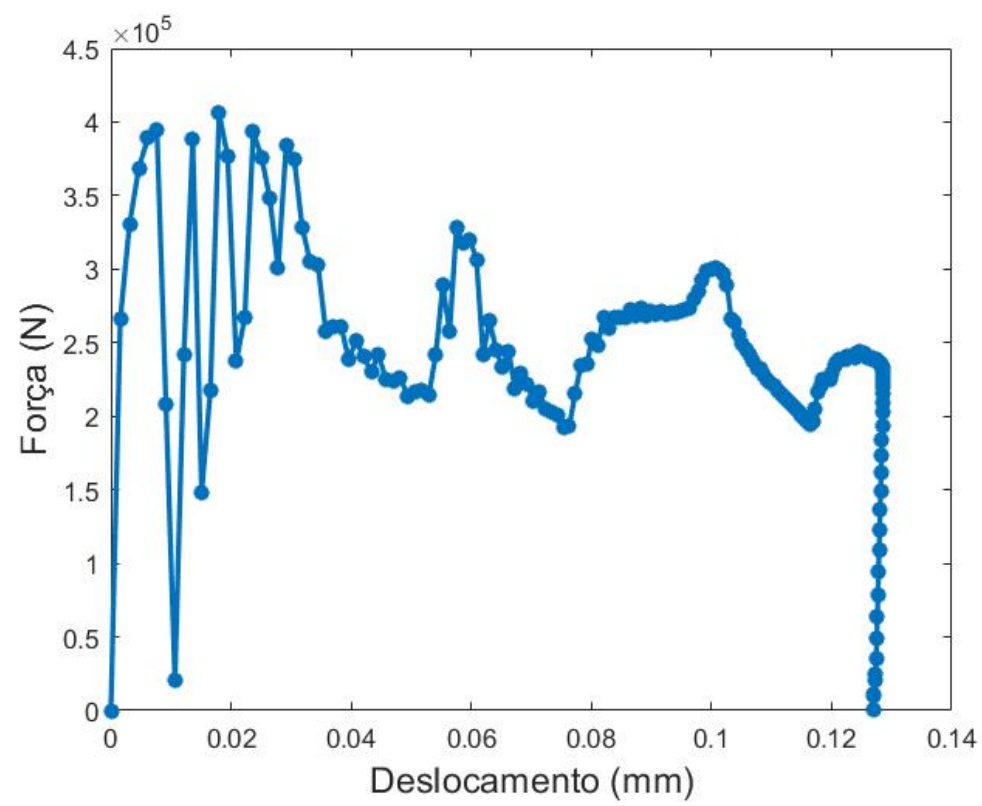

Figura 44: Força por deslocamento do Projeto A.

O Projeto A, do ponto de vista qualitativo, possui um bom desempenho como absorvedor de energia, uma vez que absorve toda a energia do impacto e apresenta uma eficiência (razão entre força média e força de pico) acima de 50\%. No entanto, vale notar que a longarina de $400 \mathrm{~mm}$ de comprimento utiliza apenas $130 \mathrm{~mm}$ de deslocamento. Em outras palavras, é possível projetar uma longarina com menor peso e menos material, que possua a mesma capacidade de proteção (ou melhor), quando comparada ao Projeto A.

Para testar o quanto que uma mudança na geometria pode afetar do desempenho da longarina, em seguida, foi confeccionada uma longarina com metade da espessura do Projeto A, ou seja, 1,5 mm. As outras dimensões foram mantidas constantes. Esse 
absorvedor foi chamado de Projeto B e seu estado após a deformação pode ser conferido na Figura 45.

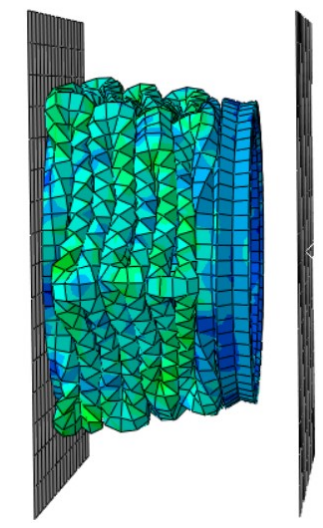

Figura 45: Projeto B deformado após o impacto.

A diminuição da espessura resultou em uma grande redução na rigidez do componente, que consequentemente alterou seus valores de desempenho, mostrados na Tabela 6.

Tabela 6: Valores de saída do Projeto B.

\begin{tabular}{|l|c|}
\hline \multicolumn{2}{|c|}{ Projeto B } \\
\hline Energia absorvida & $30426 \mathrm{~J}$ \\
\hline Força de pico & $470154 \mathrm{~N}$ \\
\hline Energia específica & $0,1639 \mathrm{~J} / \mathrm{mm}^{3}$ \\
\hline Eficiência & $28,08 \%$ \\
\hline
\end{tabular}

Com metade da espessura do Projeto A, o Projeto B manifestou o dobro de energia específica. No entanto, houve um aumento na força de pico e uma queda abrupta em sua eficiência. A Figura 46 complementa as informações do desempenho da segunda longarina.

Apesar de o pico de força do Projeto B apresentar a mesma ordem de grandeza que o do projeto A, a força de reação máxima de cada projeto é ocasionado por fenômenos diferentes. No caso do exemplo A, o pico principal é ocasionado pela dificuldade em iniciar a deformação na peça. No exemplo B, dada a menor rigidez, a força necessária para iniciar a deformação no componente é muito menor, porém, a deformação é suficiente para que o absorvedor atinja o fim de seu curso, o que aumenta subitamente a rigidez do sistema. Essa diferença de comportamento entre projetos justifica analisar o gráfico de força por deslocamento em conjunto com as métricas nominais de desempenho, como as apresentadas pela Tabela 6, por exemplo.

O comportamento do Projeto B é um indicativo de subdimensionamento, onde é necessário adicionar mais material para que o desempenho seja aceitável. Como contra- 


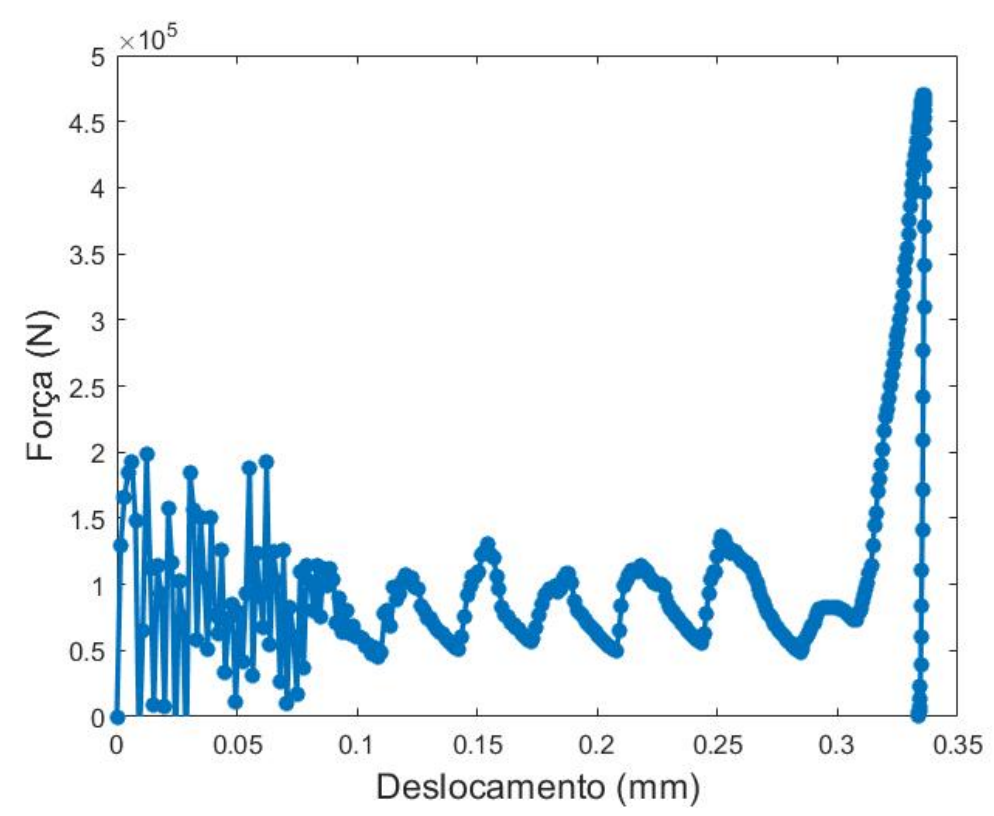

Figura 46: Força por deslocamento do Projeto B.

medida, foram feitos mais dois espécimes baseados na segunda longarina, chamados de C1 e C2. Neles, foram aumentados respectivamente o comprimento e o raio do tubo. As dimensões desses projetos se encontram na Tabela 7.

Tabela 7: Parâmetros geométricos dos Projetos C1 e C2.

\begin{tabular}{|l|c|c|}
\hline & Projeto C1 & Projeto C2 \\
\hline Raio & $45 \mathrm{~mm}$ & $60 \mathrm{~mm}$ \\
\hline Comprimento & $600 \mathrm{~mm}$ & $400 \mathrm{~mm}$ \\
\hline Ângulo & $1,0^{\circ}$ & $1,0^{\circ}$ \\
\hline Espessura & $1,5 \mathrm{~mm}$ & $1,5 \mathrm{~mm}$ \\
\hline
\end{tabular}

A Figura 47 contempla ambos os projetos após sofrerem impacto. Assim como o Projeto A, o Projeto C1 possui uma região livre de rótulas plásticas, enquanto o Projeto C2, por sua vez, mostra um comportamento análogo ao Projeto B, em que é atingido o fim de curso do componente. Vale notar que C1 teve um melhor aproveitamento de volume que o Projeto A, ou seja, uma energia específica maior. Observa-se também que o Projeto C2 teve uma força de pico menor do que o Projeto B, respectivamente $305 \mathrm{kN}$ contra $470 \mathrm{kN}$. Tais características indicam um progresso com relação aos dois primeiros projetos. 


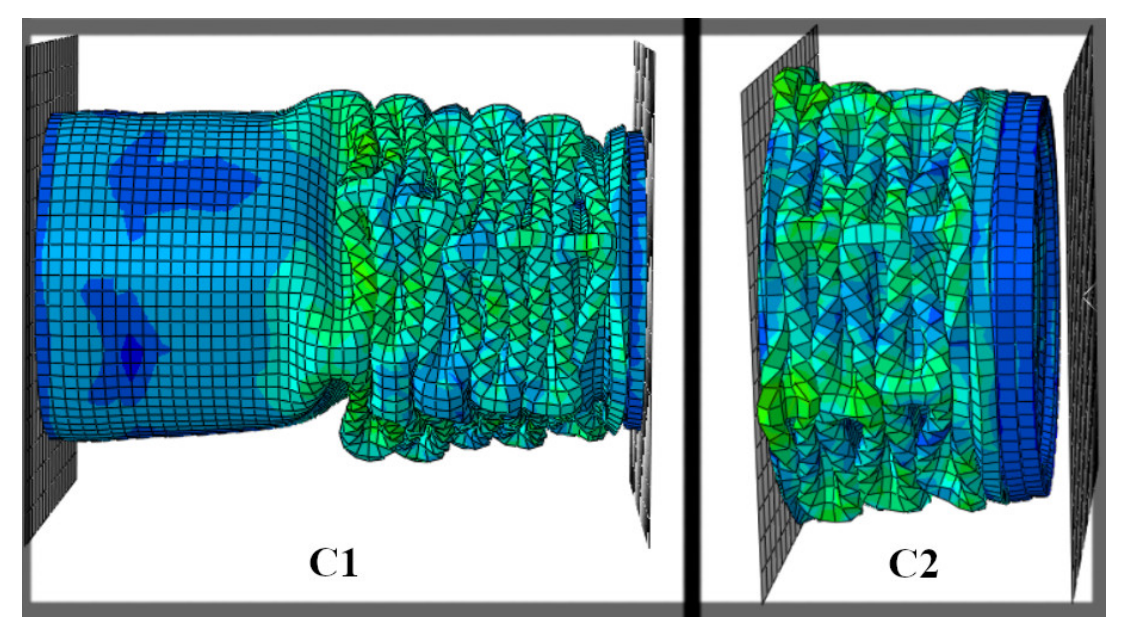

Figura 47: Projetos C1 e C2 completamente deformados após o mesmo impacto.

No caso, a área não aproveitada de C1 é menor que a de A, mostrando maior energia específica. O pico do fim de curso de C2 é menor que o de B. O desempenho de C1 e C2 é mostrado na Tabela 8.

Tabela 8: Valores de saída dos Projeto C1 e C2.

\begin{tabular}{|l|c|c|}
\hline & Projeto C1 & Projeto C2 \\
\hline Energia absorvida & $30964 \mathrm{~J}$ & $30570 \mathrm{~J}$ \\
\hline Força de pico & $200703 \mathrm{~N}$ & $305223 \mathrm{~N}$ \\
\hline Energia específica & $0,1074 \mathrm{~J} / \mathrm{mm}^{3}$ & $0,1262 \mathrm{~J} / \mathrm{mm}^{3}$ \\
\hline Eficiência & $42,69 \%$ & $40,91 \%$ \\
\hline
\end{tabular}

Por fim, a Figura 48 compara o comportamento de força por deslocamento de C1 e C2. O maior raio de $\mathrm{C} 2$ faz com que sua força de reação média seja ligeiramente maior que a de C2. Porém, ao deslocar $320 \mathrm{~mm}$ (ou ainda 80\% de seu comprimento inicial), C2 atinge o fim de seu curso, fazendo com que atinja a força de pico no final de deslocamento. Mesmo com um raio de $45 \mathrm{~mm}$, o maior comprimento de C1 permitiu absorver toda a energia cinética dentro de uma força de pico na ordem de $200 \mathrm{kN}$. Dos projetos da Seção 4.1, C1 é o único absorvedor a atender a restrição de força de pico inferior a $250 \mathrm{kN}$. Esse no entanto, apresenta uma energia específica baixa em relação aos outros três exemplos. 


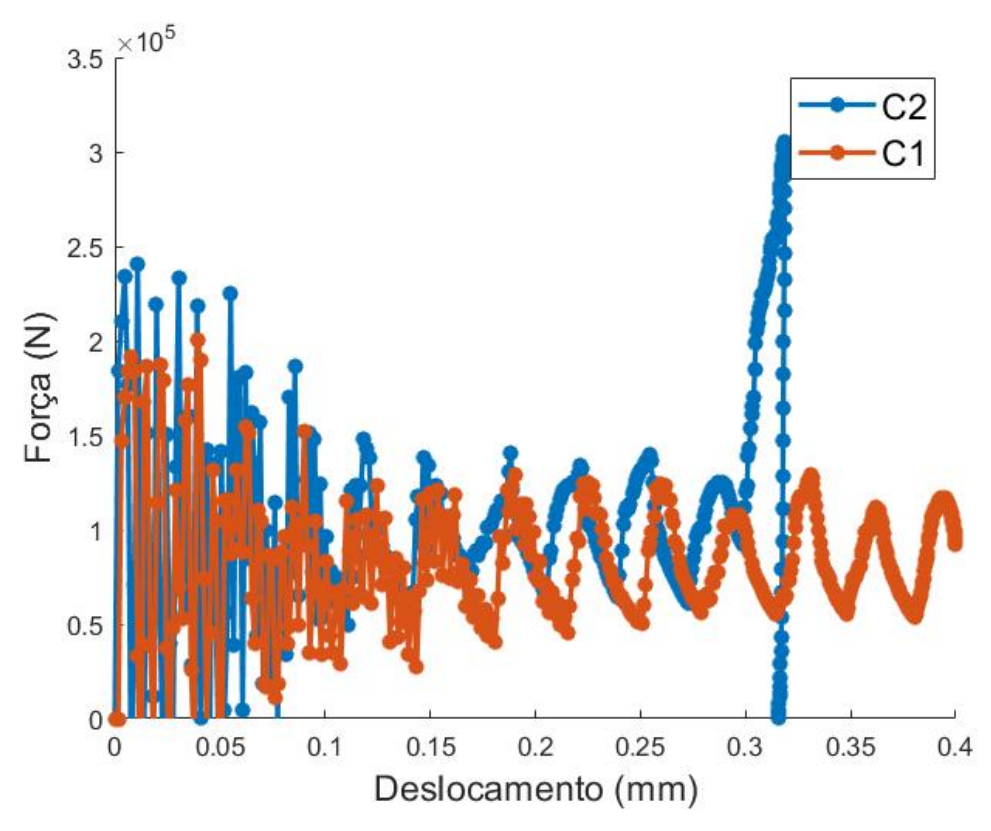

Figura 48: Força por deslocamento de C1 e C2.

Esta Seção demonstra duas das dificuldades em projetar absorvedores de energia com desempenho otimizado, sendo elas:

- Restrição da força de reação: como discutido na Seção 2.3, o pico da força de reação deve ser relativamente pequeno, de forma a diminuir a aceleração transferida para a cabine. A existência dessa restrição compete com a maximização de energia específica do absorvedor, dado um mesmo material. Isso acontece porque tubos com menos material são mais propícios a apresentar picos de força gerados pelo final de curso de deslocamento.

- Correlação entre os parâmetros de entrada: o efeito de um parâmetro geométrico possui dependência direta dos outros parâmetros. Reduzir a espessura de um tubo longo pode diminuir a força de pico, pois deixa o componente menos rígido. Porém, diminuir a espessura de um tubo mais curto pode fazer com que a longarina não possua deslocamento suficiente para absorver toda a energia de impacto, causando um fim de curso no componente e aumentando a força de pico. Ressaltando que não há um valor numérico que separe um tubo longo de um tubo curto.

Com relação ao dimensionamento de absorvedores de energia, uma abordagem iterativa faria do desenvolvimento do absorvedor lento e repetitivo. O posterior uso de metamodelos e algoritmos de otimização visa: automatizar a busca de um bom conjunto de parâmetros e garantir que o projeto calculado é o melhor possível dentro das restrições. 


\subsection{Otimização Forçada}

Posteriormente à análise paramétrica, foi feita uma otimização por força bruta do problema. Para tal, foram gerados 1000 pontos aleatórios com Hipercubo Latino usando a faixa de valores da Tabela 3. Vale ressaltar que, durante esta etapa, não foi feito o uso de algoritmos de otimização ou metamodelos.

A busca aleatória foi feita com duas finalidades principais. Primeiramente, busca-se obter uma visão geral do domínio de variáveis estudado, permitindo visualizar alguns valores esperados para as otimizações. Em segundo lugar, cria-se uma referência para avaliar o desempenho dos métodos de otimização. A otimização forçada gera projetos aleatórios, em que não é usado um direcionamento para a obtenção de projetos melhores, ou seja, não há uma convergência característica de uma otimização. Logo, se algum método de otimização obtiver um desempenho inferior a um DoE com o mesmo número de pontos, o método se mostra inapropriado para o estudo em questão, uma vez que seria mais eficiente utilizar projetos totalmente aleatórios. O histórico das 1000 iterações se encontra na Figura 49.

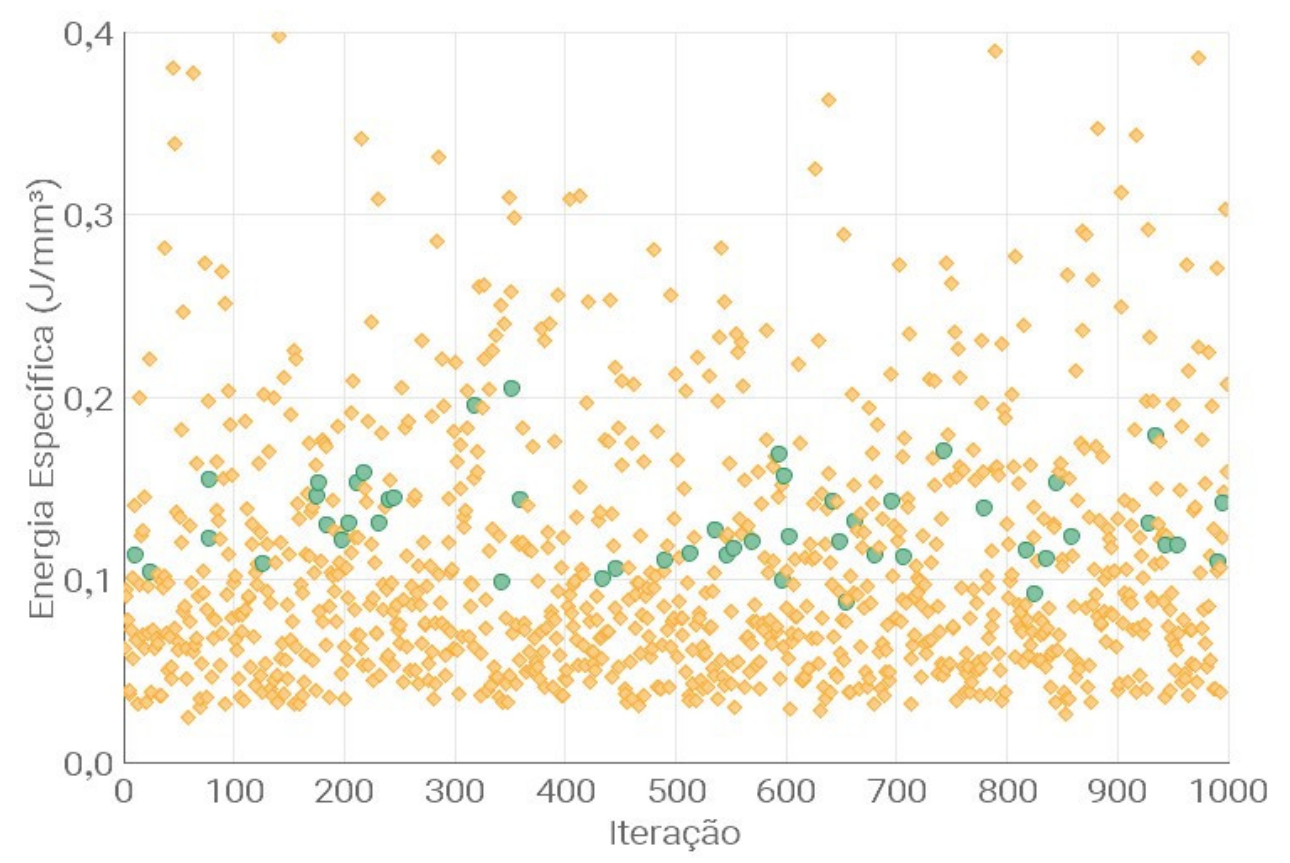

Figura 49: Energia específica por do número de iterações para o DoE de 1000 pontos.

Na Figura 49, os círculos em verde denotam os projetos viáveis, ou seja, aqueles que atendem às restrições, no caso, força de pico menor que $250 \mathrm{kN}$ e proporção de raio sobre comprimento maior que 0,07. Já os losangos em amarelo representam espécimes que violaram as restrições. Olhando atentamente ao gráfico de dispersão, é possível notar 
que a maioria dos pontos violam as restrições, sendo que apenas 70 pontos atendem à restrição de força e somente 51 projetos atendem às duas restrições.

É antecipado que os algoritmos de otimização possuam dificuldade para aderir ao domínio viável, já que ele representou apenas 5,1\% dos projetos, justificando o uso de pontos iniciais esparsos para a otimização dos algoritmos. A partir da Figura 49 também é possível observar que os projetos com a maior energia específica são inviáveis, sendo que apenas uma simulação conseguiu ser simultaneamente viável e obter uma energia específica maior que $0,20 \mathrm{~J} / \mathrm{mm}^{3}$. A Tabela 9 mostra parâmetros e energia específica das 5 melhores longarinas obtidas pela otimização por força bruta.

Tabela 9: Melhores projetos da otimização por força bruta.

\begin{tabular}{|c|c|c|c|c|c|}
\hline Ângulo & Comprimento & Espessura & Raio & Energia específica & Força de pico \\
\hline $0,496^{\circ}$ & $383 \mathrm{~mm}$ & $1,92 \mathrm{~mm}$ & $30,3 \mathrm{~mm}$ & $0,205 \mathrm{~J} / \mathrm{mm}^{3}$ & $191 \mathrm{kN}$ \\
\hline $1,59^{\circ}$ & $282 \mathrm{~mm}$ & $2,33 \mathrm{~mm}$ & $32,8 \mathrm{~mm}$ & $0,196 \mathrm{~J} / \mathrm{mm}^{3}$ & $239 \mathrm{kN}$ \\
\hline $1,19^{\circ}$ & $467 \mathrm{~mm}$ & $1,52 \mathrm{~mm}$ & $33,1 \mathrm{~mm}$ & $0,178 \mathrm{~J} / \mathrm{mm}^{3}$ & $184 \mathrm{kN}$ \\
\hline $0,212^{\circ}$ & $332 \mathrm{~mm}$ & $2,04 \mathrm{~mm}$ & $40,1 \mathrm{~mm}$ & $0,171 \mathrm{~J} / \mathrm{mm}^{3}$ & $250 \mathrm{kN}$ \\
\hline $1,79^{\circ}$ & $337 \mathrm{~mm}$ & $2,20 \mathrm{~mm}$ & $33,2 \mathrm{~mm}$ & $0,169 \mathrm{~J} / \mathrm{mm}^{3}$ & $234 \mathrm{kN}$ \\
\hline
\end{tabular}

As simulações realizadas também permitiram criar um estudo de sensibilidade das variáveis com relação à função objetivo e à restrição de força. O coeficiente de determinação da análise é de $92,9 \%$ e os dados são válidos apenas para o domínio da Tabela 3 e o Aço A36 como material. As informações de sensibilidade constam na Tabela 10.

Tabela 10: Análise de sensibilidade dos parâmetros.

\begin{tabular}{|c|c|c|}
\hline & Energia específica & Força de pico \\
\hline Ângulo & $0,4 \%$ & $0,1 \%$ \\
\hline Comprimento & $29,2 \%$ & $25,3 \%$ \\
\hline Espessura & $61,9 \%$ & $69,4 \%$ \\
\hline Raio & $8,6 \%$ & $5,2 \%$ \\
\hline
\end{tabular}

Analisando a Tabela 10, é possível notar que a espessura e o comprimento são os parâmetros que respectivamente mais influenciam nos dados de saída. O raio apresenta uma atuação pequena, porém ainda perceptível. Já o ângulo longitudinal mostrou uma ação irrelevante no desempenho da longarina. Ressalta-se que a influência de cada variável pode ser alterada caso haja uma mudança em seu limite inferior e superior. Em outras palavras, a influência do comprimento pode mudar caso seu domínio seja alterado de $200 \leq$ Comprimento $\leq 600$ para $400 \leq$ Comprimento $\leq 500$, por exemplo. 


\subsection{Planejamento de Experimentos}

Cada otimização direta exigiu a criação de um planejamento de experimentos para dar início ao processo. Todos os algoritmos utilizaram um DoE de 10 projetos baseados na Tabela 3. O algoritmo AFSQP e Powell utilizaram o mesmo DoE, gerado por Hipercubo Latino, exposto na Tabela 11.

Tabela 11: Projeto de experimentos por Hipercubo Latino.

\begin{tabular}{|c|c|c|c|c|c|c|}
\hline $\mathrm{N}^{\mathrm{o}}$ & Angulo & Comprimento & Espessura & Raio & Energia específica & Força de pico \\
\hline 1 & $0,428^{\circ}$ & $215 \mathrm{~mm}$ & $3,33 \mathrm{~mm}$ & $30,8 \mathrm{~mm}$ & $0,200 \mathrm{~J} / \mathrm{mm}^{3}$ & $378 \mathrm{kN}$ \\
\hline 2 & $1,56^{\circ}$ & $244 \mathrm{~mm}$ & $4,50 \mathrm{~mm}$ & $58,7 \mathrm{~mm}$ & $0,0672 \mathrm{~J} / \mathrm{mm}^{3}$ & $773 \mathrm{kN}$ \\
\hline 3 & $0,750^{\circ}$ & $512 \mathrm{~mm}$ & $1,20 \mathrm{~mm}$ & $37,0 \mathrm{~mm}$ & $0,187 \mathrm{~J} / \mathrm{mm}^{3}$ & $416 \mathrm{kN}$ \\
\hline 4 & $1,04^{\circ}$ & $466 \mathrm{~mm}$ & $1,87 \mathrm{~mm}$ & $54,9 \mathrm{~mm}$ & $0,0950 \mathrm{~J} / \mathrm{mm}^{3}$ & $308 \mathrm{kN}$ \\
\hline 5 & $1,29^{\circ}$ & $596 \mathrm{~mm}$ & $1,60 \mathrm{~mm}$ & $46,4 \mathrm{~mm}$ & $0,0962 \mathrm{~J} / \mathrm{mm}^{3}$ & $215 \mathrm{kN}$ \\
\hline 6 & $1,63^{\circ}$ & $287 \mathrm{~mm}$ & $2,96 \mathrm{~mm}$ & $49,7 \mathrm{~mm}$ & $0,104 \mathrm{~J} / \mathrm{mm}^{3}$ & $427 \mathrm{kN}$ \\
\hline 7 & $0,0339^{\circ}$ & $333 \mathrm{~mm}$ & $4,70 \mathrm{~mm}$ & $51,2 \mathrm{~mm}$ & $0,0570 \mathrm{~J} / \mathrm{mm}^{3}$ & $737 \mathrm{kN}$ \\
\hline 8 & $0,380^{\circ}$ & $433 \mathrm{~mm}$ & $3,78 \mathrm{~mm}$ & $34,3 \mathrm{~mm}$ & $0,0796 \mathrm{~J} / \mathrm{mm}^{3}$ & $462 \mathrm{kN}$ \\
\hline 9 & $0,804^{\circ}$ & $551 \mathrm{~mm}$ & $2,27 \mathrm{~mm}$ & $39,7 \mathrm{~mm}$ & $0,0886 \mathrm{~J} / \mathrm{mm}^{3}$ & $272 \mathrm{kN}$ \\
\hline 10 & $1,82^{\circ}$ & $372 \mathrm{~mm}$ & $4,09 \mathrm{~mm}$ & $44,4 \mathrm{~mm}$ & $0,0610 \mathrm{~J} / \mathrm{mm}^{3}$ & $579 \mathrm{kN}$ \\
\hline
\end{tabular}

Cada projeto da Tabela 11 representa um ponto inicial para os algoritmos AFSQP e Powell. Ou seja, esses algoritmos realizaram a otimização 10 vezes cada, partindo de um ponto diferente em cada execução e, em outras palavras, possuindo 10 chances de encontrar o ponto ótimo dentro do domínio de estudo. Os espécimes gerados possuem combinações de parâmetros diferentes, o que permite a análise e otimização de longarinas variadas. Porém, vale notar que, dos projetos gerados por Hipercubo Latino, apenas o projeto $\mathrm{N}^{0} 5$ pertence à região viável do problema. Só é possível saber se o ponto é viável após a realização do experimento.

Já o algoritmo MOGA-II foi iniciado através de um DoE gerado pela sequência de Sobol. Os 10 pontos gerados compõe a primeira geração do algoritmo genético. A partir desses projetos, são geradas novas gerações compostas de outros 10 projetos até que se atinja um limite de 100 gerações, ou seja, 1000 projetos. A Tabela 12 contém os pontos iniciais obtidos por Sobol.

Assim como o DoE gerado por Hipercubo Latino, da Tabela 11, o DoE feito por Sobol possui apenas 1 projeto pertencente ao domínio viável, no caso, o projeto $\mathrm{N}^{\circ} 4$ da Tabela 12. Vale notar que para o segundo caso, o projeto No 10 por Sobol, apesar de estar no domínio inviável, está próximo à transição de viabilidade. 
Tabela 12: Projeto de experimentos por Sobol.

\begin{tabular}{|c|c|c|c|c|c|c|}
\hline $\mathrm{N}^{\mathrm{o}}$ & Ângulo & Comprimento & Espessura & Raio & Energia específica & Força de pico \\
\hline 1 & $0,000^{\circ}$ & $200 \mathrm{~mm}$ & $1,00 \mathrm{~mm}$ & $30,0 \mathrm{~mm}$ & $0,690 \mathrm{~J} / \mathrm{mm}^{3}$ & $3701 \mathrm{kN}$ \\
\hline 2 & $0,500^{\circ}$ & $500 \mathrm{~mm}$ & $4,00 \mathrm{~mm}$ & $52,5 \mathrm{~mm}$ & $0,0435 \mathrm{~J} / \mathrm{mm}^{3}$ & $602 \mathrm{kN}$ \\
\hline 3 & $1,50^{\circ}$ & $300 \mathrm{~mm}$ & $2,00 \mathrm{~mm}$ & $37,5 \mathrm{~mm}$ & $0,191 \mathrm{~J} / \mathrm{mm}^{3}$ & $460 \mathrm{kN}$ \\
\hline 4 & $1,75^{\circ}$ & $550 \mathrm{~mm}$ & $1,50 \mathrm{~mm}$ & $41,2 \mathrm{~mm}$ & $0,119 \mathrm{~J} / \mathrm{mm}^{3}$ & $186 \mathrm{kN}$ \\
\hline 5 & $0,750^{\circ}$ & $350 \mathrm{~mm}$ & $3,50 \mathrm{~mm}$ & $56,2 \mathrm{~mm}$ & $0,0673 \mathrm{~J} / \mathrm{mm}^{3}$ & $578 \mathrm{kN}$ \\
\hline 6 & $0,250^{\circ}$ & $450 \mathrm{~mm}$ & $2,50 \mathrm{~mm}$ & $33,8 \mathrm{~mm}$ & $0,123 \mathrm{~J} / \mathrm{mm}^{3}$ & $267 \mathrm{kN}$ \\
\hline 7 & $1,25^{\circ}$ & $250 \mathrm{~mm}$ & $4,50 \mathrm{~mm}$ & $48,8 \mathrm{~mm}$ & $0,0782 \mathrm{~J} / \mathrm{mm}^{3}$ & $706 \mathrm{kN}$ \\
\hline 8 & $1,38^{\circ}$ & $525 \mathrm{~mm}$ & $2,75 \mathrm{~mm}$ & $58,1 \mathrm{~mm}$ & $0,0513 \mathrm{~J} / \mathrm{mm}^{3}$ & $467 \mathrm{kN}$ \\
\hline 9 & $0,375^{\circ}$ & $325 \mathrm{~mm}$ & $4,75 \mathrm{~mm}$ & $43,1 \mathrm{~mm}$ & $0,0661 \mathrm{~J} / \mathrm{mm}^{3}$ & $718 \mathrm{kN}$ \\
\hline 10 & $0,875^{\circ}$ & $425 \mathrm{~mm}$ & $1,75 \mathrm{~mm}$ & $50,6 \mathrm{~mm}$ & $0,121 \mathrm{~J} / \mathrm{mm}^{3}$ & $254 \mathrm{kN}$ \\
\hline
\end{tabular}

Os dois algoritmos de DoE preencheram o espaço estudado de uma forma distinta. A comparação visual entre os dois preenchimentos pode ser vista na Figura 50.

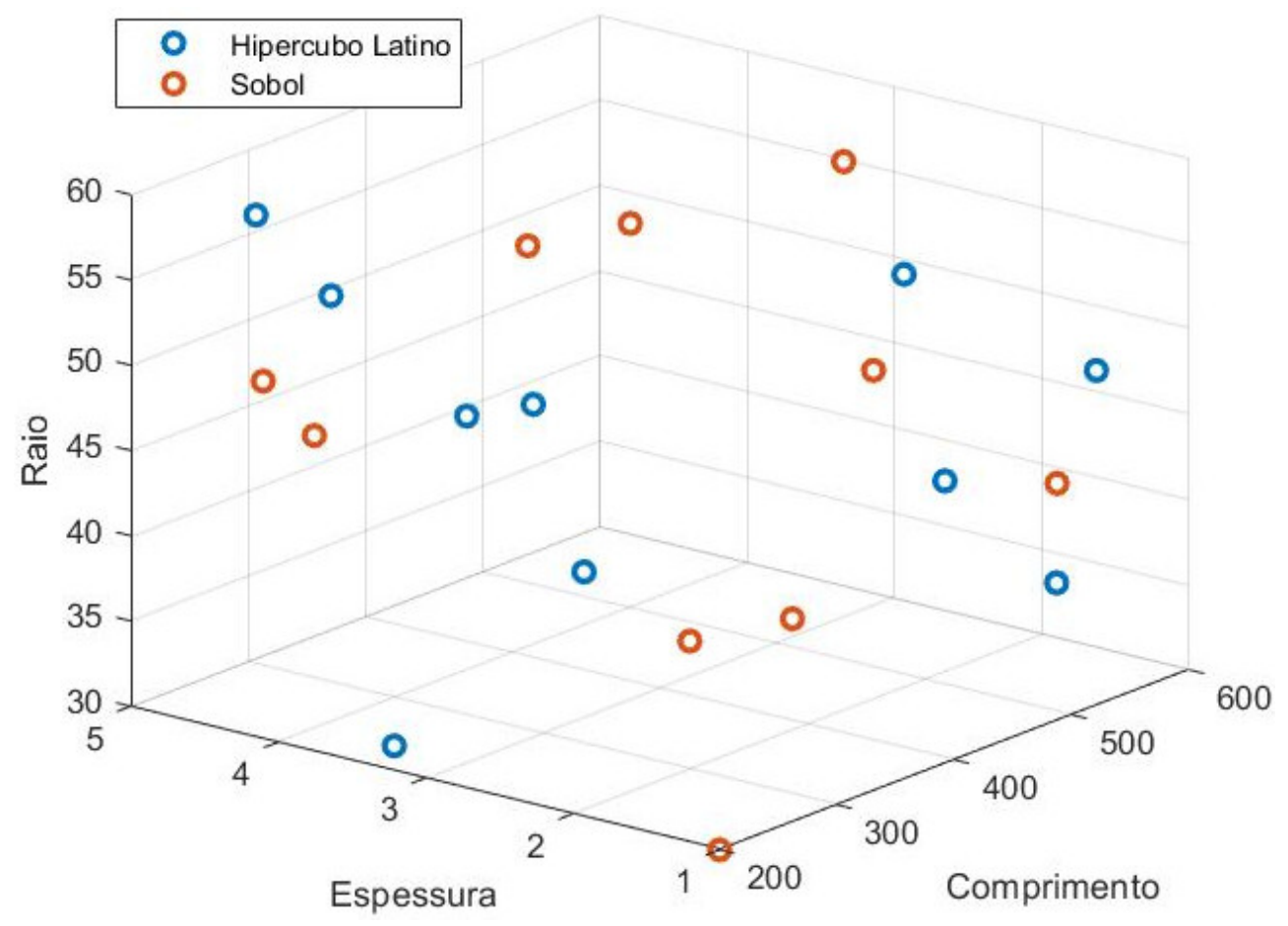

Figura 50: Preenchimento de espaço por Sobol e Hipercubo Latino.

Note que para facilitar a visualização dos algoritmos de preenchimento de espaço, a Figura 50 contém apenas 3 das 4 dimensões estudadas. 


\subsection{Otimização por AFSQP}

Para o problema em questão, o algoritmo AFSQP, com o método das diferenças progressivas, realiza 4 simulações para definir as derivadas do fenômeno e em seguida, faz mais uma simulação, baseada nas derivadas, com o intuito de gerar um projeto melhor. Caso o último projeto seja inferior ao penúltimo, a segunda etapa é repetida até que seja encontrado um projeto superior. Somente a primeira etapa, do cálculo das derivadas, pode ser executada com simulações em paralelo, no caso, 4 experimentos simultâneos.

Um usuário que busca diminuir o tempo de uma otimização com experimentos em elementos finitos pode utilizar diferentes abordagens. A primeira é dividir a simulação numérica em subdomínios, o que distribui o custo de processamento dos cálculos nos diferentes núcleos da unidade de processamento central do computador (CPU, do inglês Central Processing Unit). Vale notar que o rendimento desse método não é linear, uma vez que um número maior de divisões pode impactar de forma negativa no tempo de processamento.

A segunda alternativa é realizar mais de uma simulação de maneira simultânea, o que é mais eficiente que o primeiro método, porém depende da lógica do algoritmo usado, ou seja, um algoritmo exclusivamente sequencial não pode se beneficiar da segunda alternativa. É possível também combinar as duas estratégias, desde que o número de subdomínios multiplicado pela quantidade de simulações simultâneas não ultrapasse o número de núcleos do CPU. Por exemplo, com um CPU de 8 núcleos, é possível otimizar com 2 simulações simultâneas com 4 subdomínios cada.

Como no caso do algoritmo AFSQP é impossível prever o quão sequencial é o seu comportamento, optou-se por realizar todas as simulações de forma sequencial com 6 subdomínios. Foram necessárias 683 iterações para otimizar os 10 pontos da Tabela 11, totalizando 164 horas e 52 minutos, ou ainda, uma média de cerca de 14 minutos e 30 segundos por simulação.

O histórico de convergência do algoritmo se encontra na Figura 51. Nele, apenas 6 dos 10 pontos geraram projetos viáveis, o que indica uma forte dependência com relação ao ponto inicial escolhido.

Para o algoritmo com gradiente utilizado, o comportamento complexo do sistema dificulta a otimização a partir de determinados pontos iniciais, resultando em convergências prematuras, o que torna a otimização ineficaz para esses mesmos pontos, podendo inclusive gerar um resultado final questionável. 


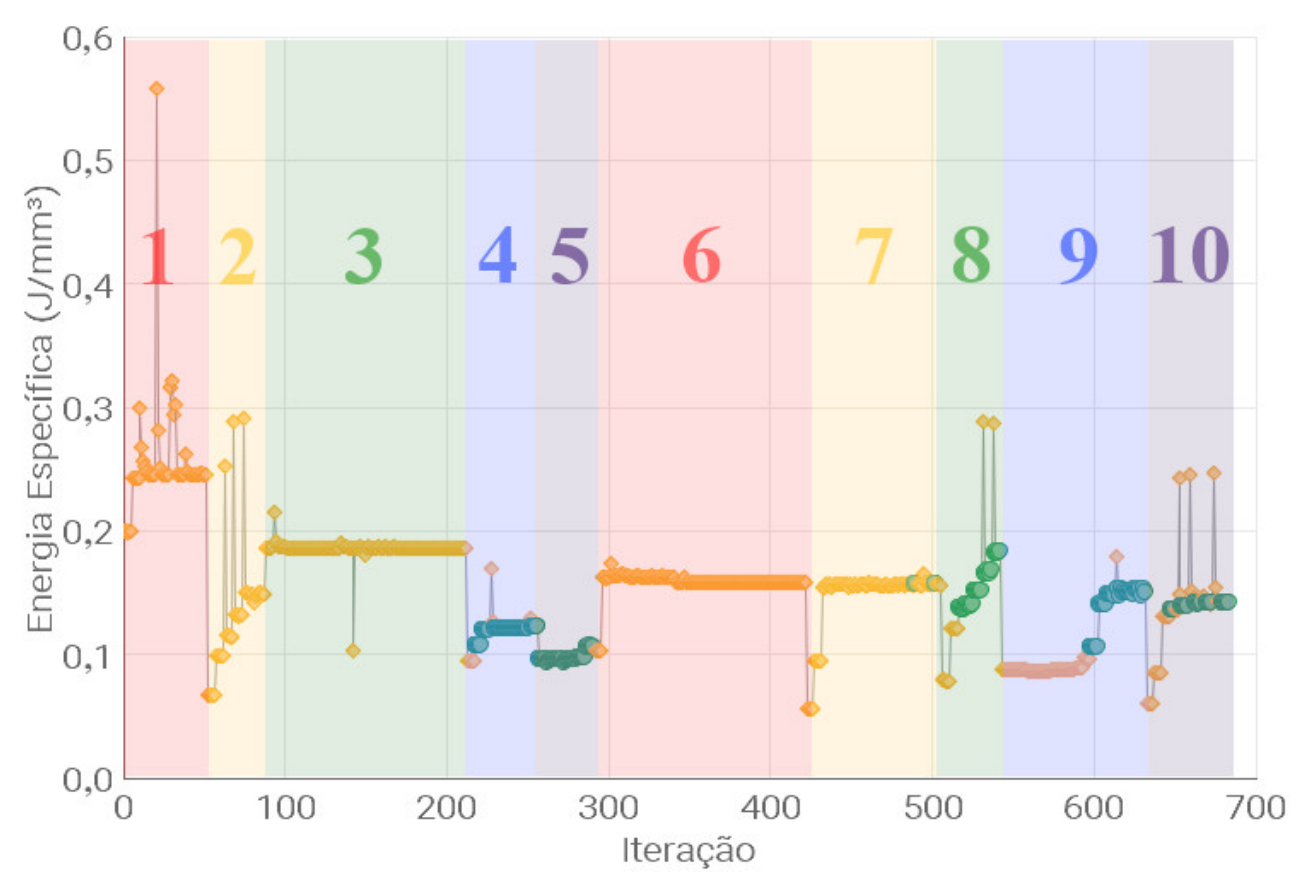

Figura 51: Histórico de convergência da otimização por AFSQP.

Tendo essas informações em vista, ao realizar uma otimização numérica, revela-se a importância da utilização de um algoritmo de planejamento de experimentos de spacefilling, pois os mesmos são capazes de gerar pontos iniciais que preencham uniformemente o domínio desejado. A Tabela 13 mostra os projetos otimizados para cada ponto da Tabela 11.

Tabela 13: Otimização por AFSQP.

\begin{tabular}{|c|c|c|c|c|c|c|}
\hline $\mathrm{N}^{\mathrm{o}}$ & Ângulo & Comprimento & Espessura & Raio & Energia específica & Força de pico \\
\hline 1 & $0,428^{\circ}$ & $215 \mathrm{~mm}$ & $2,71 \mathrm{~mm}$ & $30,7 \mathrm{~mm}$ & $0,247 \mathrm{~J} / \mathrm{mm}^{3}$ & $295 \mathrm{kN}$ \\
\hline 2 & $1,68^{\circ}$ & $244 \mathrm{~mm}$ & $2,10 \mathrm{~mm}$ & $59,3 \mathrm{~mm}$ & $0,150 \mathrm{~J} / \mathrm{mm}^{3}$ & $353 \mathrm{kN}$ \\
\hline 3 & $0,751^{\circ}$ & $512 \mathrm{~mm}$ & $1,20 \mathrm{~mm}$ & $37,0 \mathrm{~mm}$ & $0,187 \mathrm{~J} / \mathrm{mm}^{3}$ & $376 \mathrm{kN}$ \\
\hline 4 & $0,962^{\circ}$ & $466 \mathrm{~mm}$ & $1,43 \mathrm{~mm}$ & $54,9 \mathrm{~mm}$ & $0,123 \mathrm{~J} / \mathrm{mm}^{3}$ & $222 \mathrm{kN}$ \\
\hline 5 & $1,61^{\circ}$ & $596 \mathrm{~mm}$ & $1,37 \mathrm{~mm}$ & $46,4 \mathrm{~mm}$ & $0,107 \mathrm{~J} / \mathrm{mm}^{3}$ & $179 \mathrm{kN}$ \\
\hline 6 & $1,41^{\circ}$ & $287 \mathrm{~mm}$ & $1,98 \mathrm{~mm}$ & $49,5 \mathrm{~mm}$ & $0,159 \mathrm{~J} / \mathrm{mm}^{3}$ & $291 \mathrm{kN}$ \\
\hline 7 & $0,339^{\circ}$ & $333 \mathrm{~mm}$ & $1,76 \mathrm{~mm}$ & $51,3 \mathrm{~mm}$ & $0,157 \mathrm{~J} / \mathrm{mm}^{3}$ & $248 \mathrm{kN}$ \\
\hline 8 & $0,380^{\circ}$ & $433 \mathrm{~mm}$ & $1,69 \mathrm{~mm}$ & $34,3 \mathrm{~mm}$ & $0,182 \mathrm{~J} / \mathrm{mm}^{3}$ & $190 \mathrm{kN}$ \\
\hline 9 & $0,000^{\circ}$ & $551 \mathrm{~mm}$ & $1,44 \mathrm{~mm}$ & $39,1 \mathrm{~mm}$ & $0,153 \mathrm{~J} / \mathrm{mm}^{3}$ & $170 \mathrm{kN}$ \\
\hline 10 & $1,95^{\circ}$ & $371 \mathrm{~mm}$ & $1,80 \mathrm{~mm}$ & $44,7 \mathrm{~mm}$ & $0,142 \mathrm{~J} / \mathrm{mm}^{3}$ & $239 \mathrm{kN}$ \\
\hline
\end{tabular}

Todos os projetos da Tabela 13 superam os respectivos pontos da Tabela 11, aumentando a energia específica (com exceção do ponto $\mathrm{N}^{\circ} 3$ ) e reduzindo a força de pico. Em todos os casos o algoritmo AFSQP foi capaz de melhorar os pontos iniciais. No entanto, 
sabe-se que o algoritmo de otimização por gradiente foi incapaz de encontrar o melhor projeto dentro do domínio, uma vez que a otimização por força bruta, da Tabela 9, encontrou 2 projetos com energia específica superior.

O melhor projeto obtido por AFSQP foi o $\mathrm{N}^{\circ} 8$, com 0,182 $\mathrm{J} / \mathrm{mm}^{3}$ de energia específica e $190 \mathrm{kN}$ de força de pico, presente na Figura 52. A busca aleatória encontrou um ponto com $0,205 \mathrm{~J} / \mathrm{mm}^{3}$ e $191 \mathrm{kN}$ respectivamente.

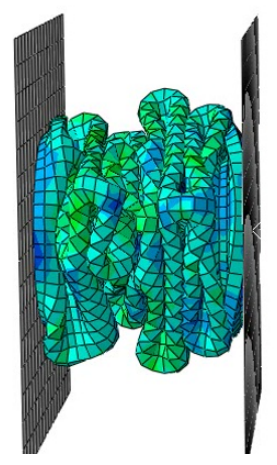

Figura 52: Animação de simulação de impacto do melhor projeto por AFSQP.

Apesar de não ter atingido um desempenho tão bom quanto a busca aleatória, o projeto No8 apresentou deformação em todo o seu volume, ao mesmo tempo em que não mostrou um pico de força alto ao final de seu curso, como mostrado na Figura 53.

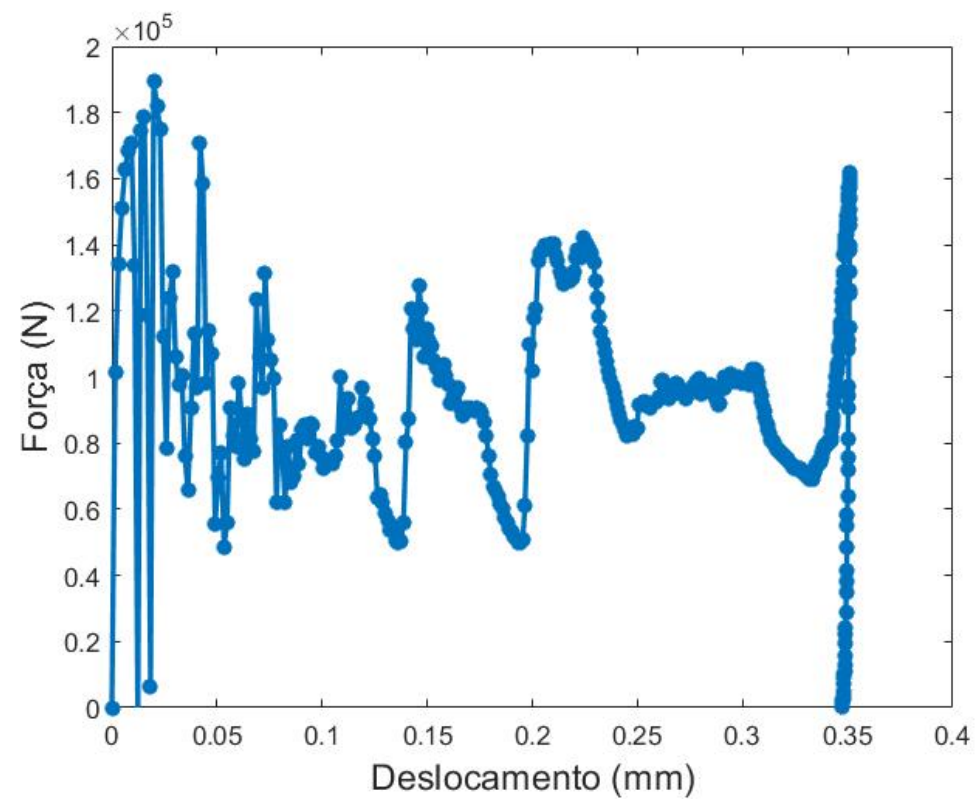

Figura 53: Força por deslocamento do melhor projeto obtido por AFSQP 


\subsection{Otimização por Powell}

O funcionamento do algoritmo das direções conjugadas de Powell é exclusivamente sequencial, uma vez que o cálculo de uma direção possui dependência direta do resultado da direção anterior. Assim como no algoritmo AFSQP, foi feita uma simulação numérica de cada vez, utilizando 6 subdomínios. Para otimizar os projetos da Tabela 11, realizaramse 783 iterações, totalizando 184 horas e 58 minutos de trabalho. O tempo médio de cada iteração foi de 14 minutos e 10 segundos. O histórico de convergência da otimização por Powell encontra-se na Figura 54.

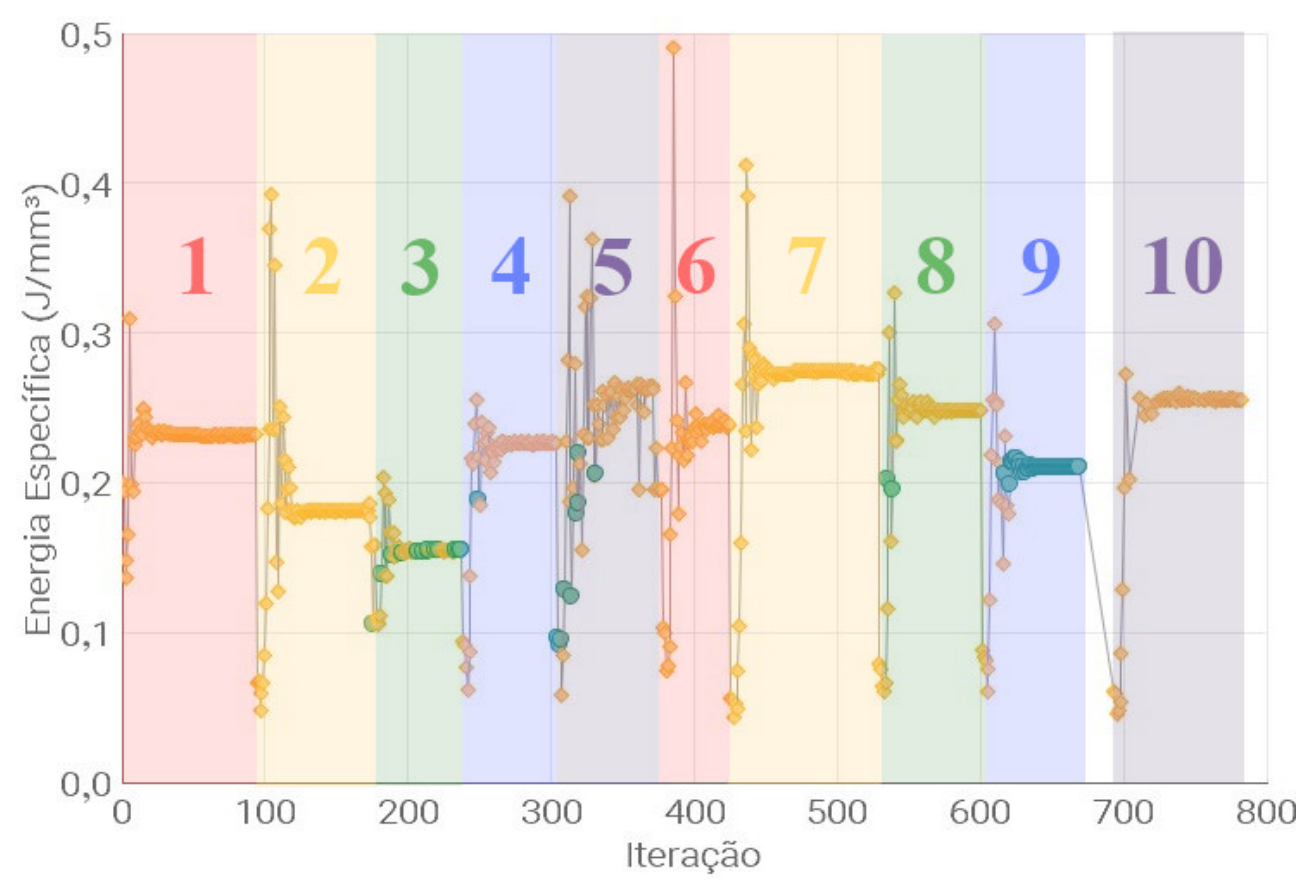

Figura 54: Histórico de convergência de otimização por Powell.

De maneira semelhante à otimização por AFSQP, a qualidade dos pontos iniciais teve uma influência considerável no resultado de cada projeto. Na otimização por Powell, apenas 5 das 10 tentativas retornaram projetos viáveis. Durante a otimização do projeto No10 da Tabela 3, foram geradas simulações das quais não foi possível fazer a extração de resultados, gerando um espaço em branco entre as tentativas 9 e 10 da Figura 54. A Tabela 14 mostra os resultados de otimização gerados a partir da Tabela 11.

A otimização por Powell obteve três projetos com, simultaneamente, energia específica superior a $0,200 \mathrm{~J} / \mathrm{mm}^{3}$ e força de pico abaixo de $250 \mathrm{kN}$. Dois deles mostraram desempenho superior ao melhor ponto obtido pela otimização por força bruta, indicando que o algoritmo de Powell foi capaz de otimizar o problema de forma estatisticamente relevante.

De um modo geral, ao comparar a otimização por AFSQP com a otimização por 
Tabela 14: Otimização por Powell.

\begin{tabular}{|c|c|c|c|c|c|c|}
\hline $\mathrm{N}^{\mathrm{o}}$ & Angulo & Comprimento & Espessura & Raio & Energia específica & Força de pico \\
\hline 1 & $0,684^{\circ}$ & $222 \mathrm{~mm}$ & $2,82 \mathrm{~mm}$ & $30,0 \mathrm{~mm}$ & $0,232 \mathrm{~J} / \mathrm{mm}^{3}$ & $301 \mathrm{kN}$ \\
\hline 2 & $1,89^{\circ}$ & $290 \mathrm{~mm}$ & $2,01 \mathrm{~mm}$ & $40,3 \mathrm{~mm}$ & $0,182 \mathrm{~J} / \mathrm{mm}^{3}$ & $330 \mathrm{kN}$ \\
\hline 3 & $0,938^{\circ}$ & $543 \mathrm{~mm}$ & $1,33 \mathrm{~mm}$ & $38,0 \mathrm{~mm}$ & $0,156 \mathrm{~J} / \mathrm{mm}^{3}$ & $247 \mathrm{kN}$ \\
\hline 4 & $0,715^{\circ}$ & $434 \mathrm{~mm}$ & $1,68 \mathrm{~mm}$ & $32,1 \mathrm{~mm}$ & $0,188 \mathrm{~J} / \mathrm{mm}^{3}$ & $176 \mathrm{kN}$ \\
\hline 5 & $1,41^{\circ}$ & $351 \mathrm{~mm}$ & $2,03 \mathrm{~mm}$ & $30,0 \mathrm{~mm}$ & $0,220 \mathrm{~J} / \mathrm{mm}^{3}$ & $197 \mathrm{kN}$ \\
\hline 6 & $1,39^{\circ}$ & $261 \mathrm{~mm}$ & $2,19 \mathrm{~mm}$ & $47,2 \mathrm{~mm}$ & $0,166 \mathrm{~J} / \mathrm{mm}^{3}$ & $301 \mathrm{kN}$ \\
\hline 7 & $0,0251^{\circ}$ & $315 \mathrm{~mm}$ & $2,01 \mathrm{~mm}$ & $47,1 \mathrm{~mm}$ & $0,160 \mathrm{~J} / \mathrm{mm}^{3}$ & $292 \mathrm{kN}$ \\
\hline 8 & $0,328^{\circ}$ & $394 \mathrm{~mm}$ & $1,92 \mathrm{~mm}$ & $30,0 \mathrm{~mm}$ & $0,203 \mathrm{~J} / \mathrm{mm}^{3}$ & $192 \mathrm{kN}$ \\
\hline 9 & $0,0724^{\circ}$ & $292 \mathrm{~mm}$ & $2,47 \mathrm{~mm}$ & $30,0 \mathrm{~mm}$ & $0,216 \mathrm{~J} / \mathrm{mm}^{3}$ & $238 \mathrm{kN}$ \\
\hline 10 & $1,60^{\circ}$ & $363 \mathrm{~mm}$ & $2,27 \mathrm{~mm}$ & $40,7 \mathrm{~mm}$ & $0,129 \mathrm{~J} / \mathrm{mm}^{3}$ & $292 \mathrm{kN}$ \\
\hline
\end{tabular}

Powell, a segunda apresentou uma maior facilidade de maximizar a função objetivo, porém, também mostrou uma maior dificuldade em reduzir a força de pico. A comparação entre os resultados dos dois métodos encontra-se na Tabela 15.

Tabela 15: Diferença de desempenho observada do método Powell com relação ao AFSQP.

\begin{tabular}{|c|c|c|}
\hline $\mathrm{N}^{\mathrm{O}}$ & Energia específica & Força de pico \\
\hline 1 & $-6,1 \%$ & $+2,0 \%$ \\
\hline 2 & $+21 \%$ & $-6,5 \%$ \\
\hline 3 & $-17 \%$ & $-34 \%$ \\
\hline 4 & $+53 \%$ & $-21 \%$ \\
\hline 5 & $+106 \%$ & $+10 \%$ \\
\hline 6 & $+4,4 \%$ & $+3,4 \%$ \\
\hline 7 & $+1,9 \%$ & $+18 \%$ \\
\hline 8 & $+12 \%$ & $+1,1 \%$ \\
\hline 9 & $+41 \%$ & $+40 \%$ \\
\hline 10 & $-9,2 \%$ & $+22 \%$ \\
\hline Média & $+20,7 \%$ & $+3,5 \%$ \\
\hline
\end{tabular}

Na Tabela 15, quanto maior o valor da segunda coluna e menor o valor da terceira coluna, maior é a vantagem do resultado de Powell em comparação ao AFSQP. O algoritmo de Powell gerou projetos com função objetivo superior, ao custo de um ligeiro aumento na restrição. Sua otimização No5 gerou o melhor projeto observado até então, ilustrado na Figura 55. 


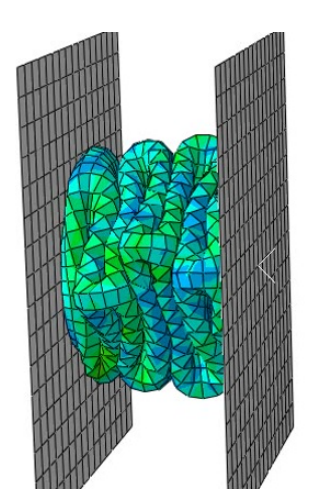

Figura 55: Animação do projeto N5 obtido por Powell.

O gráfico de força por deslocamento do melhor projeto obtido pelo algoritmo de Powell é exposto na Figura 56. Nele, é possível observar que a força de pico do final do curso é da mesma ordem de grandeza que a força de pico necessária para iniciar a deformação na longarina.

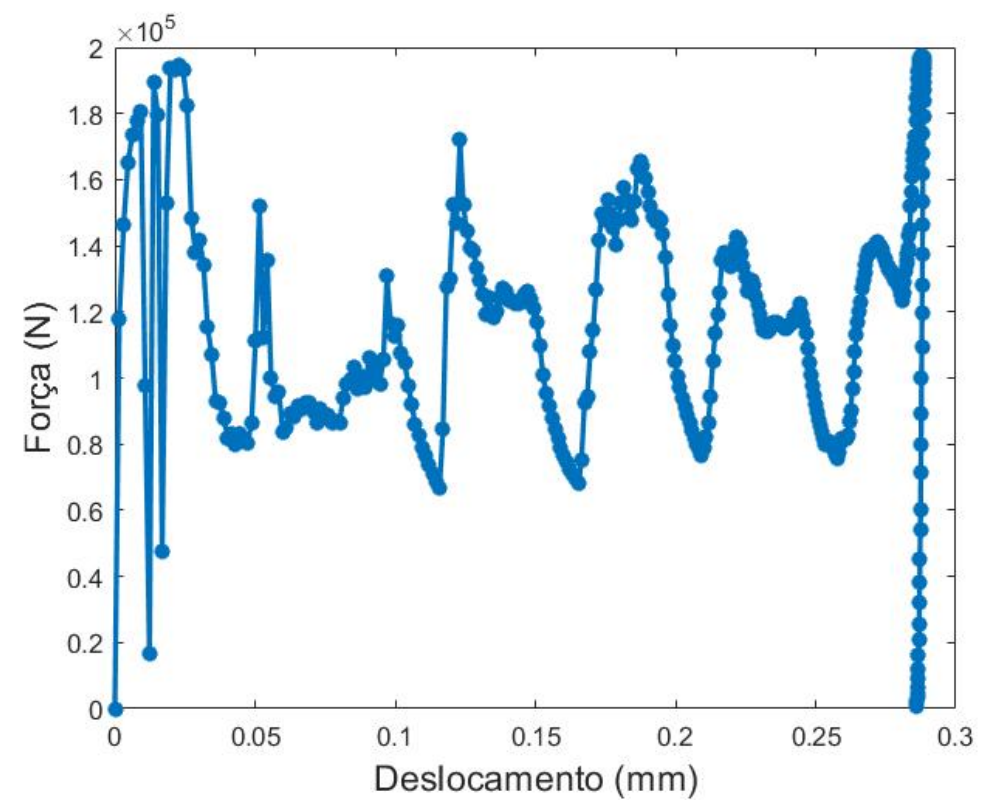

Figura 56: Força por deslocamento da melhor longarina otimizada pelo algoritmo de Powell.

Apesar de, qualitativamente, o absorvedor da longarina da Figura 53 ter um comportamento similar ao da longarina da Figura 56, a segunda foi capaz de absorver a mesma quantidade de energia com um volume 16,2\% menor, ao custo de uma força de pico 4,2\% maior, estando ambas dentro da restrição estabelecida. 


\subsection{Otimização por MOGA-II}

A abordagem de otimização do algoritmo genético diverge em certos aspectos com relação ao funcionamento dos outros dois algoritmos utilizados. Apesar de também possuir 10 projetos iniciais, o algoritmo MOGA realiza apenas uma otimização, baseada nas diferentes características das longarinas geradas pela sequência de Sobol. Para os algoritmos como Powell e AFSQP, um número maior de pontos iniciais representa uma quantidade maior de tentativas, enquanto para o MOGA-II, caracteriza uma maior variabilidade de projetos e combinações.

Como cada população de 10 projetos é independente entre si, foi possível realizar simulações simultâneas para a geração de resultados. Optou-se por fazer o uso de 4 simulações simultâneas, onde cada uma utiliza 2 subdomínios. Por não possuir um indicador de convergência, o algoritmo MOGA-II utilizou-se do número máximo de iterações estipulado, ou seja, 1000 simulações. O tempo total foi de 152 horas e 30 minutos, representando um tempo médio de 6 minutos e 34 minutos por experimento. O histórico da análise é apresentado na Figura 57.

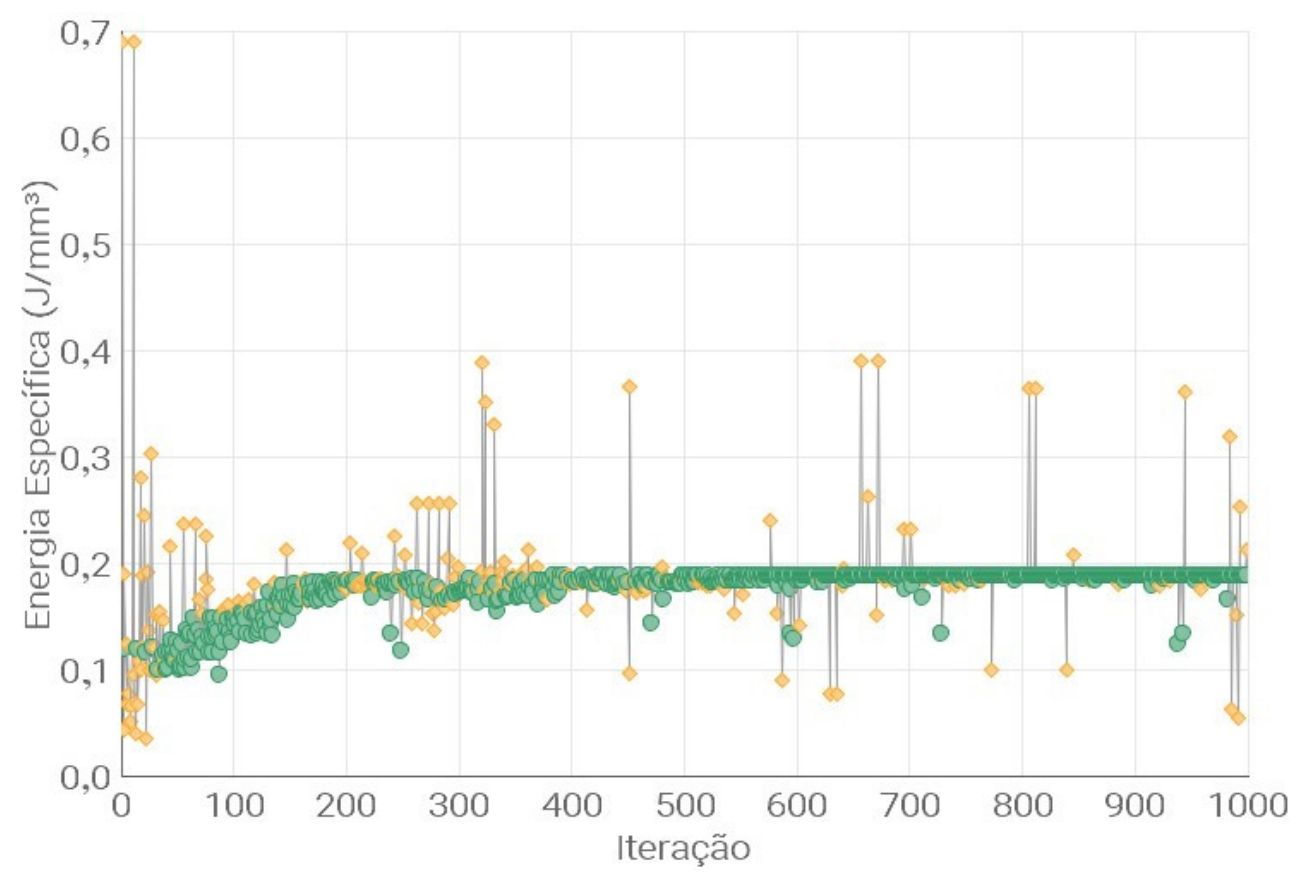

Figura 57: Histórico da otimização por MOGA-II.

Analisando a Figura 57, os resultados dos projetos começaram a se estabilizar por volta da $200^{\mathrm{a}}$ iteração. A partir da $400^{\mathrm{a}}$ iteração, não houve mais mudanças significativas entre as longarinas viáveis e, do ponto de vista paramétrico, os absorvedores de energia ficaram muito semelhantes uns aos outros. A Tabela 16 mostra os parâmetros dos 10 
espécimes da 100ª geração, ou seja, da iteração 991 até a 1000.

Tabela 16: Última geração obtida por MOGA-II.

\begin{tabular}{|c|c|c|c|c|c|c|}
\hline It. & Angulo & Comprimento & Espessura & Raio & Energia específica & Força de pico \\
\hline 991 & $0,0162^{\circ}$ & $600 \mathrm{~mm}$ & $1,44 \mathrm{~mm}$ & $35,6 \mathrm{~mm}$ & $0,151 \mathrm{~J} / \mathrm{mm}^{3}$ & $145 \mathrm{kN}$ \\
\hline 992 & $1,34^{\circ}$ & $504 \mathrm{~mm}$ & $4,04 \mathrm{~mm}$ & $35,6 \mathrm{~mm}$ & $0,0545 \mathrm{~J} / \mathrm{mm}^{3}$ & $522 \mathrm{kN}$ \\
\hline 993 & $0,0237^{\circ}$ & $504 \mathrm{~mm}$ & $1,00 \mathrm{~mm}$ & $35,6 \mathrm{~mm}$ & $0,253 \mathrm{~J} / \mathrm{mm}^{3}$ & $667 \mathrm{kN}$ \\
\hline 994 & $0,0237^{\circ}$ & $504 \mathrm{~mm}$ & $1,42 \mathrm{~mm}$ & $35,6 \mathrm{~mm}$ & $0,188 \mathrm{~J} / \mathrm{mm}^{3}$ & $246 \mathrm{kN}$ \\
\hline 995 & $0,0237^{\circ}$ & $504 \mathrm{~mm}$ & $1,42 \mathrm{~mm}$ & $35,6 \mathrm{~mm}$ & $0,188 \mathrm{~J} / \mathrm{mm}^{3}$ & $246 \mathrm{kN}$ \\
\hline 996 & $0,0237^{\circ}$ & $504 \mathrm{~mm}$ & $1,42 \mathrm{~mm}$ & $35,6 \mathrm{~mm}$ & $0,188 \mathrm{~J} / \mathrm{mm}^{3}$ & $246 \mathrm{kN}$ \\
\hline 997 & $0,0237^{\circ}$ & $504 \mathrm{~mm}$ & $1,42 \mathrm{~mm}$ & $35,6 \mathrm{~mm}$ & $0,188 \mathrm{~J} / \mathrm{mm}^{3}$ & $246 \mathrm{kN}$ \\
\hline 998 & $0,0237^{\circ}$ & $504 \mathrm{~mm}$ & $1,42 \mathrm{~mm}$ & $35,6 \mathrm{~mm}$ & $0,188 \mathrm{~J} / \mathrm{mm}^{3}$ & $246 \mathrm{kN}$ \\
\hline 999 & $0,0237^{\circ}$ & $504 \mathrm{~mm}$ & $1,21 \mathrm{~mm}$ & $35,6 \mathrm{~mm}$ & $0,213 \mathrm{~J} / \mathrm{mm}^{3}$ & $606 \mathrm{kN}$ \\
\hline 1000 & $0,0237^{\circ}$ & $504 \mathrm{~mm}$ & $1,42 \mathrm{~mm}$ & $35,6 \mathrm{~mm}$ & $0,188 \mathrm{~J} / \mathrm{mm}^{3}$ & $246 \mathrm{kN}$ \\
\hline
\end{tabular}

A última geração de projetos possui 6 projetos replicados e os outros 4, de um modo geral, com dimensões semelhantes. Com relação à energia específica, o melhor espécime viável obtido por MOGA-II, da Figura 58, é ligeiramente superior ao melhor projeto concebido por AFSQP e inferior aos melhores resultados gerados pela otimização bruta e Powell. Vale notar também que o resultado produzido por MOGA-II, apesar de sub-ótimo, é muito melhor que as longarinas propostas pela sequência de Sobol, na Tabela 12.

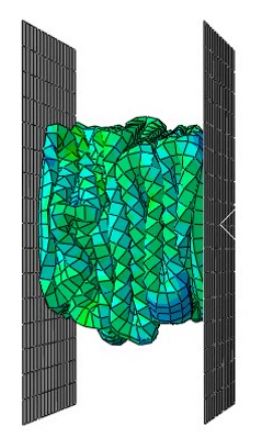

Figura 58: Animação do melhor projeto obtido por MOGA-II.

A Figura 59 auxilia a compreender o desempenho da longarina gerada. A menor espessura desse projeto, quando comparada às espessuras dos projetos da Figura 52 e 55, favorece a um menor esforço para causar deformações no absorvedor de energia. No entanto, a força de pico nominal do projeto é aumentada significativamente pelo fim de curso do componente (246 kN contra $154 \mathrm{kN}$ do início da deformação), o que indica um ligeiro subdimensionamento, do qual a restrição de força não é suficiente para detectá-lo. 


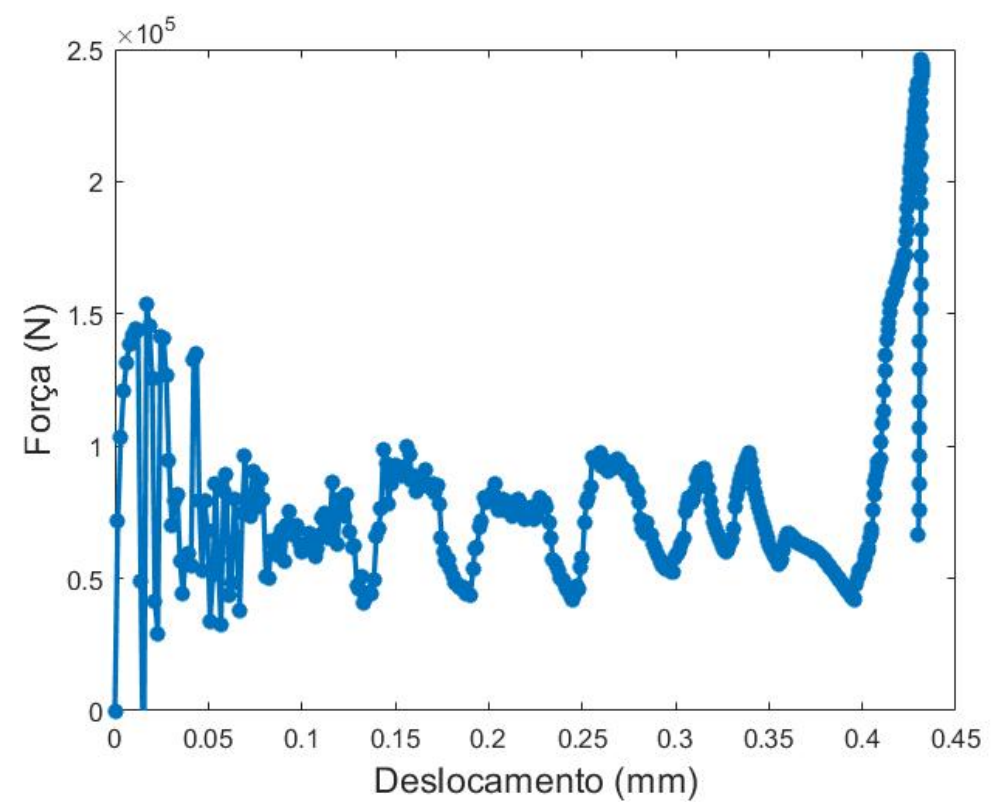

Figura 59: Força por deslocamento da melhor longarina otimizada por MOGA-II.

Um pequeno aumento em alguma das dimensões dessa longarina seria capaz de sanar o problema de subdimensionamento, porém essa ação causaria um decréscimo na absorção de energia específica.

\subsection{Otimização com Metamodelos}

O primeiro passo para a confecção dos metamodelos partiu da criação de um DoE de 200 pontos por Hipercubo Latino. Ele preenche o espaço da Tabela 3 de maneira uniforme e apresenta uma saída de acordo com a Figura 60.

Como os pontos de DoE são independentes entre si, foi possível realizar 4 experimentos simultâneos com 2 subdomínios cada. Para fazer as 200 simulações foram necessárias 25 horas e 26 minutos, uma média de 7 minutos e 38 segundos por teste. Apesar de utilizar o mesmo método de ensaio que o MOGA-II, o tempo médio de cálculo por longarina foi ligeiramente maior. Tal diferença é justificada pelo tamanho médio das longarinas geradas. Uma vez que o tamanho do elemento finito usado é constante, um aumento no comprimento resulta em um maior número de elementos e um pequeno aumento no custo computacional.

Assim como na otimização por força bruta, na Figura 49, houve uma baixa proporção de projetos viáveis com relação ao número de simulações. Das 200 longarinas, apenas 9 atendem às restrições e entre essas, o espécime de maior energia específica apresentou um 
valor de $0,151 \mathrm{~J} / \mathrm{mm}^{3}$, que é um valor relativamente baixo se comparado aos resultados anteriores.

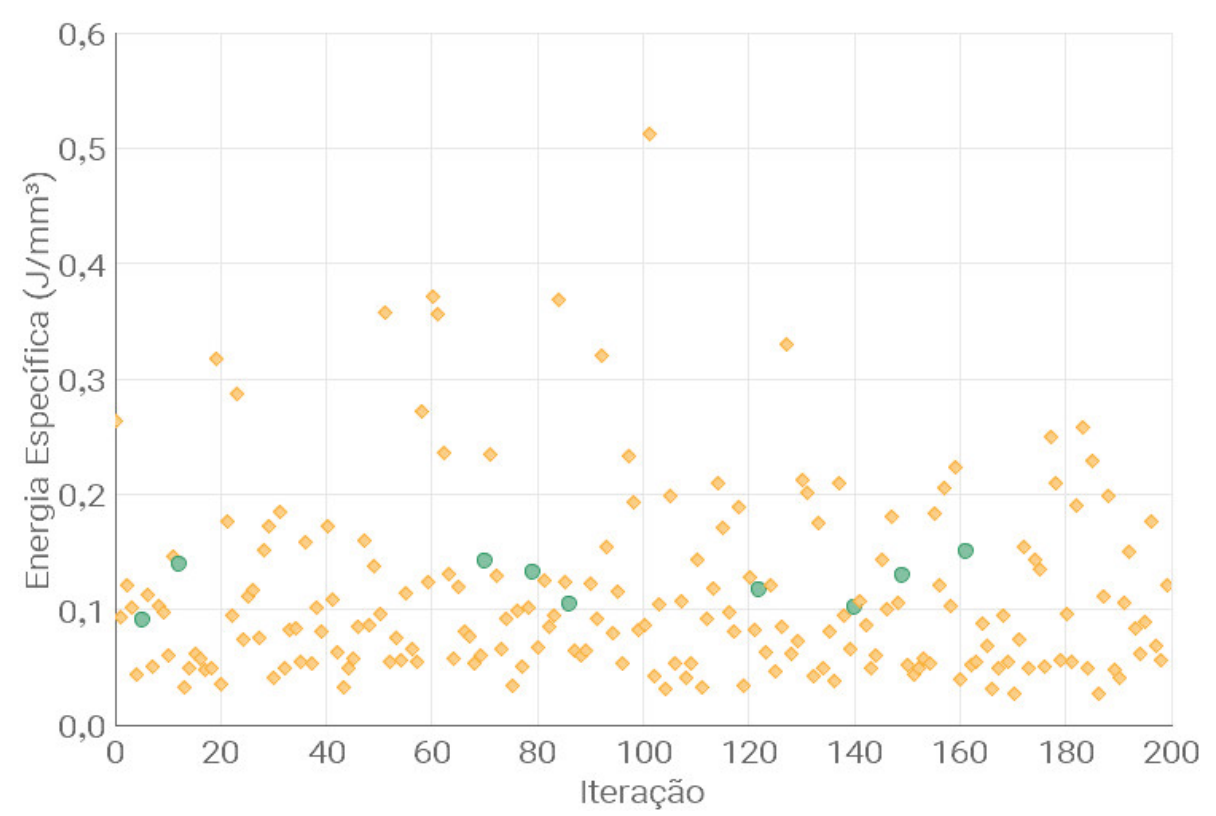

Figura 60: Histórico de iterações do DoE para o primeiro treinamento de metamodelos

Em seguida, foi feito o treinamento dos 5 metamodelos propostos na Seção 3.4, utilizando 190 pontos para a construção e 10 para a primeira validação, gerando os valores de aderência apresentados pela Tabela 17. O tempo necessário total para o treinamento das fórmulas foi de 10 segundos.

\begin{tabular}{|c|c|c|c|}
\hline Propriedade & Algoritmo & Erro relativo médio & $\mathrm{R}^{2}$ \\
\hline \multirow{4}{*}{ Energia } & AKR & $1,091 \mathrm{E}-2$ & 0,330 \\
\cline { 2 - 4 } & KR & $1,091 \mathrm{E}-2$ & 0,330 \\
\cline { 2 - 4 } & ANN & $1,049 \mathrm{E}-2$ & 0,453 \\
\cline { 2 - 4 } & RBF & $1,097 \mathrm{E}-2$ & 0,330 \\
\cline { 2 - 4 } Força Máxima & SVD & $2,096 \mathrm{E}-2$ & $-0,261$ \\
\hline & AKR & $4,560 \mathrm{E}-2$ & 0,989 \\
\cline { 2 - 4 } & KR & $1,395 \mathrm{E}-1$ & 0,918 \\
\cline { 2 - 4 } & ANN & $1,430 \mathrm{E}-1$ & 0,932 \\
\cline { 2 - 4 } & RBF & $5,375 \mathrm{E}-2$ & 0,992 \\
\cline { 2 - 4 } & SVD & $2,052 \mathrm{E}-1$ & 0,828 \\
\hline \multirow{5}{*}{ Volume } & AKR & $4,602 \mathrm{E}-4$ & 1,00 \\
\cline { 2 - 4 } & KR & $6,872 \mathrm{E}-4$ & 1,00 \\
\cline { 2 - 4 } & ANN & $1,207 \mathrm{E}-3$ & 1,00 \\
\cline { 2 - 4 } & RBF & $7,834 \mathrm{E}-4$ & 1,00 \\
\cline { 2 - 4 } & SVD & $1,681 \mathrm{E}-4$ & 1,00 \\
\hline
\end{tabular}

Tabela 17: Primeiro treinamento de metamodelos

Como o volume das longarinas é oriundo de uma fórmula matemática simples, todos os algoritmos apresentaram facilidade para prever o valor do volume, com o coeficiente de 
determinação igual a 1 e erros relativos médios na ordem de $10^{-4}$ (com exceção das redes neurais).

Dando sequência, foi feita uma otimização por AFSQP exclusivamente no metamodelo. Selecionou-se ANN para estimar a energia, AKR para a força máxima e SVD para o volume. Foram feitas $10^{4}$ iterações, necessitando de um tempo total da ordem de 4 segundos, que é ínfimo quando comparado aos ensaios numéricos. A partir da otimização por metamodelagem, foram encontrados dois projetos com desempenho ótimo, listados na Tabela 18.

Tabela 18: Otimização obtida pelo primeiro grupo de metamodelos.

\begin{tabular}{|c|c|c|c|c|c|c|}
\hline $\mathrm{N}^{\mathrm{o}}$ & $\hat{A}^{\text {ngulo }}$ & Comprimento & Espessura & Raio & Energia específica & Força de pico \\
\hline 1 & $1^{\circ} 827^{\circ}$ & $202 \mathrm{~mm}$ & $2,98 \mathrm{~mm}$ & $30,0 \mathrm{~mm}$ & $0,236 \mathrm{~J} / \mathrm{mm}^{3}$ & $250 \mathrm{kN}$ \\
\hline 2 & $0,202^{\circ}$ & $341 \mathrm{~mm}$ & $1,99 \mathrm{~mm}$ & $30,0 \mathrm{~mm}$ & $0,227 \mathrm{~J} / \mathrm{mm}^{3}$ & $250 \mathrm{kN}$ \\
\hline
\end{tabular}

Vale notar que os valores de energia específica e força máxima expostos pela Tabela 18 não são necessariamente reais, são na verdade valores retornados pelos modelos matemáticos. Para aferir a precisão dos pontos escolhidos, foi feita uma segunda etapa de validação, em que foram feitas simulações numéricas com os parâmetros da Tabela 18. A comparação é exibida pela Tabela 19.

Tabela 19: Comparação entre o desempenho real e o estimado pelo primeiro grupo de metamodelos.

\begin{tabular}{|c|c|c|c|c|c|c|}
\hline & \multicolumn{3}{|c|}{ Energia específica } & \multicolumn{3}{c|}{ Força de pico } \\
\hline $\mathrm{N}^{\mathrm{o}}$ & Estimado & Real & Erro & Estimado & Real & Erro \\
\hline 1 & $0,236 \mathrm{~J} / \mathrm{mm}^{3}$ & $0,227 \mathrm{~J} / \mathrm{mm}^{3}$ & $3,96 \%$ & $250 \mathrm{kN}$ & $349 \mathrm{kN}$ & $-28,37 \%$ \\
\hline 2 & $0,227 \mathrm{~J} / \mathrm{mm}^{3}$ & $0,228 \mathrm{~J} / \mathrm{mm}^{3}$ & $-0,44 \%$ & $250 \mathrm{kN}$ & $323 \mathrm{kN}$ & $-22,60 \%$ \\
\hline
\end{tabular}

Apenas com um treinamento de metamodelos, já foi possível prever a função objetivo com certa precisão. No entanto, o mesmo não pode ser dito para as estimativas da restrição da força de pico. Como os dois pontos encontrados pertencem a uma região específica do domínio paramétrico, optou-se por reduzir o domínio estudado. Ao invés de utilizar os valores da Tabela 3, foi feito um novo DoE com 100 pontos e com os limites propostos pela Tabela 20. Como o volume foi previsto com facilidade, os próximos treinamentos de metamodelo focam em refinar a aderência com relação à energia específica e a força de pico. 
Tabela 20: Nova faixa de valores utilizados para construção de metamodelos.

\begin{tabular}{|l|l|l|}
\hline \multirow{2}{*}{ Propriedades } & \multicolumn{2}{|c|}{ Valores } \\
\cline { 2 - 3 } & Mínimo & Máximo \\
\hline Raio $[\mathrm{mm}]$ & 30 & 35 \\
\hline Comprimento $[\mathrm{mm}]$ & 200 & 400 \\
\hline Angulo $\left[^{\circ}\right]$ & 0,0 & 2,0 \\
\hline Espessura $[\mathrm{mm}]$ & 1,5 & 3,0 \\
\hline
\end{tabular}

A partir do novo planejamento de experimentos, foi possível encontrar uma região com longarinas de desempenho mais desejável. Desta vez, com 100 pontos, foi possível obter 13 projetos viáveis, que é uma proporção mais interessante do que o DoE da Figura 60 ou até mesmo da Figura 49. Dentre as longarinas viáveis, destacam-se uma com 0,197 $\mathrm{J} / \mathrm{mm}^{3}$ e outra com $0,194 \mathrm{~J} / \mathrm{mm}^{3}$ de energia específica, visíveis na Figura 61 .

Para a geração do segundo DoE, foram necessárias mais 12 horas e 6 minutos, totalizando, até então, 37 horas e 32 minutos para a geração de DoE para os metamodelos.

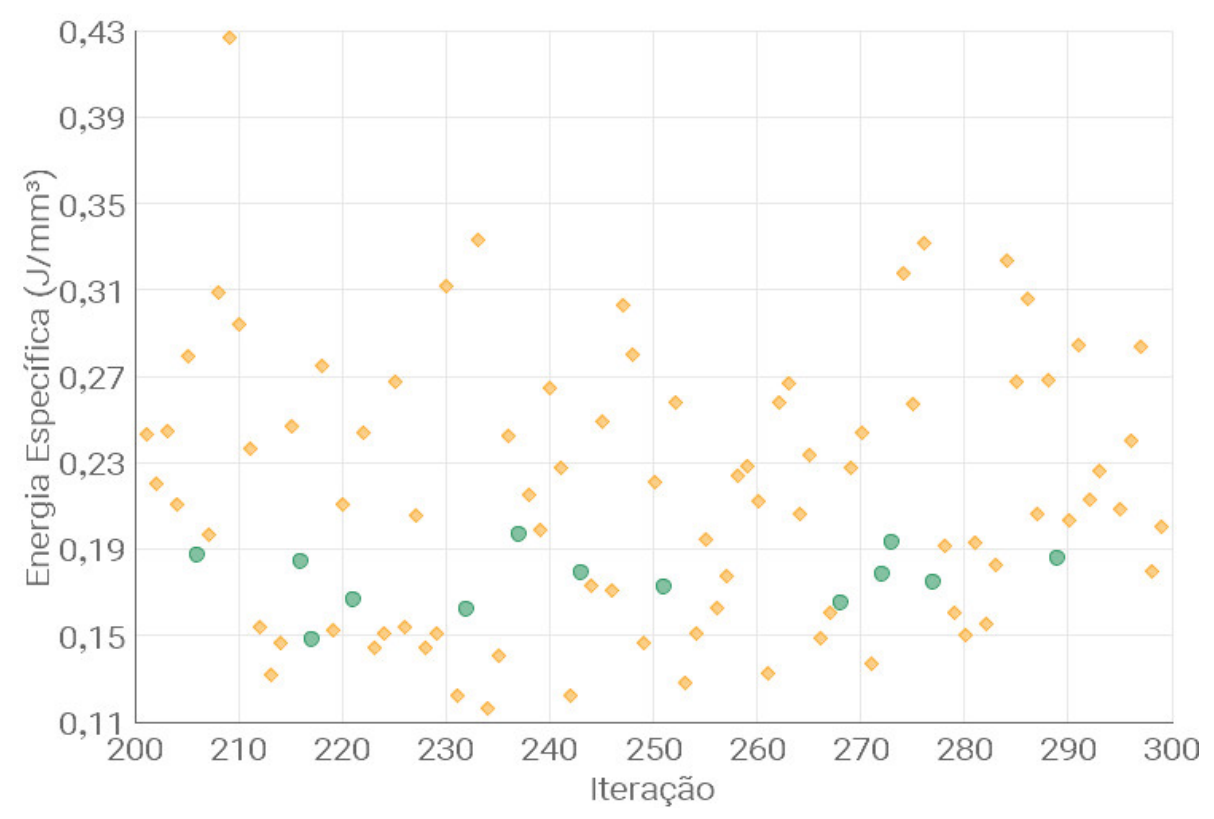

Figura 61: Histórico de iterações do DoE para o segundo treinamento de metamodelos

O segundo treinamento dos metamodelos utilizou 90 projetos para confecção e 10 pontos para a primeira etapa de validação, resultando nos dados apresentados pela Tabela 21.

Considerando apenas a primeira etapa de validação, o segundo treinamento mostrou uma melhora na previsão da energia em 3 dos 5 algoritmos. Apresentou também uma ligeira piora na estimativa da força máxima para todos os algoritmos. O processo de otimização no metamodelo permaneceu igual, ou seja, foram feitas mais $10^{4}$ iterações de 


\begin{tabular}{|c|c|c|c|}
\hline Propriedade & Algoritmo & Erro relativo médio & $\mathrm{R}^{2}$ \\
\hline \multirow{4}{*}{ Energia } & AKR & $4,923 \mathrm{E}-3$ & 0,907 \\
\cline { 2 - 4 } & KR & $4,923 \mathrm{E}-3$ & 0,907 \\
\cline { 2 - 4 } & ANN & $1,438 \mathrm{E}-2$ & 0,216 \\
\cline { 2 - 4 } & RBF & $5,049 \mathrm{E}-3$ & 0,907 \\
\cline { 2 - 4 } Força Máxima & SVD & $2,898 \mathrm{E}-2$ & $-6,06$ \\
\hline & AKR & $6,081 \mathrm{E}-2$ & 0,961 \\
\cline { 2 - 4 } & $\mathrm{KR}$ & $1,161 \mathrm{E}-1$ & 0,897 \\
\cline { 2 - 4 } & $\mathrm{ANN}$ & $7,453 \mathrm{E}-2$ & 0,939 \\
\cline { 2 - 4 } & $\mathrm{RBF}$ & $8,165 \mathrm{E}-2$ & 0,943 \\
\cline { 2 - 4 } & $\mathrm{SVD}$ & $2,667 \mathrm{E}-1$ & 0,501 \\
\hline
\end{tabular}

Tabela 21: Segundo treinamento de metamodelos

otimização virtual por AFSQP.

Para a otimização numérica, utilizou-se novamente o conjunto de metamodelos que apresentaram as melhores métricas de desempenho, desta vez o algoritmo Kriging para a energia e o Kriging anisotrópico para a força de pico.

A partir do segundo treinamento, o projeto com melhor desempenho apresentou as características expostas pela Tabela 22.

Tabela 22: Otimização obtida pelo segundo grupo de metamodelos.

\begin{tabular}{|c|c|c|c|c|c|}
\hline Ângulo & Comprimento & Espessura & Raio & Energia específica & Força de pico \\
\hline $0,00^{\circ}$ & $317 \mathrm{~mm}$ & $2,33 \mathrm{~mm}$ & $30,0 \mathrm{~mm}$ & $0,210 \mathrm{~J} / \mathrm{mm}^{3}$ & $250 \mathrm{kN}$ \\
\hline
\end{tabular}

Em seguida, o ponto virtual ótimo foi validado através de outra simulação numérica, resultando na comparação da Tabela 23.

Tabela 23: Comparação entre o desempenho real e o estimado pelo segundo grupo de metamodelos.

\begin{tabular}{|c|c|c|c|c|c|}
\hline \multicolumn{3}{|c|}{ Energia específica } & \multicolumn{3}{c|}{ Força de pico } \\
\hline Estimado & Real & Erro & Estimado & Real & Erro \\
\hline $0,210 \mathrm{~J} / \mathrm{mm}^{3}$ & $0,214 \mathrm{~J} / \mathrm{mm}^{3}$ & $-1,87 \%$ & $250 \mathrm{kN}$ & $222 \mathrm{kN}$ & $12,61 \%$ \\
\hline
\end{tabular}

Apesar da piora na estimativa de força de pico, mostrada pela Tabela 21, a região do projeto ótimo mostrou uma melhora significativa na previsão da força máxima. Em outras palavras, a aderência local melhorou apesar da piora global. Vale notar também que validação global (primeira etapa de validação) analisa 10 pontos aleatórios, o que não garante o mesmo desempenho para todos os outros pontos. 
Como o domínio de parâmetros já encontra-se reduzido, o refinamento dos próximos metamodelos deu-se pela adição dos pontos de interesse encontrados. Ou seja, a partir do segundo DoE, foi adicionado o ponto da Tabela 22 com os resultados reais, gerando o terceiro DoE e consequentemente o terceiro grupo de metamodelos. A Tabela 24 mostra a segunda etapa de validação para os grupos de metamodelos do 3 ao 5 . A cada etapa foram selecionados os algoritmos com as melhores métricas.

Tabela 24: Comparação entre o desempenho real e o estimado do terceiro ao quinto grupo de metamodelos.

\begin{tabular}{|c|c|c|c|c|c|c|}
\hline \multirow{2}{*}{ Grupo } & \multicolumn{3}{|c|}{ Energia específica } & \multicolumn{3}{c|}{ Força de pico } \\
\cline { 2 - 7 } & Estimado & Real & Erro & Estimado & Real & Erro \\
\hline 3 & $0,219 \mathrm{~J} / \mathrm{mm}^{3}$ & $0,220 \mathrm{~J} / \mathrm{mm}^{3}$ & $-0,45 \%$ & $249 \mathrm{kN}$ & $223 \mathrm{kN}$ & $11,66 \%$ \\
\hline 4 & $0,219 \mathrm{~J} / \mathrm{mm}^{3}$ & $0,221 \mathrm{~J} / \mathrm{mm}^{3}$ & $-0,90 \%$ & $242 \mathrm{kN}$ & $210 \mathrm{kN}$ & $15,24 \%$ \\
\hline 5 & $0,228 \mathrm{~J} / \mathrm{mm}^{3}$ & $0,229 \mathrm{~J} / \mathrm{mm}^{3}$ & $-0,44 \%$ & $250 \mathrm{kN}$ & $204 \mathrm{kN}$ & $22,55 \%$ \\
\hline
\end{tabular}

A Tabela 25 mostra qual superfície de resposta foi usada para prever as variáveis de saída em cada etapa.

\begin{tabular}{|c|c|c|c|}
\hline Grupo & Energia & Força Máxima & Volume \\
\hline 1 & ANN & AKR & SVD \\
\hline 2 & KR/AKR & AKR & ANN \\
\hline 3 & KR/AKR & AKR & AKR \\
\hline 4 & KR/AKR & RBF & RBF \\
\hline 5 & KR/AKR & RBF & AKR \\
\hline
\end{tabular}

Tabela 25: Algoritmos que apresentaram as melhores métricas de acordo com seu respectivo grupo.

Para o cálculo da energia, houve uma clara predominância dos algoritmos de Kriging. A energia foi a única variável em que a versão comum e a anisotrópica de Kriging geraram superfícies de resposta iguais. Já para a previsão da força de pico, o Kriging anisotrópico e as funções de bases radiais se sobressaíram, ocupando sempre as duas primeiras posições na primeira etapa de validação. Já o volume, por ser uma variável mais simples, não exibiu um algoritmo dominante, uma vez que todos foram capazes de prevê-lo com boa precisão.

O fenômeno estudado possui um grau de não linearidade tão grande que a adição de novos pontos para treinamento gerou pioras em algumas métricas de desempenho dos modelos, como mostrado na Tabela 26. No entanto, tal condição não implica necessariamente em uma piora do metamodelo. Uma interpretação para essa ocorrência é de que a 
região pertencente aos novos projetos possui um comportamento discordante com relação às outras regiões.

\begin{tabular}{|c|c|c|c|}
\hline Propriedade & Algoritmo & Erro relativo médio & $\mathrm{R}^{2}$ \\
\hline \multirow{4}{*}{ Energia } & AKR & $1,164 \mathrm{E}-2$ & 0,209 \\
\cline { 2 - 4 } & KR & $1,164 \mathrm{E}-2$ & 0,209 \\
\cline { 2 - 4 } & ANN & $3,176 \mathrm{E}-2$ & $-8,45$ \\
\cline { 2 - 4 } & $\mathrm{RBF}$ & $1,265 \mathrm{E}-2$ & 0,0761 \\
\cline { 2 - 4 } & $\mathrm{SVD}$ & $2,173 \mathrm{E}-2$ & $-1,02$ \\
\hline \multirow{5}{*}{ Força Máxima } & $\mathrm{AKR}$ & $5,687 \mathrm{E}-2$ & 0,978 \\
\cline { 2 - 4 } & $\mathrm{KR}$ & $1,257 \mathrm{E}-1$ & 0,922 \\
\cline { 2 - 4 } & $\mathrm{ANN}$ & $1,143 \mathrm{E}-1$ & 0,919 \\
\cline { 2 - 4 } & $\mathrm{RBF}$ & $5,241 \mathrm{E}-2$ & 0,990 \\
\cline { 2 - 4 } & $\mathrm{SVD}$ & $2,129 \mathrm{E}-1$ & 0,810 \\
\hline
\end{tabular}

Tabela 26: Quinto treinamento de metamodelos.

No caso da previsão da energia, houve uma grande piora nos índices de $\mathrm{R}^{2}$, junto a uma ligeira piora nos números de erro relativo médio, mantendo-se próximos à ordem de grandeza dos resultados da Tabela 21. Vale notar que como as longarinas possuem, de um modo geral, um valor constante de absorção de energia total, a piora nos índices não prejudicou a previsão de energia específica, uma vez que essa mostrou erros de módulo menor que 1\%. Por conta de sua simplicidade, a previsão de volume continuou boa, como mostra a Tabela 27.

\begin{tabular}{|c|c|c|c|}
\hline Propriedade & Algoritmo & Erro relativo médio & $\mathrm{R}^{2}$ \\
\hline \multirow{4}{*}{ Volume } & AKR & $3,287 \mathrm{E}-4$ & 1,00 \\
\cline { 2 - 4 } & KR & $6,264 \mathrm{E}-4$ & 1,00 \\
\cline { 2 - 4 } & ANN & $6,170 \mathrm{E}-4$ & 1,00 \\
\cline { 2 - 4 } & RBF & $3,306 \mathrm{E}-4$ & 1,00 \\
\cline { 2 - 4 } & SVD & $3,264 \mathrm{E}-4$ & 1,00 \\
\hline
\end{tabular}

Tabela 27: Quinto treinamento de metamodelos para o volume.

A Figura 62 mostra visualmente a superfície de resposta gerada por Kriging anisotrópico para prever o valor de energia, a partir do quinto treinamento. A representação considera um valor fixo de raio a $30 \mathrm{~mm}$ e ângulo longitudinal a $0,00^{\circ}$. A variação do comprimento e espessura são baseadas na Tabela 20.

A resposta de absorção de energia parte de $28400 \mathrm{~J}$ até $31400 \mathrm{~J}$, onde os valores menores pertencem às longarinas com dimensões menores. Em outras palavras, segundo o metamodelo, componentes subdimensionados são incapazes de absorver toda a energia cinética. Tal comportamento mostra que a superfície foi capaz de capturar o fenômeno físico de forma qualitativa. 


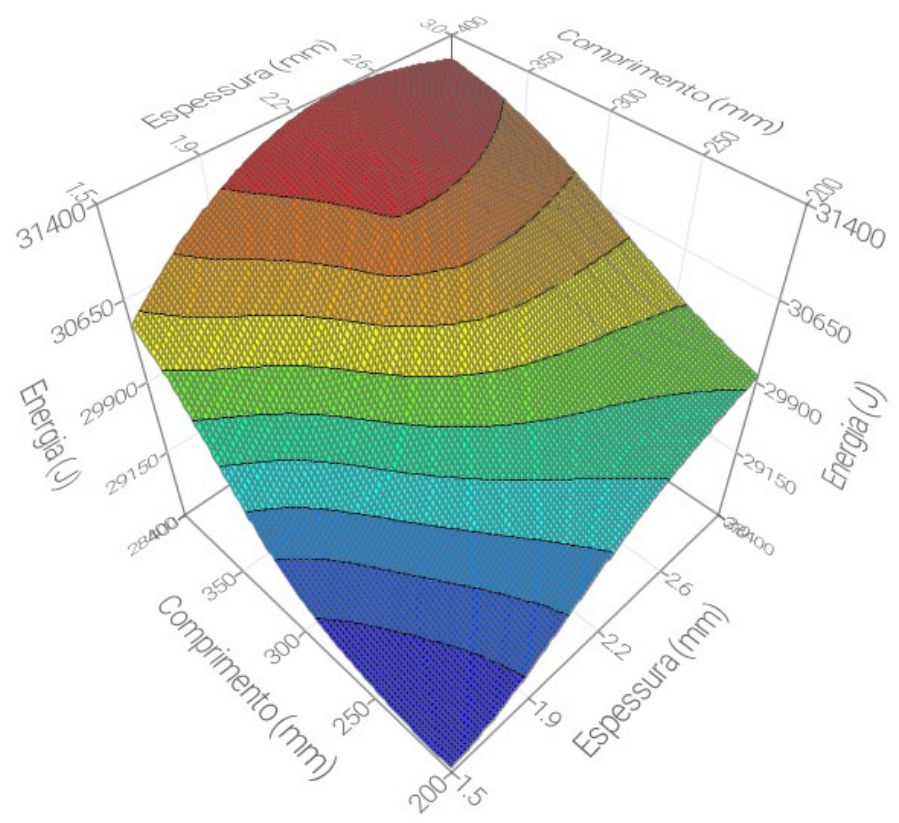

Figura 62: Superfície para estimar a energia absorvida, obtida a partir do quinto treinamento por Kriging anisotrópico.

O erro abaixo de 1\% para a previsão de energia específica da Tabela 24 mostra também uma boa aderência quantitativa do fenômeno real, pelo menos para o ponto analisado.

Utilizando as mesmas configurações da Figura 62, foi feita a representação da curva de resposta para a força máxima, gerada pelas funções de bases radiais no quinto treinamento, exibida na Figura 63.

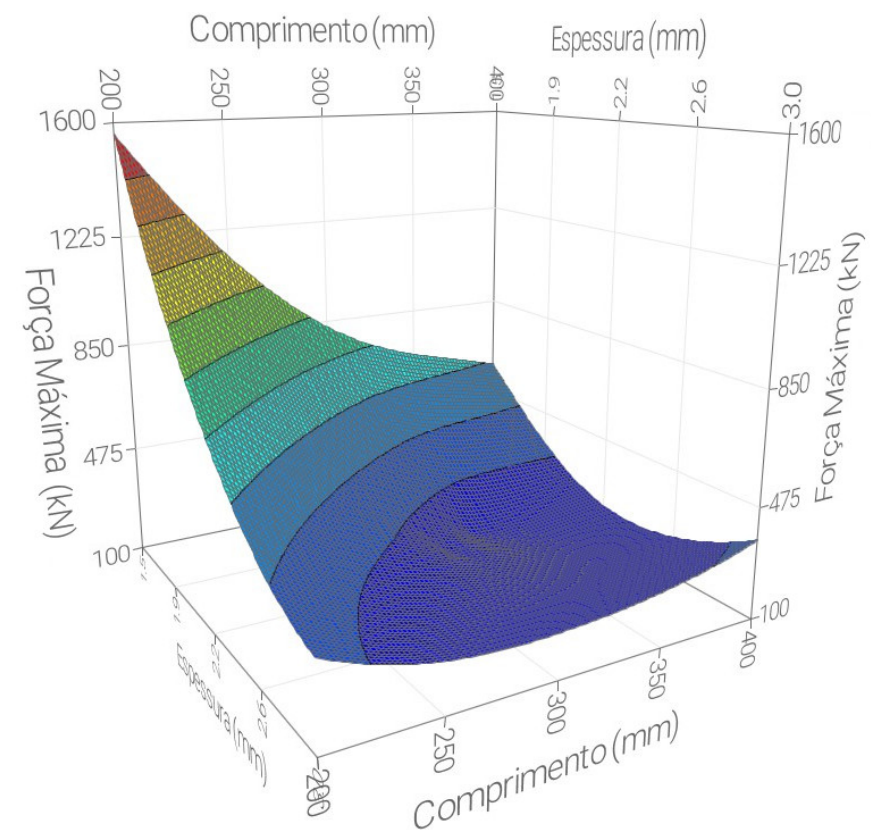

Figura 63: Superfície para estimar a força máxima, obtida a partir do quinto treinamento por RBF. 
No último caso, houve um intervalo de respostas muito maior proporcionalmente, partindo de $100 \mathrm{kN}$ até $1600 \mathrm{kN}$. A superfície prevê valores de força máxima maiores conforme a geometria da longarina é reduzida. O principal fenômeno capturado aparenta ser o pico de força gerado pelo final de curso de uma longarina subdimensionada. A superfície também prevê um ligeiro aumento da força máxima para longarinas com espessura próxima de 3,0 mm, representando um aumento na rigidez do componente.

A força máxima mostrou-se como a variável mais difícil de prever. Apesar do aumento da adesão dos modelos com relação à sua primeira etapa de validação, ao comparar a Tabela 26 com a Tabela 21, o aumento de precisão não se manifestou no ponto de interesse. Nesse ponto, a diferença entre o estimado e o real ficou acima de $20 \%$.

A imprecisão pontual do metamodelo não impediu que fosse encontrado um projeto com características desejáveis. A longarina oriunda da otimização do último grupo de metamodelos apresentou a maior energia específica do trabalho, com 0,229 J/ $\mathrm{mm}^{3}$ de energia específica e uma força de pico de apenas $204 \mathrm{kN}$, lembrando que esses números são os reais, obtidos a partir da simulação numérica. A ilustração de tal componente encontra-se na Figura 64.

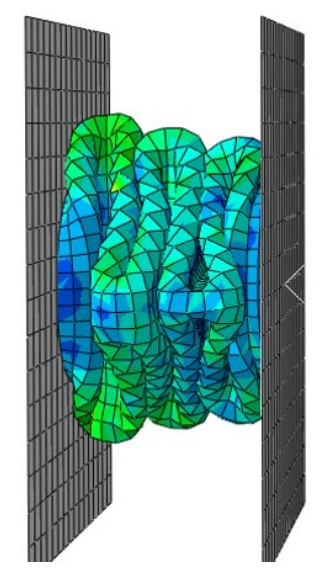

Figura 64: Animação do melhor projeto obtido pela combinação de AFSQP com metamodelos.

O tempo computacional total para a construção de todos os metamodelos e suas respectivas validações foi em torno de 39 horas, valor muito abaixo do tempo gasto para as otimizações otimizações diretas, onde a mais rápida levou mais de 152 horas. Os parâmetros do projeto otimizado pela combinação de AFSQP com metamodelos estão na Tabela 28.

O comportamento de força por deslocamento do componente da Tabela 28 é exposto na Figura 65. Os picos de força gerados pelo impacto concentram-se na mesma ordem de grandeza, indicando um bom dimensionamento da peça. A eficiência da força também 
Tabela 28: Otimização obtida por AFSQP unido ao quinto grupo de metamodelos.

\begin{tabular}{|c|c|c|c|c|c|}
\hline Angulo & Comprimento & Espessura & Raio & Energia específica & Força de pico \\
\hline $0,008^{\circ}$ & $325 \mathrm{~mm}$ & $2,13 \mathrm{~mm}$ & $30,0 \mathrm{~mm}$ & $0,229 \mathrm{~J} / \mathrm{mm}^{3}$ & $204 \mathrm{kN}$ \\
\hline
\end{tabular}

apresenta um valor desejável, com 63,5\%.

Vale ressaltar que, como a restrição de força não se encontra no limite de $250 \mathrm{kN}$, existe a possibilidade encontrar um projeto com energia específica maior, já que é possível retirar material do componente sem ultrapassar o limite de projeto imposto.

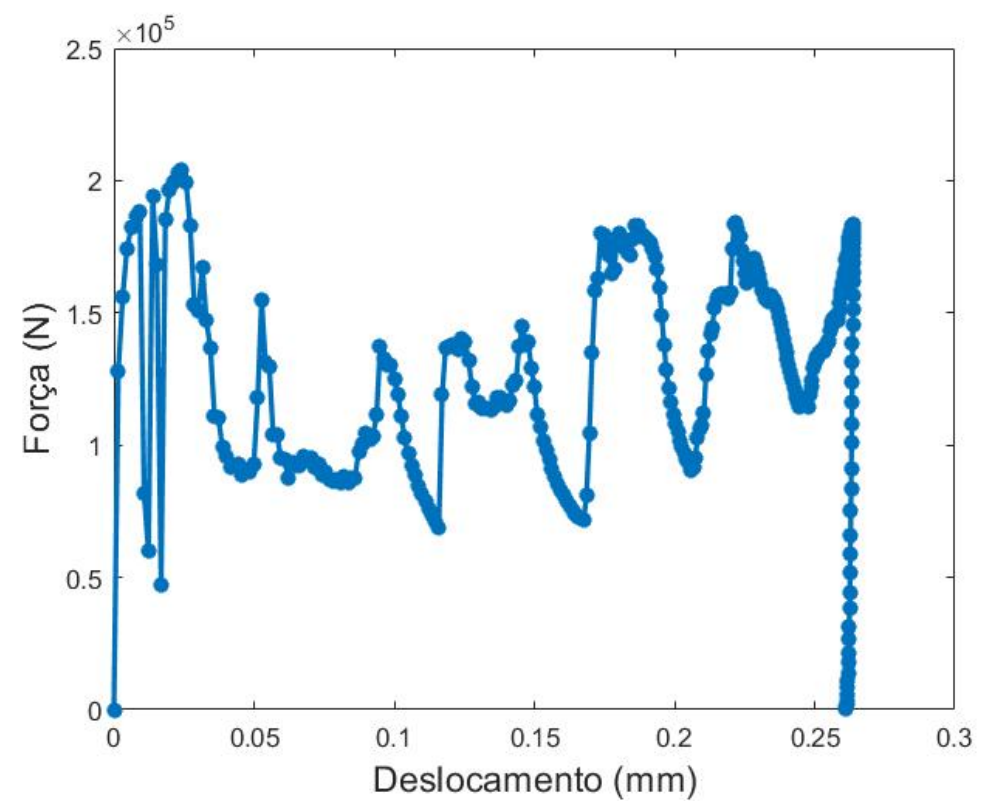

Figura 65: Comportamento da longarina obtida por AFSQP e metamodelagem.

Em seguida, o último trio de metamodelos foi utilizado para fazer uma otimização utilizando as direções conjugadas de Powell. A diferença entre o ponto estimado e o real é mostrada pela Tabela 29.

Tabela 29: Comparação entre o desempenho real e o estimado pela otimização por Powell, a partir do quinto grupo de metamodelos.

\begin{tabular}{|c|c|c|c|c|c|}
\hline \multicolumn{3}{|c|}{ Energia específica } & \multicolumn{3}{c|}{ Força de pico } \\
\hline Estimado & Real & Erro & Estimado & Real & Erro \\
\hline $0,228 \mathrm{~J} / \mathrm{mm}^{3}$ & $0,226 \mathrm{~J} / \mathrm{mm}^{3}$ & $0,88 \%$ & $250 \mathrm{kN}$ & $235 \mathrm{kN}$ & $6,38 \%$ \\
\hline
\end{tabular}

A força de pico do ponto virtual encontrado pelo algoritmo de Powell possui maior proximidade do fenômeno real, quando comparado ao último ponto da Tabela 24. A dife- 
rença da energia específica continuou abaixo de 1\%. Os parâmetros reais dessa longarina encontram-se na Tabela 30.

Tabela 30: Otimização obtida por Powell unido ao quinto grupo de metamodelos.

\begin{tabular}{|c|c|c|c|c|c|}
\hline Ângulo & Comprimento & Espessura & Raio & Energia específica & Força de pico \\
\hline $0,0178^{\circ}$ & $321 \mathrm{~mm}$ & $2,16 \mathrm{~mm}$ & $30,0 \mathrm{~mm}$ & $0,226 \mathrm{~J} / \mathrm{mm}^{3}$ & $235 \mathrm{kN}$ \\
\hline
\end{tabular}

Dentre as otimizações com metamodelos, a otimização por Powell obteve parâmetros próximos à da otimização por AFSQP, com desempenho ligeiramente inferior tanto na energia específica quanto na força de pico. Vale notar que essa otimização alcançou um desempenho superior ao melhor projeto otimizado sem o auxílio de metamodelos $(0,226$ contra $0,220 \mathrm{~J} / \mathrm{mm}^{3}$ ), em um tempo computacional reduzido. O comportamento de força por deslocamento é ilustrado pela Figura 66.

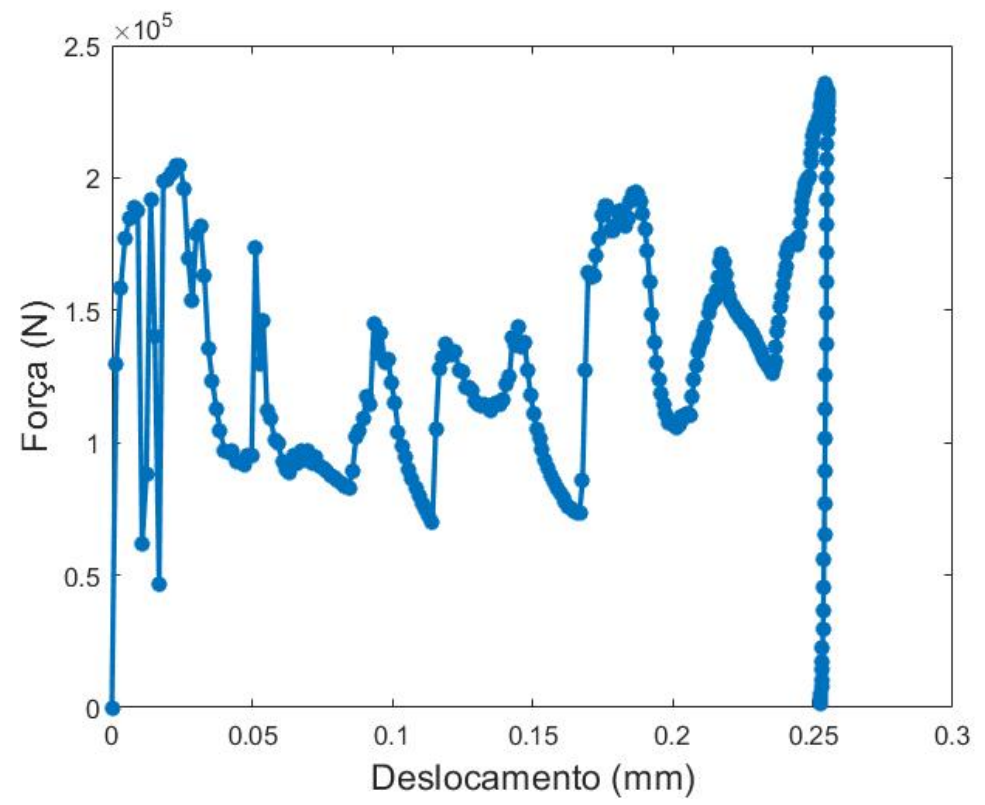

Figura 66: Comportamento da longarina obtida por Powell e metamodelagem.

Por apresentar parâmetros de entrada semelhantes, a Figura 66 possui um comportamento muito parecido com a Figura 64, porém com uma força de pico levemente maior ao final de seu deslocamento.

Logo depois, o quinto grupo de metamodelos foi usado para fazer uma otimização por MOGA-II, com os mesmos procedimentos dos algoritmos anteriores, gerando os resultados da Tabela 31. 
Tabela 31: Comparação entre o desempenho real e o estimado pela otimização por MOGA-II, a partir do quinto grupo de metamodelos.

\begin{tabular}{|c|c|c|c|c|c|}
\hline \multicolumn{3}{|c|}{ Energia específica } & \multicolumn{3}{c|}{ Força de pico } \\
\hline Estimado & Real & Erro & Estimado & Real & Erro \\
\hline $0,218 \mathrm{~J} / \mathrm{mm}^{3}$ & $0,218 \mathrm{~J} / \mathrm{mm}^{3}$ & $0,00 \%$ & $250 \mathrm{kN}$ & $378 \mathrm{kN}$ & $-33,86 \%$ \\
\hline
\end{tabular}

Apesar de a energia específica ter sido prevista com exatidão, o algoritmo MOGA-II acabou selecionando uma região do metamodelo em que há uma grande divergência entre a força máxima prevista e a real, com uma diferença que supera 30\%. Caso o projetista quisesse fazer o uso dos metamodelos usados junto ao MOGA-II para a obtenção de uma longarina viável, seria necessário fazer mais etapas de refinamento do metamodelo, utilizando pontos da região em questão. Como o foco deste trabalho é de comparar os algoritmos utilizando as mesmas superfícies de resposta, foi selecionado um ponto subotimizado da otimização virtual por MOGA-II, conforme a Figura 67, que possui uma quantidade maior de material em sua construção.

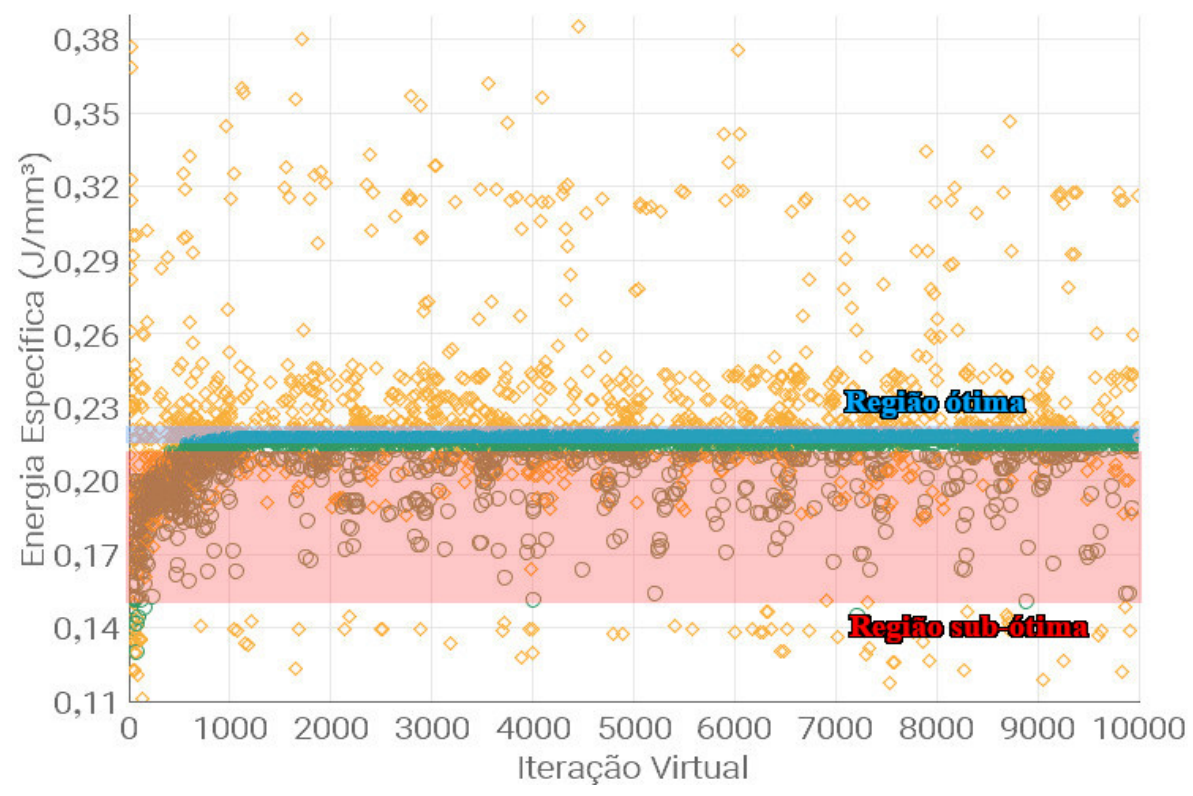

Figura 67: Regiões da otimização virtual por MOGA-II.

No caso, foi selecionado um ponto com um valor menor de força de pico estimada. O projeto escolhido foi o presente na iteração virtual 5000, com valores de saída mostrados na Tabela 32.

Com características diferentes às obtidas pelas duas otimizações anteriores, o projeto retirado da região sub-ótima possui desempenho inferior, porém dentro da restrição de força máxima. Nota-se que, mesmo com esse défice, o projeto possui características 
Tabela 32: Comparação entre o desempenho real e o estimado pela otimização por MOGA-II, a partir do quinto grupo de metamodelos.

\begin{tabular}{|c|c|c|c|c|c|}
\hline \multicolumn{3}{|c|}{ Energia específica } & \multicolumn{3}{c|}{ Força de pico } \\
\hline Estimado & Real & Erro & Estimado & Real & Erro \\
\hline $0,204 \mathrm{~J} / \mathrm{mm}^{3}$ & $0,207 \mathrm{~J} / \mathrm{mm}^{3}$ & $-1,45 \%$ & $207 \mathrm{kN}$ & $217 \mathrm{kN}$ & $-4,61 \%$ \\
\hline
\end{tabular}

mais desejáveis que as respostas alcançadas pelas otimizações diretas. Os parâmetros de entrada e saída do projeto real estão na Tabela 33.

Tabela 33: Sub-otimização obtida por MOGA-II unido ao quinto grupo de metamodelos.

\begin{tabular}{|c|c|c|c|c|c|}
\hline Ângulo & Comprimento & Espessura & Raio & Energia específica & Força de pico \\
\hline $0,00^{\circ}$ & $382 \mathrm{~mm}$ & $1,82 \mathrm{~mm}$ & $33,4 \mathrm{~mm}$ & $0,207 \mathrm{~J} / \mathrm{mm}^{3}$ & $217 \mathrm{kN}$ \\
\hline
\end{tabular}

O comportamento da última longarina obtida é exposto na Figura 68. Com uma espessura menor e comprimento maior, o componente exibe um deslocamento maior e picos intermediários menores. A força máxima encontra-se no final do deslocamento, com módulo um pouco maior que a força que iniciou a deformação.

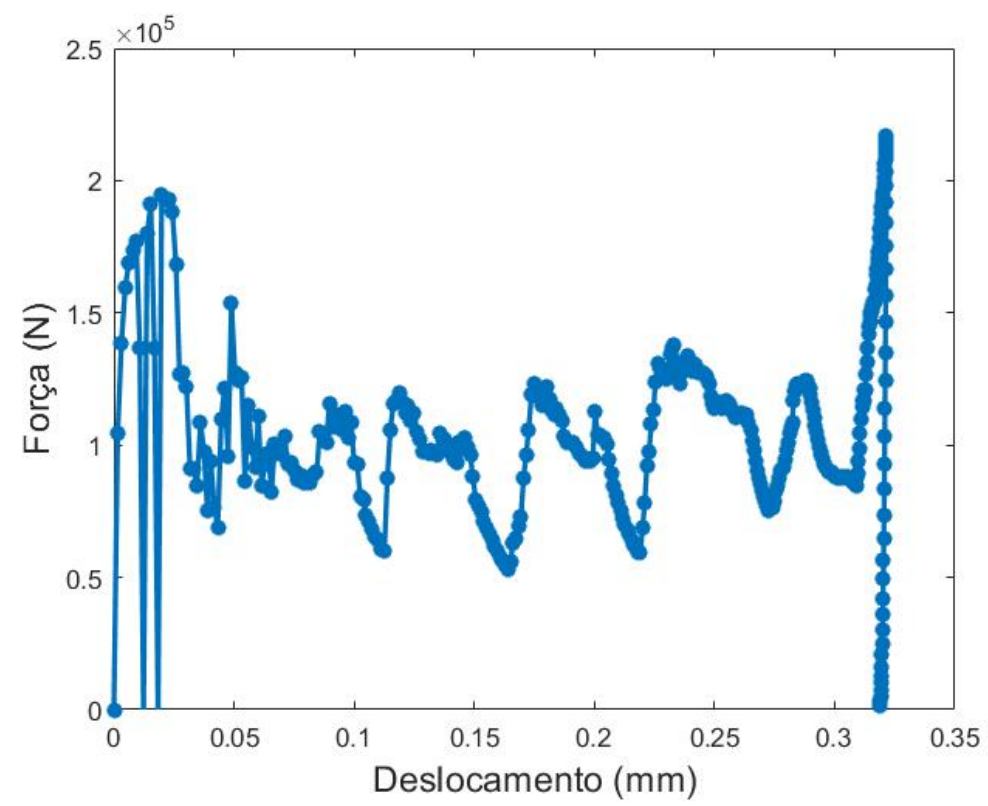

Figura 68: Longarina sub-ótima obtida por MOGA-II e metamodelos.

Por fim, a Tabela 34 compara os resultados dos três algoritmos de otimização acompanhados ou não do uso de metamodelos. 
Tabela 34: Comparação entre os resultados das metodologias utilizadas.

\begin{tabular}{|l|l|l|l|l|}
\hline Algoritmo & Metamodelo & Objetivo & Restrição & Tempo \\
\hline \multirow{2}{*}{ AFSQP } & Não & $0,182 \mathrm{~J} / \mathrm{mm}^{3}$ & $190 \mathrm{kN}$ & 165 horas \\
\cline { 2 - 5 } & Sim & $0,229 \mathrm{~J} / \mathrm{mm}^{3}$ & $204 \mathrm{kN}$ & 39 horas \\
\hline \multirow{2}{*}{ Powell } & Não & $0,220 \mathrm{~J} / \mathrm{mm}^{3}$ & $197 \mathrm{kN}$ & 185 horas \\
\cline { 2 - 5 } & Sim & $0,226 \mathrm{~J} / \mathrm{mm}^{3}$ & $235 \mathrm{kN}$ & 39 horas \\
\hline \multirow{2}{*}{ MOGA-II } & Não & $0,118 \mathrm{~J} / \mathrm{mm}^{3}$ & $246 \mathrm{kN}$ & 152 horas \\
\cline { 2 - 5 } & Sim & $0,207 \mathrm{~J} / \mathrm{mm}^{3}$ & $217 \mathrm{kN}$ & 40 horas \\
\hline
\end{tabular}

Analisando a Tabela 34, nota-se que todos os algoritmos, quando acompanhados de metamodelos, superaram o desempenho alcançado pela busca aleatória da Seção 4.2 de 0,205 J/ $\mathrm{mm}^{3}$, o que não ocorre na otimização direta por AFSQP e MOGA-II. Ressaltase também a diferença de tempo entre as metodologias usadas. Das otimizações com metamodelagem, o MOGA-II apresentou um tempo ligeiramente maior por conta da busca adicional por um ponto viável e sua respectiva validação. 


\section{CONSIDERAÇÕES FINAIS}

O comportamento não linear do problema mostrou-se desafiador do ponto de vista de análise e otimização. No entanto, sempre foi possível obter projetos viáveis e com desempenho superior ao inicial, possibilitando a criação de uma longarina que atenda a normas de impacto da NCAP com o mínimo de material possível.

A maior vantagem de utilizar otimizações diretas é a facilidade de implementar uma execução automatizada, pois elimina a intervenção do usuário ao longo do processo. Por outro lado, dada a complexidade do comportamento do estudo, os algoritmos de otimização apresentaram dificuldades. Considerando a ausência de metamodelos, para os algoritmos AFSQP e Powell, pelo menos metade de seus resultados gerou projetos inviáveis. Já o MOGA-II, apesar de sua maior robustez de análise, obteve respostas com menor desempenho, quando comparado aos outros métodos.

Para uma otimização paramétrica em absorvedores de energia, caso o projetista possua um conhecimento mais aprofundado sobre o assunto e esteja munido de um conjunto bom de pontos iniciais, uma otimização direta pelo algoritmo de Powell pode auxiliar na obtenção de um componente com desempenho desejável. Sem as superfícies de resposta, foi o algoritmo que gerou as melhores longarinas.

Os melhores resultados foram provenientes de otimizações assistidas por metamodelos. No contexto deste trabalho, as maiores dificuldades envolveram a aderência do modelo ao fenômeno físico. Utilizar uma proporção de 1 ponto validado para 10 pontos de regressão não foi suficiente para atestar a precisão do modelo em todo o domínio. Mesmo com grandes divergências locais, o uso de superfícies de resposta permitiu a obtenção de projetos com características superiores, utilizando um tempo computacional cerca de quatro vezes menor. O uso dos métodos de regressão também possibilitou uma compreensão qualitativa sobre a influência dos parâmetros no desempenho do absorvedor de energia.

Os algoritmos do método Kriging mostraram uma clara superioridade para prever a energia absorvida pelas longarinas, pelo menos quando comparados aos outros metamode- 
los usados. Já para estimar a força máxima, o Kriging anisotrópico e as funções de bases radiais manifestaram as melhores métricas de desempenho de forma consistente. $\mathrm{O}$ volume foi bem aproximado por todos os algoritmos e foi usado como um teste simplificado, uma vez que poderia ter sido extraído a partir de uma fórmula matemática já conhecida.

Com relação aos parâmetros geométricos, o ângulo longitudinal aparentou não influenciar no desempenho das longarinas, podendo ser desconsiderado em futuras otimizações. A espessura e o comprimento foram as propriedades que respectivamente mais afetaram o resultado da absorção de energia específica e a força de pico. O raio desempenhou um papel secundário para o aumento de desempenho do componente. Teve como maior função manter esbeltez suficiente para garantir estabilidade ao absorvedor de energia.

\subsection{Trabalhos Futuros}

Criar metodologias que automatizem a criação e refinamento de metamodelos seria uma grande contribuição para processos de otimização. Caso bem implementadas, ofereceria as vantagens do uso de um metamodelo sem a necessidade de múltiplas intervenções do usuário, facilitando e agilizando o uso de superfícies de resposta.

Atualmente, a homologação e testes de novos veículos leva em conta tipos diferentes de impacto. Levando isso em consideração, seria de interesse avaliar a metodologia usada para a execução de otimizações multiobjetivo, encontrando o melhor desempenho que atenda a múltiplas normas de um mesmo programa, ou ainda encontrando um único projeto otimizado que satisfaça normas de diferentes países, poupando recursos de pesquisa para produtos globalizados.

O uso de metamodelagem em otimização é utilizada em diferentes aplicações. Um trabalho que investigasse quais metamodelos são mais apropriados para determinadas classes de estudo poderia ter uma grande relevância. Analogamente, poderia-se explorar a concepção ou modificação de superfícies de resposta, visando maior aderência com certos campos de pesquisa.

Foi constatado que um dos parâmetros utilizados possui influência insignificante no desempenho da longarina. Sabe-se que variáveis consideradas como ruído influenciam negativamente na convergência de algoritmos de otimização e na aderência de metamodelos. Seria de interesse uma análise que identifique o ganho de desempenho dos algoritmos ao eliminar ruídos ou ainda reduzir o número de dimensões trabalhadas. 


\section{REFERÊNCIAS}

[1] FOLKSON, R.; PEARSON, R. J.; TURNER, J. W. G. Alternative fuels and Advanced vehicle technologies for improved environmental performance. 1. ed. Sawston: Woodhead Publishing, 2014. 762 p. ISBN 978-0-85709-742-2.

[2] Pan American Health Organization. Acidentes de trânsito. [S.1.], 2016. Disponível em: $<$ https: / $/$ www.paho.org/bra/index.php?option $=$ com_content\&view $=$ article\&id $=5147$ : acidentes-de-transito-folha-informativa\&Itemid $=779>$.

[3] World Health Organization. Violence and Injury Prevention. [S.l.], 2015. Disponível em: <http://www.who.int/violence_injury_prevention/road_safety_status/2015/GSR RS2015_data/en/>.

[4] FECHOVÁ, E. et al. Material properties and safety of cars at crash tests. In: Procedia Engineering. [S.l.: s.n.], 2016. ISSN 18777058.

[5] LUCHTER, S.; SMITH, A.; WANG, J. Fatal Injuries in Light Vehicle Crashes - Time to Death and Cause of Death. [S.1.], 1998.

[6] CHAVAlI, K. H.; SHARMA, B. R.; HARISH, D. Head Injury: The Principal Killer in Road Traffic Accidents. [S.1.], 2006.

[7] MACKAY, M. The increasing importance of the biomechanics of impact trauma. Sadhana - Academy Proceedings in Engineering Sciences, 2007. ISSN 02562499.

[8] IBRAHIM, H. K. Design Optimization of Vehicle Structures for Crashworthiness Improvement. Tese (Doutorado) - Concordia University, 2009.

[9] CARNEY, J. F.; YEH, C. Closure to "viscoplastic response of clamped beams under impact loading". Journal of Structural Engineering, v. 119, n. 3, p. 998, 1993.

[10] LU, G.; YU, T. Energy Absorption of Structures and Materials. [S.l.]: Elsevier Ltd, 2003. 1-403 p. ISBN 9781855736887.

[11] SABOORI, P.; MANSOOR-BAGHAEI, S.; SADEGH, A. M. Evaluation of head injury criteria under different impact loading. In: ASME International Mechanical Engineering Congress and Exposition, Proceedings (IMECE). [S.1.]: American Society of Mechanical Engineers (ASME), 2013. v. 3 A. ISBN 9780791856215.

[12] DECK, C.; WILLINGER, R. Improved head injury criteria based on head FE model. International Journal of Crashworthiness, v. 13, n. 6, p. 667-678, 12 2008. ISSN 13588265 .

[13] SEIFFERT, U.; WECH, L. Automotive safety handbook. [S.l.]: SAE International, 2007. 293 p. ISBN 9780768017984. 
[14] Toyota Motor Corporation. Toyota Updates its THUMS Virtual Crash Dummy Software. [S.1.], 2019. 2 p.

[15] Latin New Car Assessment Programme. Quem somos. Disponível em: <https://www.latinncap.com/po/quem-somos>.

[16] Brasil. Lei $n^{o}$ 9.503, de 23 de setembro de 1997. Institui o Código de Trânsito Brasileiro. Diário Oficial da União: Capítulo IX Seção II, Brasília, DF. Disponível em: $<$ http://www.planalto.gov.br/ccivil_03/leis/L9503Compilado.htm>.

[17] JOHNSON, W. The elements of crashworthiness : scope and actuality. [S.1.], 1990.

[18] BOIS, P. D. et al. VEHICLE CRASHWORTHINESS AND OCCUPANT PROTECTION Automotive Applications Committee American Iron and Steel Institute Southfield, Michigan. [S.l.], 2004.

[19] NÉMETH, S. Analysis of car safety in terms of the materials used in the deformation zones of the car body. In: Strojárstvo, vol. 7. 2014.

[20] MALEN, D. E. Fundamentals of Automobile Body Structure Design. 1. ed. Sawston: Society of Automotive Engineers, 2011. 455 p. ISBN 978-0768021691.

[21] U.S. Department of Transportation, National Highway Traffic Safety Administration. Federal Motor Vehicle Safety Standards and Regulations: With Amendments and Interpretations Issued Through December 1992. [S.l.: s.n.], 1994.

[22] KAMAL, M. M. Analysis and Simulation of Vehicle to Barrier Impact. [S.l.], 1970.

[23] LIMA, A. Desenvolvimento de um veículo urbano seguro utilizando otimização baseada em metamodelos. 346 p. Tese (Doutorado) — Escola Politécnica da USP, 2016.

[24] MARZBANRAD, J.; PAHLAVANI, M. A System Identification Algorithm for Vehicle Lumped Parameter Model in Crash Analysis. International Journal of Modeling and Optimization, 2011. ISSN 20103697.

[25] OfOCHEBE, S. M.; OZOEGWU, C. G.; ENIBE, S. O. Performance evaluation of vehicle front structure in crash energy management using lumped mass spring system. Advanced Modeling and Simulation in Engineering Sciences, 2015. ISSN 22137467.

[26] HEIMBS, S. Energy Absorption in Aircraft Structures. Munich, 2012. 10 p.

[27] MARX, J.; RABIEI, A. Tensile properties of composite metal foam and composite metal foam core sandwich panels. Journal of Sandwich Structures and Materials, SAGE Publications Ltd, 2020. ISSN 15307972.

[28] NAJAFI, M.; AHMADI, H.; LIAGHAT, G. Experimental investigation on energy absorption of auxetic structures. Materials Today: Proceedings, 2020. ISSN 2214-7853.

[29] LI, Y.; YOU, Z. Origami concave tubes for energy absorption. International Journal of Solids and Structures, Elsevier Ltd, v. 169, p. 21-40, 9 2019. ISSN 00207683.

[30] SILVA, J. E. C. S. et al. Study of an Origami Crashbox Through Metamodels. ABCM, São Paulo, p. 17, 42019. 
[31] YUAN, L.; MA, J.; YOU, Z. Energy absorption capability of origami automobile bumper system. Proceedings of the Institution of Mechanical Engineers, Part C: Journal of Mechanical Engineering Science, SAGE Publications Ltd, v. 233, n. 18, p. 6577-6587, 9 2019. ISSN 20412983.

[32] MA, J. Thin-walled Tubes with Pre-folded Origami Patterns as Energy Absorption Devices. 194 p. Tese (Doutorado) — University of Oxford, 2011.

[33] TARLOCHAN, F. et al. Design of thin wall structures for energy absorption applications: Enhancement of crashworthiness due to axial and oblique impact forces. Thin-Walled Structures, v. 1, p. 11, 2013.

[34] JONES, N. Structural Impact. [S.l.]: Cambridge University Press, 2012. 606 p. ISBN 9781107010963.

[35] KARAGIOZOVA, D.; ALVES, M. Dynamic Elastic-Plastic Buckling of Structural Elements: A Review. Applied Mechanics Reviews, 2008. ISSN 00036900.

[36] GUILLOW, S. R.; LU, G.; GRZEBIETA, R. H. Quasi-static axial compression of thin-walled circular aluminium tubes. [S.l.], 2001. v. 43, 2103-2123 p.

[37] KARAGIOZOVA, D.; ALVES, M. Transition from progressive buckling to global bending of circular shells under axial impact - Part I: Experimental and numerical observations. International Journal of Solids and Structures, Elsevier Ltd, v. 41, n. 5-6, p. 1565-1580, 2004. ISSN 00207683.

[38] JOHNSON, W.; SODEN, P. D.; HASSANI, S. T. al. Inextensional collapse of thinwalled tubes under axial compression. The Journal of Strain Analysis for Engineering Design, v. 12, n. 4, p. 317-330, 1977. ISSN 20413130.

[39] SINGACE, A. A. Axial crushing analysis of tubes deforming in the multi-lobe mode. [S.l.], 1999. v. 41, 865-890 p.

[40] PUGSLEY, A.; MACAULAY, M. THE LARGE-SCALE CRUMPLING OF THIN CYLINDRICAL COLUMNS. Bristol, 1960. 9 p. Disponível em: $<$ http://qjmam.oxfordjournals.org/>.

[41] QUEIPO, N. V. et al. Surrogate-based Analysis and Optimization. Gainesville, 2005. 76 p. Disponível em: <https://ntrs.nasa.gov/search.jsp?R=20050186653>.

[42] NESBAKKEN, A. Master of Science in Physics and Mathematics Evaluation of Modern Design Methods for use in Computer Experiments. [S.l.], 2011. 66 p.

[43] MUNRO, R. A.; RAMU, G.; ZRYMIAK, D. J. The certified six sigma green belt handbook. 2. ed. Milwaukee, Wisconsin: ASQ Quality Press, 2008. 600 p. ISBN 9780873898911 .

[44] MCKAY, M. D.; BECKMAN, R. J.; CONOVER, W. J. Comparison of three methods for selecting values of input variables in the analysis of output from a computer code. Technometrics, v. 21, n. 2, p. 239-245, 1979. ISSN 15372723.

[45] SANTOS, K. R. M. Técnicas de amostragem inteligente em simulação de Monte Carlo. 191 p. Tese (Doutorado) - Escola de Engenharia de São Carlos, São Carlos, 2014. 
[46] SOBOL, I. M. Distribution of points in a cube and approximate evaluation of integrals. Moscow, 1966. 27 p.

[47] ESTECO. modeFRONTIER User Guide. 2018.

[48] AZMIN, F. M.; STOBART, R. Benefiting from Sobol Sequences Experiment Design Type for Model-based Calibration. In: SAE Technical Papers. [S.l.]: SAE International, 2015. v. 2015-April, n. April. ISSN 01487191.

[49] BRATLEY, P.; FOX, B. L. ALGORITHM 659 Implementing Sobol's Quasirandom Sequence Generator. Montréal, 1988. 88-100 p.

[50] JIRIWIBHAKORN, S.; COONICK, A. H. Fast Critical Clearing Time Estimation of A Large Power System Using Neural Networks and Sobol Sequences. [S.l.], 2000.

[51] AHMAD, A.; BAIT-SHIGINAH, F. A nonconventional approach to generating efficient binary gray code sequences. IEEE Potentials, v. 31, n. 3, p. 16-19, 2012. ISSN 02786648.

[52] FANG, H. et al. A comparative study of metamodeling methods for multiobjective crashworthiness optimization. Computers and Structures, 2005. ISSN 00457949.

[53] FORRESTER, A. I. J.; KEANE, A. J. Recent advances in surrogate-based optimization. [S.l.], 2009. 77 p.

[54] LIU, H.; CAI, J.; ONG, Y. S. An adaptive sampling approach for Kriging metamodeling by maximizing expected prediction error. Computers and Chemical Engineering, Elsevier Ltd, v. 106, p. 171-182, 2017. ISSN 00981354.

[55] LECHEVALIER, D. et al. A neural network meta-model and its application for manufacturing. In: Proceedings - 2015 IEEE International Conference on Big Data, IEEE Big Data 2015. [S.1.: s.n.], 2015. ISBN 9781479999255.

[56] AGGARWAL, C. C. Neural Networks and Deep Learning. Yorktown Heights, NY: Springer, 2018. 512 p. ISBN 978-3-319-94462-3.

[57] PIERREVAL, H. A METAMODELING APPROACH BASED ON NEURAL NETWORKS. Aubière, Cedex, 1996. 23 p.

[58] MALIKI, M.; ZURICH, E.; SUDRET, B. Metamodeling for crashworthiness design: A comparative study of Kriging and support vector regression Machine learning for hybrid simulation View project Rice Crop Growth Stage Estimation using High-Frequency PolSAR Data View project. [S.l.], 2015. Disponível em: $<$ https://www.researchgate.net/publication/279683303>.

[59] MESSAC, A. Optimization in Practice with MATLAB® for Engineering Students and Professionals. 1. ed. New York: Cambridge University Press, 2015. 496 p.

[60] TURCO, A. Adaptive Filter SQP-Description. [S.l.], 2009. 13 p.

[61] POWELL, M. J. D. An efficient method for finding the minimum of a function of several variables without calculating derivatives. The Computer Journal, v. 7, n. 2, p. 155-162, 1964. Disponível em: <http://comjnl.oxfordjournals.org/>. 
[62] POLES, S. MOGA-II An improved Multi-Objective Genetic Algorithm. [S.l.], 2003. $16 \mathrm{p}$.

[63] COSTA, L. P. da; DRIEMEIER, L. Metodologia de Otimização de Absorção de Energia em Impacto de Automóveis. DINCON, São Carlos, SP, p. 7, 2019.

[64] POLES, S. et al. MOGA-II for an Automotive Cooling Duct Optimization on Distributed Resources. In: OBAYASHI, S. et al. (Ed.). Evolutionary Multi-Criterion Optimization. Berlin, Heidelberg: Springer Berlin Heidelberg, 2007. p. 633-644. ISBN 978-3-540-70928-2. 